GEOLOGICAL SURVEY CIRCULAR 917

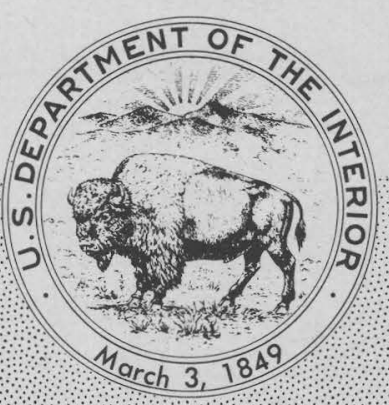

Comparison of Computer-Based and Manual Coal Resource Estimation Methods for the Cache Coal Bed, Recluse Geologic Model Area, Wyoming 

Comparison of Computer-Based and Manual Coal Resource Estimation Methods for the Cache Coal Bed, Recluse Geologic Model Area, Wyoming

By Gary B. Schneider, Sharon S. Crowley, and Mary Alice Carey
GEOLOGICAL SURVEY
CIRCULAR
917 
Department of the Interior

WILLIAM P. CLARK, Secretary

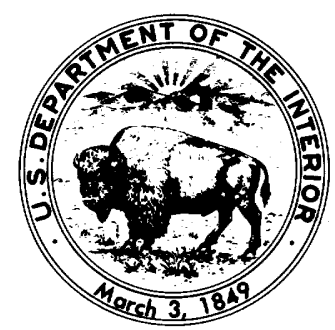

\section{U.S. Geological Survey}

Dallas L. Peck, Director 


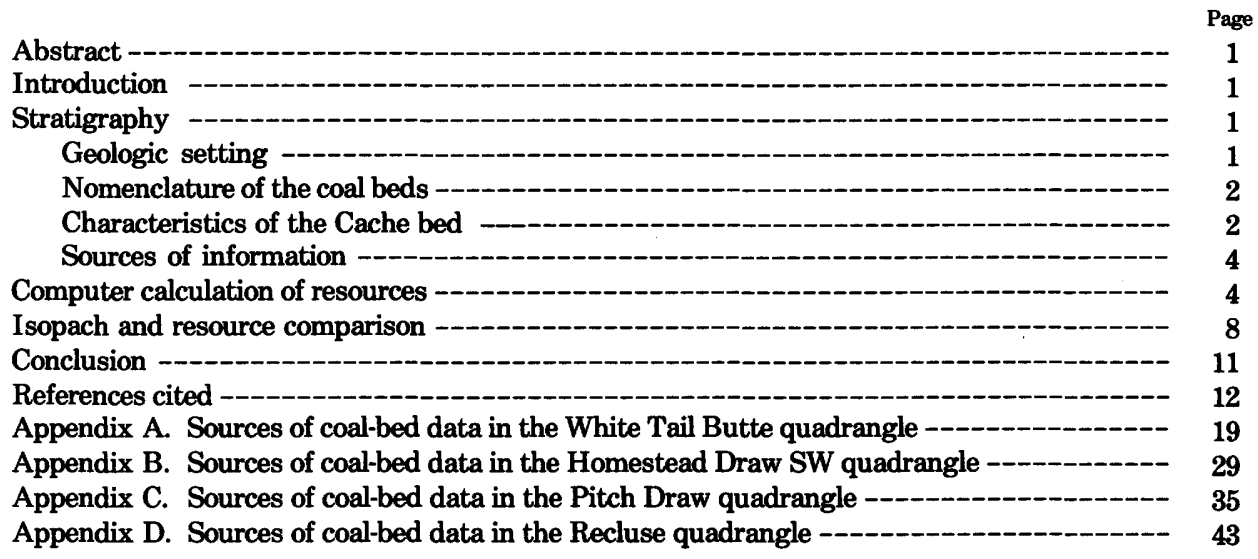

\section{ILUSTRATIONS}

Figure 1. Index map showing the location of the Recluse Geologic Model Area --_--_-

2. Generalized section of the Recluse Geologic Model Area -

3. Map showing point distribution and overburden contours

4. Hand-drawn isopach map of the Cache coal bed -

5. Computer-generated isopach map of the Cache coal bed -

6. Computer-generated resource map of the Recluse Geologic Model Area --

7. Computer-generated isopach map superimposed on hand-drawn isopach map of the Cache coal bed -

\section{TABLES}

TABLE 1. Comparison of manually calculated and computer-calculated original resources of subbituminous coal under 500 feet or less of overburden in the Cache coal bed for the Recluse Geologic Model Area, Campbell County, Wyoming, as of Jan. 1, 1980

2. Comparison of manually calculated and computer-calculated original resources of subbituminous coal under 500-1,000 feet of overburden in the Cache coal bed for the Recluse Geologic Model Area, Campbell County, Wyoming, as of Jan. 1, 1980

3. Comparison of manually calculated and computer-calculated original resources of subbituminous coal under 1,000-2,000 feet of overburden in the Cache coal bed for the Recluse Geologic Model Area, Campbell County, Wyoming, as of Jan. 1, 1980

4. Total manually calculated and computer-calculated original resources of subbituminous coal in the Cache coal bed for the Recluse Geologic Model Area, Campbell County, Wyoming 


$$
\text { • }
$$




\title{
COMPARISON OF COMPUTER-BASED AND MANUAL COAL RESOURCE ESTIMATION METHODS FOR THE CACHE COAL BED, RECLUSE GEOLOGIC MODEL AREA, WYOMING
}

\author{
By Gary B. Schneider, Sharon S. Crowley, and Mary Alice Carey
}

\begin{abstract}
Coal resources have been estimated, using both manual and computer methods, for the Cache coal bed in the Recluse Geologic Model Area, which covers the White Tail Butte, Pitch Draw, Recluse, and Homestead Draw SW 71/2-minute quadrangles in Campbell County, Wyoming. Approximately 300 coal thickness measurements from drill-hole logs are distributed throughout the area. The Cache coal bed and associated strata are in the Paleocene Tongue River Member of the Fort Union Formation. The depth to the Cache coal bed ranges from 269 to 1,257 feet. The coal bed is as much as 31 feet thick but is absent in places. Comparisons between hand-drawn and computer-generated isopach maps show minimal differences. Total coal resources estimated by hand show the bed to contain 2,228 million short tons or about 2.6 percent more than the computer-calculated figure of 2,169 million short tons.
\end{abstract}

\section{INTRODUCTION}

In 1974, the U.S. Geological Survey initiated a project entitled "Research on Geologic Analysis of Selected Coal Model Areas" to pioneer approaches to the acquisition, synthesis, evaluation, and dissemination of geologic information related to coal resource estimation and assessment activities in the United States. The Recluse area in Campbell County, northeastern Wyoming (fig. 1), is one of the selected geologic model areas. It covers 15 minutes of latitude and longitude and is comprised of the White Tail Butte, Pitch Draw, Recluse, and Homestead Draw SW 71/2-minute quadrangles. Isopach and coal resource maps of the Cache coal bed were done at 1:50,000 scale.

The Recluse Geologic Model Area provides an opportunity to demonstrate and evaluate the application of computer graphics to estimate coal resources. To make a proper evaluation, computer and manual calculation methods must be compared; ideally, the two should yield similar results. This paper compares computer-based and manual resource estimations for the Cache coal bed.

\section{STRATIGRAPHY}

\section{GEOLOGIC SETING}

The Recluse Geologic Model Area is in the Northern Great Plains province midway between the Black Hills and the Bighorn Mountains. It lies near the Montana State line in the north-central part of the Powder River Basin in Wyoming. The topography is characterized by flat-topped buttes; long, narrow, and flat divides; and even-crested ridges that rise steeply above the valley bottoms. The rocks of the area dip to the west and southwest, but surface reversals of dip indicate shallow synclines and anticlines. Other structural features in the subsurface are known from oil and gas drill holes and geophysical data.

Rocks exposed in the area are of continental origin, and are assigned to the Tongue River Member of the Paleocene Fort Union Formation and the lower part of the Eocene Wasatch Formation. The Tongue River Member consists of sandstone, siltstone, mudstone, shale, carbonaceous shale, and coal. The rocks are predominantly yellowish gray, except where the beds have been baked by burning of underlying coal to form conspicuous beds of red, purple, and violet clinker.

The contact between the Fort Union and 


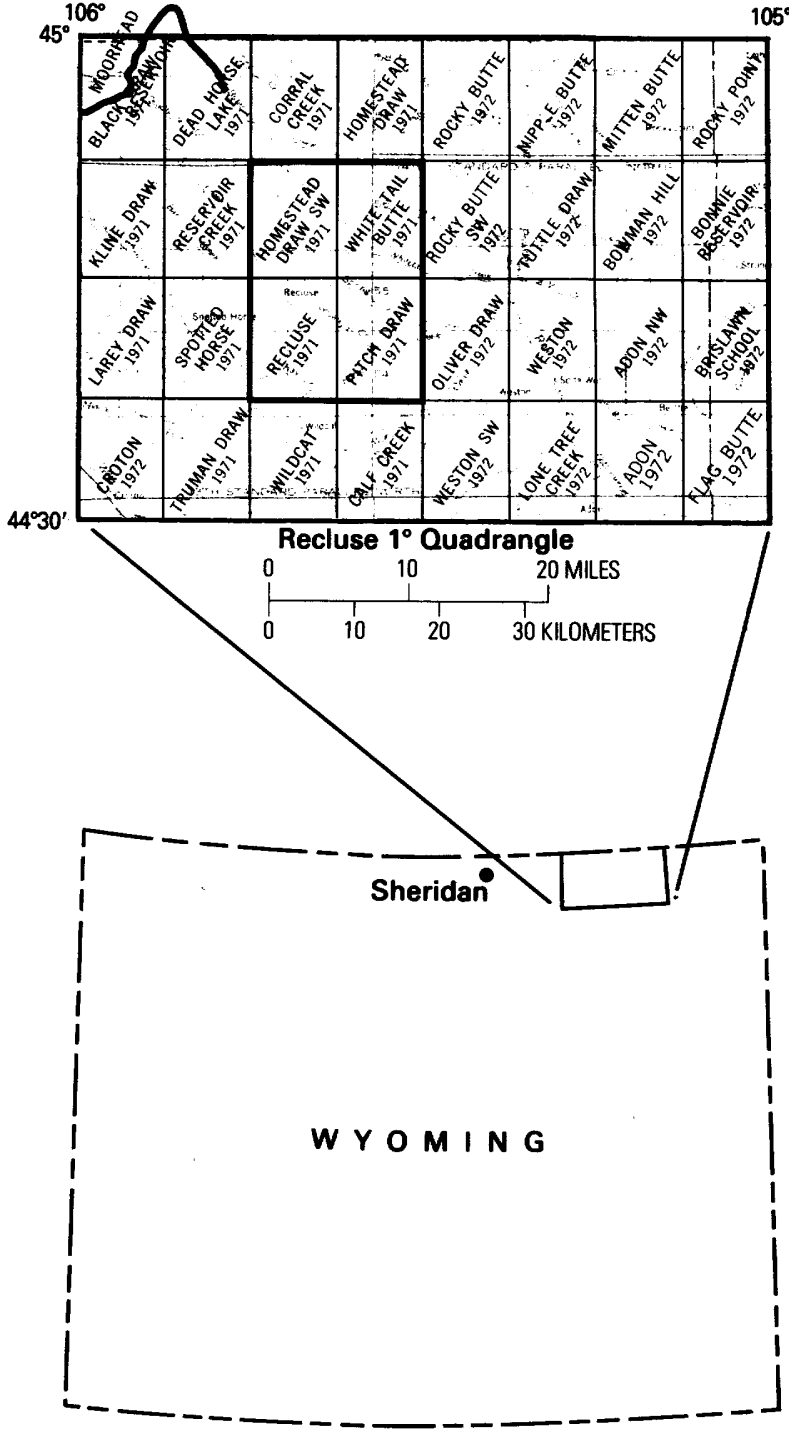

FIguRE 1. Index map showing the location of the Recluse Geologic Model Area outlined by heavy black rectangle.

Wasatch Formations, as shown in figure 2, has been problematical almost since the formations were described. Culbertson and others (1979) summarized the problem as follows:

The Wasatch Formation overlies [the] Tongue River Member of the Fort Union Formation and also consists of sandstone, siltstone, shale, and coal. The contact between the Fort Union and Wasatch Formations was defined by Thom and Dobbin (1924) to be at the Roland bed as identified by Taff (1909) near Sheridan. Wyoming.

This bed, however, pinches out a short distance from where it was named. In Montana, Baker (1929) placed the contact at a stratigraphically higher bed, which he and Bass (1924) thought to be the Roland. This bed is now referred to as the Roland of Baker (1929). Because no other contact is obvious in the gradational and changing lithologies of the Fort Union and Wasatch Formations near the Montana-Wyoming State line, most subsequent investigators in this area have used the persistent Roland coal bed of Baker (1929) as the contact between the formations, including Bryson and Bass (1973), Olive (1957), Matson, Blumer, and Wegelin (1973), and Culbertson and Mapel (1976).
Total thickness of the Fort Union Formation in the model area is about 2,500 feet, and total thickness of the overlying Wasatch Formation, which is thickest on Horse Nose Butte in the southwestern corner of the area, is $\mathbf{4 3 0}$ feet.

The only consistent general characteristic of the Wasatch Formation that distinguishes it from the underlying Fort Union Formation is a more moderate yellowish-brown color (Olive, 1957).

Coal beds in the eastern part of the Powder River Basin have a tendency to merge eastward, and the intervening strata thicken westward (Kent and others, 1980). These relations suggest that a major, through-flowing drainage channel lay west of the Recluse area during deposition of the Fort Union and Wasatch Formations. Offset stacking of sandstone units is characteristic of fluvialdeltaic deposition as is the merging and splitting of coal beds. Plant material accumulated in depressions between fluvial channels or where sand deposition was minimal. As long as the balance between base-level and subsidence remained relative and there was no major change in water depth, such deposition was continuous within the basin. Thus, the thick coal beds in the Recluse area imply stable conditions where plant material accumulated and changed to peat over long periods of time.

\section{NOMENCLATURE OF THE COAL BEDS}

Seven major coal beds (McKay, 1973; Kent and others, 1980) are recognized in a stratigraphic section about 1,300 feet thick in the Recluse Geologic Model Area (fig. 2). The coal beds from youngest to oldest are Anderson, Dietz, Canyon, Cook, Wall, Pawnee, and Cache. The Cook, Wall, Pawnee, and Cache coal beds were named in Montana coal fields many miles from the Recluse Geologic Model Area, and use of these Montana names in the Recluse area implies regional coal correlations that have not been satisfactorily established. To overcome this problem, other geologists (Kent and others, 1980) have introduced names for the coal beds below the Canyon. The authors have elected to retain the Montana names for this report.

\section{CHARACTERSTICS Of THE CACHE BaD}

The Cache coal bed, considered in detail here, dips toward the axis of the Powder River Basin, 


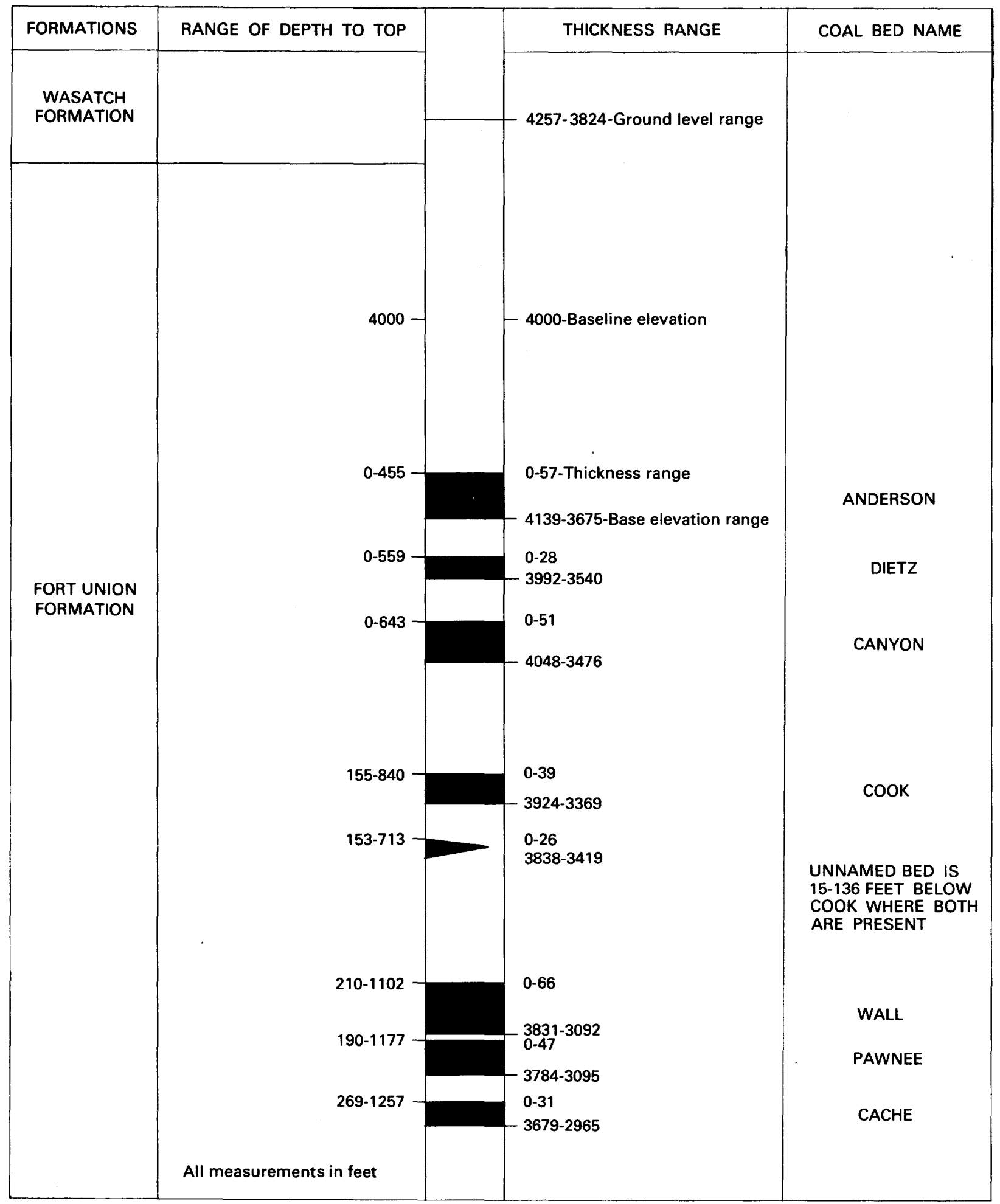

FIGURE 2. Generalized section of a part of the Tongue River Member of the Fort Union Formation and the Wasatch Formation in the Recluse Geologic Model Area, showing the relation of the Cache coal bed to other coal beds and the range of thickness and elevation for all coal beds. 
which lies 20 to 30 miles to the west. Within the model area, the maximum thickness of the Cache coal bed is 31 feet, but in places it is absent. The Cache coal bed is not exposed within the fourquadrangle model area. The coal is subbituminous in rank and low ( $<1$ percent) in sulfur. Analyses of coal from two core samples (Hobbs, 1980) show a sulfur content of about 0.4 percent and an ash content of $\mathbf{1 1 . 3}$ percent on an "as received" basis with an unweighted mathematical average heating value calculated at $6,782 \mathrm{Btu}$. Estimated total coal resources for the Cache coal bed in the model area are approximately 2.3 billion tons.

\section{SOURCES OF INFORMATION}

Figure 3 shows the locations of 298 deep oil and gas wells and coal test holes that penetrated the Cache coal bed in the model area. Information from an additional two shallow coalexploratory holes also aided in the study. Geophysical logs, including some combinations of resistivity, formation density, and gamma ray logs, are available for all of the holes shown on figure 3. Locations of wells are listed in appendixes A through D.

The coal beds in the area generally have very high resistivity, extremely low radioactivity, and specific gravities of about 1.3. Relative responses to these properties are recorded on the geophysical logs. Lithologic materials and the salt content of water or mud affect log response in a particular way. Resistivity of a coal bed also varies with ash content. The degree of assurance of the interpretation is best where all three log types are available for the same hole.

\section{COMPUTER CALCULATION OF RESOURCES}

The National Coal Resources Data System (NCRDS) of the U.S. Geological Survey supports various spatial data bases that interact with digitized data and the graphic display programs. The Program to Analyze Coal Energy Resources (PACER) (Cargill and others, 1976) is the storageretrieval system developed in-house to manage all NCRDS data bases of which the U.S. Stratigraphic Sequence file (USTRAT) is one. The Recluse Geologic Model Area data subset stored in the USTRAT data base consists of 300 drill-hole locations with their respective stratigraphic sec- tions and of 15 control points that lie outside the map boundary. Required digitized information includes $x, y$ locations (latitude and longitude) for each point, township-range intersections from the base map, and the thickness-of-overburden category determined by the geologist.

Graphic Analysis of Resources Using Numerical Evaluation Techniques (GARNET) (Olson, 1980) is the graphics package that is used to produce contour and coal-resource maps. Generation of an isopach map in GARNET requires latitude, longitude, and a coal thickness for every data point in the map area. This information is used to produce a gridded file for graphic display. Algorithms in GARNET generate grids using quadratic and weighted planar fit methods. The quadratic method is designed for dense (closely spaced) data with even distribution whereas the planar method is designed for diffuse data with uneven distribution. The planar method produced the most satisfactory grid because of the diffuse point distribution in this study (fig. 3). Figure 4 is a hand-drawn isopach for the Cache coal bed, and figure 5 is a computer-generated isopach map of the same bed data generated by the planar method.

Each of the gridding algorithms divides the map area into a large number of grid cells, the size of which is determined by the user. In this study, a cell size of 0.5 inch was used for the 16-inch $\times 22$-inch, 1:50,000-scale map, creating a total of 1,408 grid cells. The 0.5 -inch grid-cell size was chosen because it is the largest cell that can produce reliable resource estimates at reasonable computer costs.

The gridding algorithms assign a $z$-value (coal thickness in this study) to each of the grid intersections. The weighted plane method uses control points within a radius equal to one-fourth of the diagonal distance across the map area to determine the $z$-value at each intersection. The weighting function is exponential: points closer to a grid intersection are weighted more heavily, whereas points farther from a grid intersection are weighted more lightly. This function is expressed by:

$$
W E I G H T=E X P \frac{-4 * D I S T}{(A R E A /(N O . P O I N T S))}
$$

where WEIGHT is the weighting function, EXP is the exponential function $e^{z}$ (real number 2.71828...), DIST represents distance (user-defined 


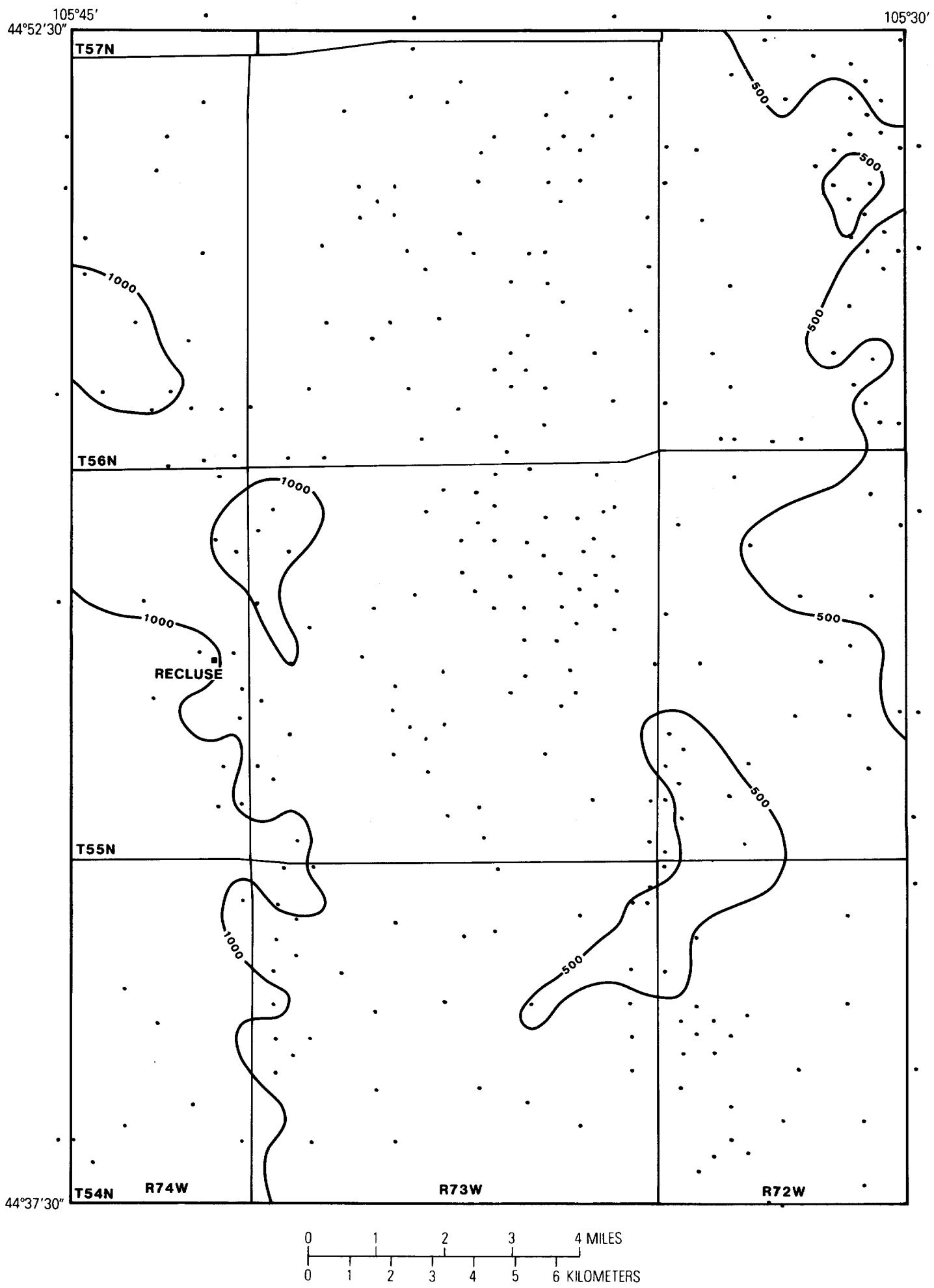

FigURE 3. Map showing diffuse distribution of data points and the 500-foot and 1000-foot overburden contours used in this study. 


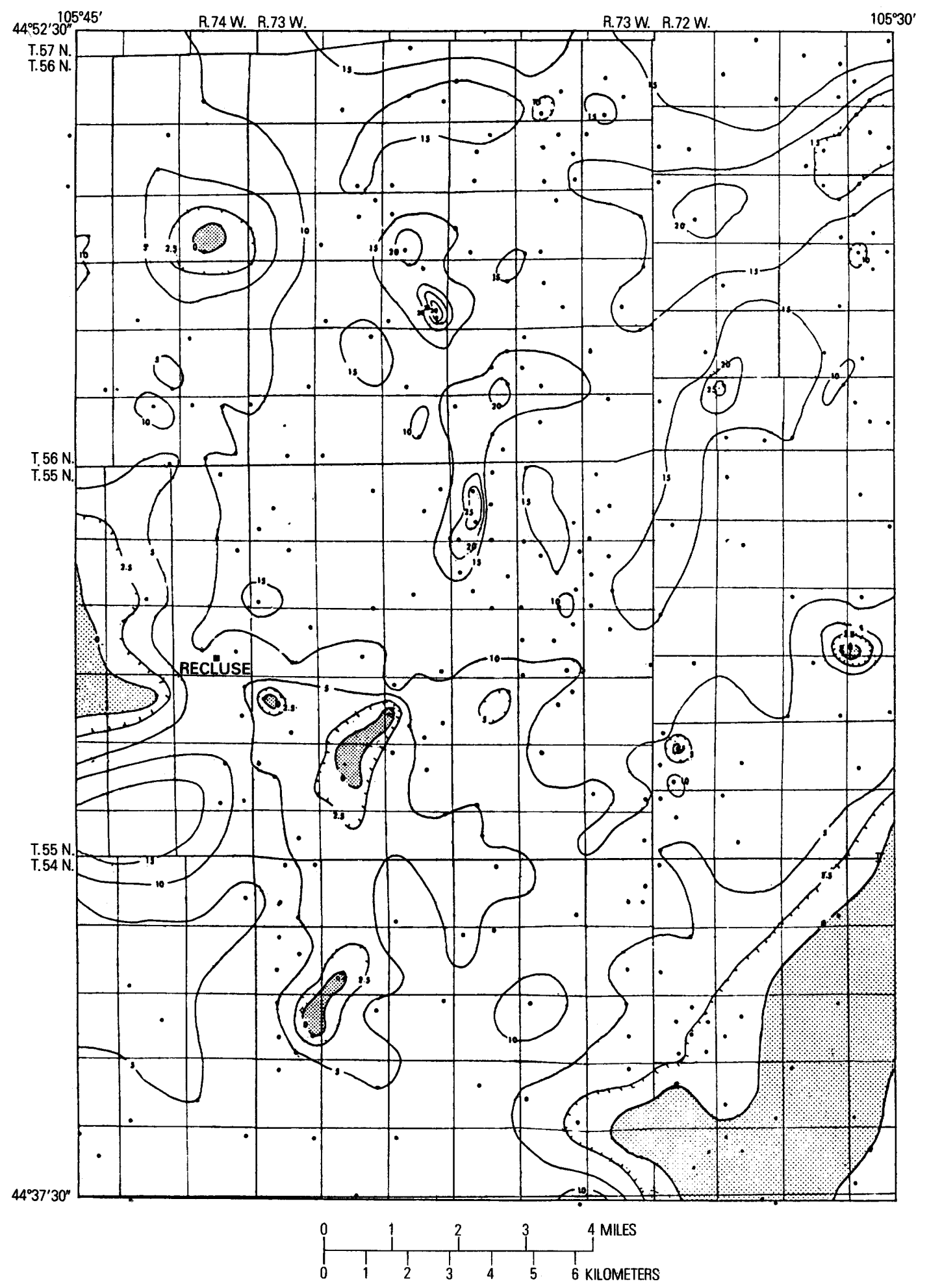

Figure 4. Hand-drawn isopach map of the Cache coal bed in the Recluse Geologic Model Area, Wyoming. Original scale at 1:50,000. Isopach intervals are $2.5,5,10,15,20,25$, and $30 \mathrm{ft} . \bullet=$ drill hole location. 


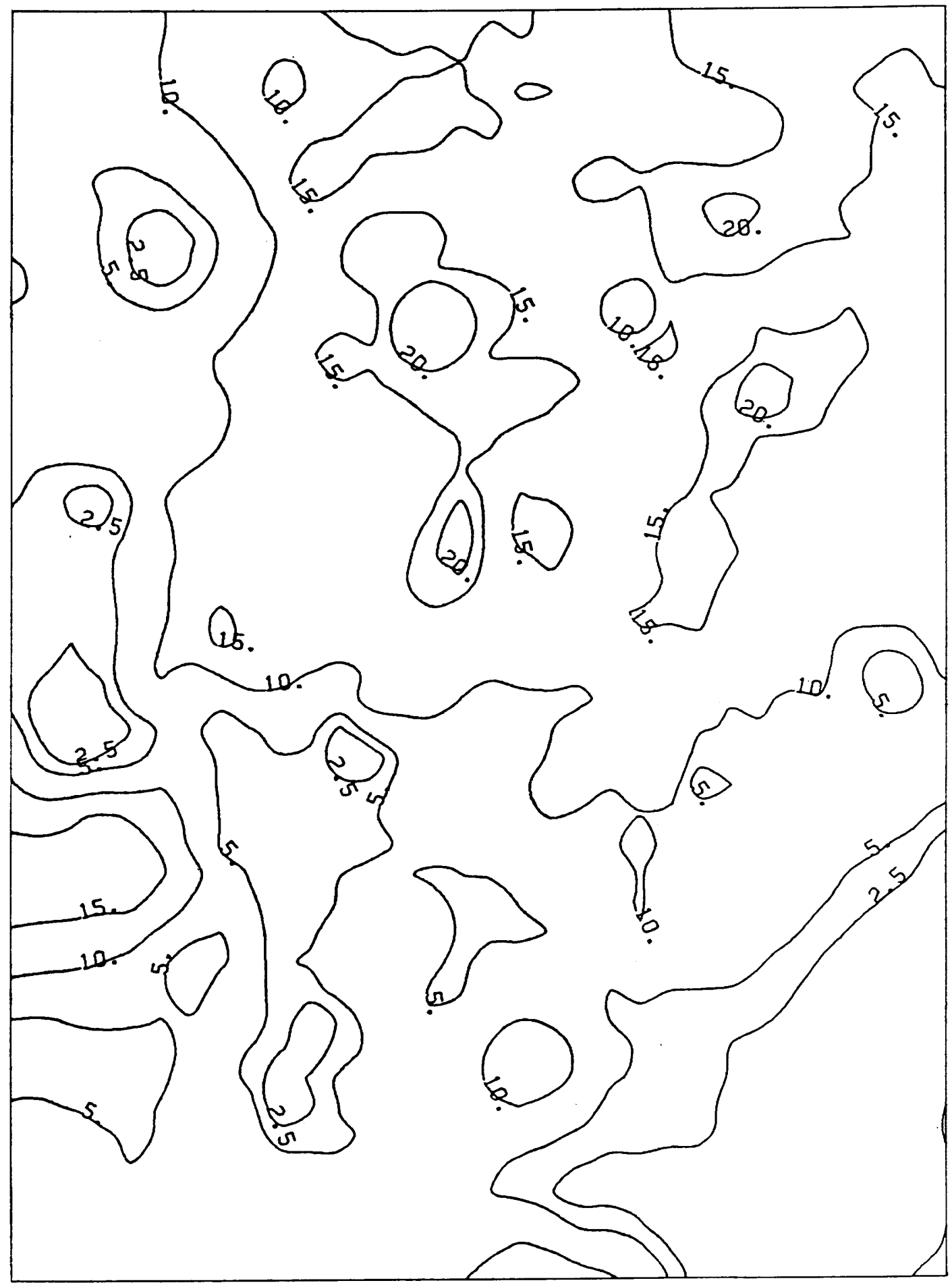

Figure 5. Computer-generated isopach map of the Cache coal bed in the Recluse Geologic Model Area, Wyoming. Isopachs represent thickness of the Cache coal bed. Isopach intervals are 2.5, 5, 10, 15, and $20 \mathrm{ft}$. (Latitude $=44^{\circ} 37^{\prime} 30^{\prime \prime}$ to $44^{\circ} 52^{\prime} 30^{\prime \prime} \mathrm{N}$, longitude $=105^{\circ} 30^{\prime} 00^{\prime \prime}$ to $105^{\circ} 45^{\prime} 00^{\prime \prime} \mathrm{W}$. Figure 4 covers the same area.) Original scale at 1:50,000. 
units, meters-on-the-ground in this study) from the data point to a grid intersection, $A R E A$ is the map area, and NO.POINTS is the number of control points (Olson, 1977).

The geologist evaluates the computer-generated isopach maps and has the option of adding, editing, or deleting point data. Interpretive points are sometimes added to modify the isopach pattern. Because the coal isopach lines generated by the computer for the Cache coal bed in the Recluse Geologic Model Area approximate the thicknesses at the data points, the authors considered the addition of interpretive points to be unnecessary.

Standardized calculation of coal resources (Wood and others, 1983) requires that resource categories be delimited by coal thickness, overburden thickness (fig. 3$)$, and the distance $(1 / 4,3 / 4$, or 3 miles) from the point of observation. Resource calculations were further delimited by townshiprange. GARNET allows interactive graphic combination of digitized and computer-generated line data files to derive boundary lines of the required categories. The combinations produced 49 subfiles for the Recluse Geologic Model Area from which GARNET calculated coal resources in the following categories: measured ( $1 / 4 \mathrm{mile})$, indicated $(1 / 4$ to $3 / 4$ mile), and inferred ( $3 / 4$ to 3 miles) resources (tables 1, 2, and 3 ) as represented by the respective circular areas on the resource map (fig. 6). The total original resources estimated by manual and computer methods are presented by townshiprange in table 4.

GARNET calculates coal resources using the gridded files generated for coal isopach maps. Volumes of coal are computed for each of the reliability circles (measured, indicated, and inferred) and then multiplied by a density factor based on the rank of the coal. The density factor for subbituminous coal is 1,770 tons/acre-foot. To compute volumes at high resolution, bilinear interpolation is used to divide each grid cell into four subgrids. This interpolation technique fits a hyperbolic surface to the four grid points of each cell by creating vertical cross sections parallel to the grid boundary. The area of each cross section is computed, and the volume is determined by integrating across the cross sectional areas within the limits of required resource categories and reliability circles (Olson, 1977).

\section{ISOPACH AND RESOURCE COMPARISON}

For comparative purposes, the authors overlaid the computer-drawn contour map (fig. 5) onto the hand-drawn isopach map (fig. 4). The combination of the maps is presented in figure 7 .

Initial visual comparison of the combined isopachs in figure 7 shows the geometry to be similar. Particularly note the 2.5-foot and 5-foot contours in the southeast (A) and the 10-foot contour in the northwest extending southward to the middle of the map, then continuing eastward (B-B'); the general proximity of the hand-drawn and computer-generated contours is impressive. The computer-generated contours are a direct result of gridding the original data points-additional data manipulation was not required.

Closer inspection of the map (fig. 7) indicates significant differences between the two methods of contouring. Note the following relationships between the " $C$ " contours: (1) the hand-drawn isopach map in the upper central part shows a clustering of contours from 20 feet to 30 feet, whereas the computer-drawn isopach map displays the area as a collective relationship of 15-foot and 20-foot contours; and (2) the small areas of the 10-foot and within the 25-foot and 30-foot contours of the hand-drawn isopach in the same area are not shown on the computer-generated isopach.

Omission of contour lines on the computergenerated map can be explained by the computer gridding technique. The software assigns only one value to a given grid cell intersection and draws contours between intersections with differing values. Contours are not drawn if the values of the grid intersection remain the same. The grid cell size used in this study ( $0.5 \mathrm{inch}$ ) may have had the effect of generalizing contours, causing the omission of contours that indicate localized peaks of coal thickness. Ten other sets of hand-drawn contours labeled " $\mathrm{D}$ " do not appear on the computergenerated map (fig. 7). Because the " $D$ " contours are confined to small areas, their omission on the computer-generated map may also be a function of the grid cell size. The computer does not plot contours that would occur totally within one grid cell, thereby eliminating contours less than 0.5 inch in diameter.

Additions of contour lines, however, may also occur in computer-generated maps. One computer 
Table 1.-Comparison of manually calculated and computercalculated original resources of subbituminous coal under 500 feet or less of overburden in the Cache coal bed for the Recluse Geologic Model Area, Campbell County, Wyoming, as of Jan. 1, 1980 [Calculations are in millions of short tons; to convert feet to meters multiply by 0.3048 , to convert short tons to metric tons multiply by 0.9071 ; Cache coal bed is in the Tongue River Member of the Paleocene Fort Union Formation]

\begin{tabular}{|c|c|c|c|c|c|c|c|c|c|c|c|c|}
\hline \multirow{2}{*}{$\frac{\text { Reliability Category }}{\text { Thickness of Coal Category (in feet) }}$} & \multicolumn{3}{|c|}{ Measured Resources } & \multirow[b]{2}{*}{ Total } & \multicolumn{3}{|c|}{ Indicated Resources } & \multirow[b]{2}{*}{ Total } & \multicolumn{3}{|c|}{ Inferred Resources } & \multirow[b]{2}{*}{ Total } \\
\hline & $2^{1 / 2-5}$ & $5-10$ & $>10$ & & $2^{1 / 2-5}$ & $5-10$ & $>10$ & & $2^{1 / 2-5}$ & 5-10 & $>10$ & \\
\hline \multicolumn{13}{|l|}{ Mode $^{1} \quad$ Index $^{2}$ Township and Range } \\
\hline M ----- T.1 T. 54 N., R. 74 W. & --- & --- & --- & --- & --- & --- & --- & --- & --- & -- & --- & --- \\
\hline C ---------- & --- & --- & --- & --- & --- & --- & --- & $---\cdot$ & --- & --- & --- & --- \\
\hline M ---- T.2 T. 55 N., R. 74 W. & -- & -- & --- & --- & -- & --- & -- &.--- & --- & --- & --- & --- \\
\hline C - - & --- & -- & --- & -- & --- & --- & --- & --- & --- & --- & --- & --- \\
\hline M ------ T.3 T. 56 N., R. 74 W. & --- & --- & -- & -- & --- & --- & --- & $-\ldots$ & --- & --- & --- & -- \\
\hline C - - & --- & --- & --- & --- & --- & --- & --- & --- & -- & --- & --- & --- \\
\hline M ---- T.4 T. 57 N., R. 74 W. & -- & -- & --- & --- & --- & --- & --- & --- & --- & --- & --- & --- \\
\hline C - - & --- & --- & -- & -- & --- & --- & --- & --- & --- & --- & --- & --- \\
\hline M ----- T.5 T. 57 N., R. 73 W. & -- & --- & --- & --- & -- & --- & --- & --- & --- & --- & -- & --- \\
\hline C - & --- & -- & --- & --- & --- & --- & --- & --- & --- & --- & -- & --- \\
\hline M ------ T.6 T. 56 N., R. 73 W. & -- & -- & --- & --- & --- & --- & --- & --- & --- & --- & --- & --- \\
\hline C - - & --- & --- & --- & --- & --- & -- & --- & -- & --- & --- & --- & --- \\
\hline M ----- T.7 T. 55 N., R. 73 W. & -- & 0.337 & 0.538 & 0.875 & -- & 0.344 & 0.671 & 1.015 & --- & --- & -- & --- \\
\hline 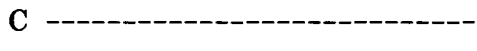 & --- & -- & .232 & .232 & --- & --- & 1.359 & 1.359 & -- & --- & --- & --- \\
\hline M - & 1.51 & 3.072 & --- & 4.582 & 3.19 & 3.030 & --- & 6.220 & -- & 0.340 & --- & 0.340 \\
\hline C - - & 1.167 & 1.169 & 1.894 & 4.230 & 1.150 & 3.815 & 2.058 & 7.023 & -- & .309 & --- & .309 \\
\hline M ----- T.9 T. 54 N., R. 72 W. & .929 & .865 & --- & 1.794 & 3.519 & 4.49 & --- & 8.009 & 0.440 & .097 & --- & .537 \\
\hline C --- & 1.32 & .748 & --- & 2.068 & 2.16 & 8.23 & --- & 10.39 & -- & .455 & --- & 1.273 \\
\hline M ----- T.10 T. 55 N., R. 72 W. & --- & 12.922 & 14.838 & 27.760 & --- & 20.059 & 36.550 & 56.609 & --- & .359 & 6.010 & 6.369 \\
\hline C - - & .476 & 9.358 & 12.886 & 22.720 & .218 & 15.662 & 38.659 & 54.539 & --- & -- & 6.390 & 6.390 \\
\hline M ----- T.11 T. 56 N., R. 72 W. & --- & --- & 48.695 & 48.695 & --- & --- & 43.872 & 43.872 & --- & --- & .009 & .009 \\
\hline C --- & --- & --- & 47.786 & 47.786 & --- & --- & 44.649 & 44.649 & --- & --- & --- & --- \\
\hline
\end{tabular}

TOTALS

\begin{tabular}{llllllllll}
\hline $\mathrm{M}$ - $-1-1$ & & &
\end{tabular}

${ }^{1} \mathbf{M}=$ manual; $\mathrm{C}=$ computer.

${ }^{2}$ Computer code for township-range designation.

contour, the 10-foot contour at location E (fig. 7), does not occur near a hand-drawn contour. An examination of the coal thicknesses in this area indicates that the contour line is feasible, and omission of the contour from the hand-drawn map may have been due to a different interpretation by the geologist.
When comparing the overall appearance of the two maps, the 2.5-foot and 10-foot contours demonstrate the most similar geometries. An isopach map more closely approximating the hand-drawn map may have been obtained by using a smaller grid cell size. However, the authors felt the 0.5-inch grid cell gave adequate isopach 
Table 2.-Comparison of manually calculated and computer-calculated original resources of subbituminous coal under 500-1,000 feet of overburden in the Cache coal bed for the Recluse Geologic Model Area, Campbell County, Wyoming, as of Jan. 1, 1980

[Calculations are in millions of short tons; to convert feet to meters multiply by 0.3048 , to convert short tons to metric tons multiply by 0.9071 ; Cache coal bed is in the Tongue River Member of the Paleocene Fort Union Formation]

\begin{tabular}{|c|c|c|c|c|c|c|c|c|c|c|c|c|}
\hline \multirow{2}{*}{$\frac{\text { Reliability Category }}{\text { Thickness of Coal Category (in feet) }}$} & \multicolumn{3}{|c|}{ Measured Resources } & \multirow[b]{2}{*}{ Total } & \multicolumn{3}{|c|}{ Indicated Resources } & \multirow[b]{2}{*}{ Total } & \multicolumn{4}{|c|}{ Inferred Resources } \\
\hline & $2^{21 / 2-5}$ & $5-10$ & $>10$ & & $2^{1 / 2-5}$ & $5-10$ & $>10$ & & $2 \frac{1}{1 / 2-5}$ & 5-10 & $>10$ & Total \\
\hline \multicolumn{13}{|l|}{ Mode $^{1} \quad$ Index $^{2}$ Township and Range } \\
\hline M ---- T.1 T. 54 N., R. 74 W. & 0.893 & --- & --- & 893 & 2.118 & 0.068 & --- & 2.186 & -- & --- & --- & --- \\
\hline ---------- & .772 & --- & -- & .772 & 1.057 & 1.666 & -- & 2.723 & --- & -- & -- & --- \\
\hline--- T.2 T. 5 & 2.741 & 3.953 & 4.047 & .741 & 5.448 & 15.591 & .01 & & 3.310 & 0.409 & 2.291 & 3.010 \\
\hline ---------- & 1.091 & 5.222 & 1.685 & 7.998 & 4.119 & 14.456 & 8.181 & 756 & 6.817 & .621 & --- & 7.438 \\
\hline -- T.3 T. 5 & 1.68 & & 3.68 & 6 & 13 & 85 & 12. & & 794 & 79 & .761 & \\
\hline -----------. & .542 & 17.032 & 1.811 & 19.385 & 6.584 & 53.368 & 5.469 & 5.421 & 1.270 & 14.636 & .467 & 16.373 \\
\hline - T.4 T. 57 & --- & --- & --- & --- & --- & --- & .269 & 269 & -- & 7.09 & 4.290 & 380 \\
\hline & --- & --- & --- & --- & --- & -- & -- & --- & -- & 7.101 & 2.826 & 9.927 \\
\hline I --_- T.5 T. $57 \mathrm{I}$ & --- & --- & .940 & .940 & --- & --- & 5.577 & 7 & --- & -- & 11.556 & 1.556 \\
\hline ------------- & --- & --- & .840 & .840 & -- & --- & 5.632 & 5.632 & --- & -- & 10.632 & 10.632 \\
\hline - T.6 T. 56 & -- & .668 & 89 & & -- & 9.350 & 147 & & --- & 8.630 & 391 & 40.521 \\
\hline ------ & -- & 3.358 & .340 & 173.698 & .199 & 9.260 & 358.789 & 368.248 & .069 & 10.969 & 27.334 & 38.372 \\
\hline [ --- T.7 T. 5 & 11.567 & 20. & & & 12.472 & 54. & & & 372 & 10.320 & 519 & .211 \\
\hline --_- & 5.878 & 21.8 & 3.271 & & 13.075 & 54.233 & 143.402 & 210.710 & 3.043 & 5.256 & 4.752 & 13.051 \\
\hline --- T.8 T. 5 & 16.221 & & --- & & 41 & 35 & --- & & 6.765 & 2 & --- & 377 \\
\hline ----------- & 6.602 & 21.917 & 1.686 & 30.205 & 16.751 & 99.074 & 10.095 & 125.920 & .645 & 19.653 & 3.645 & 23.943 \\
\hline M ---- T.9 T. 54 N., R. 72 W. & 2.176 & .630 & -- & 2.806 & 5.009 & .304 & --- & 13 & 4.188 & -- & --- & 4.188 \\
\hline & 2.773 & .835 & --- & 3.608 & 4.16 & .870 & --- & 4.990 & 3.132 & .080 & -- & 3.212 \\
\hline A ----- T.10 T. 5 & -- & 14. & 25.150 & & & & & & .236 & & 8.936 & 127 \\
\hline C - - & .730 & 10.587 & 15.197 & 26.514 & 2.910 & 37.063 & 77.093 & 117.066 & 1.876 & 5.967 & 9.761 & 17.604 \\
\hline I - T.11 T. 5 & --- & -- & & & -- & -- & 119 & & --- & -- & 29.106 & 106 \\
\hline C - & -- & --- & 67.342 & 67.342 & -- & --- & 191.883 & 191.883 & --- & --- & 29.131 & 29.131 \\
\hline
\end{tabular}

\section{TOTALS}

M --_-_-_-_-_-_-_--_-_--- 35.27877 .282417 .498530 .05869 .515243 .184786 .6751099 .37418 .66551 .29595 .350165 .310 C - - -

${ }^{1} \mathrm{M}=$ manual; $\mathrm{C}=$ computer.

${ }^{2}$ Computer code for township-range designation.

results and that further refinement was not worth the expenditure in terms of production time or computer costs.

A comparison of total calculated resource tonnages of 2,228 million short tons (manual) and 2,169 million short tons (computer) (table 4) shows a 2.6-percent difference. Point data coal thickness, overburden trace, category radii, and townshiprange limits are constants. The only real variable is the difference in the isopach lines. Because isopach lines are combined with the overburden trace and township-range limits to define areas for resource calculation, differences for several of the categories can be explained. One of these factors is the difference in the thickness value used in the respective calculations: the geologist assigns an average thickness to each area planimetered; the computer integrates areas on a cell-by-cell basis, reflecting the thickness changes illustrated by the isopach map. In simpler terms, the computer does 
Table 3.-Comparison of manually calculated and computer-calculated original resources of subbituminous coal under 1,000-2,000 feet of overburden in the Cache coal bed for the Recluse Geologic Model Area, Campbell County, Wyoming, as of Jan. 1, 1980

[Calculations are in millions of short tons; to convert feet to meters multiply by 0.3048 , to convert short tons to metric tons multiply by 0.9071 ; Cache coal bed is in the Tongue River Member of the Paleocene Fort Union Formation]

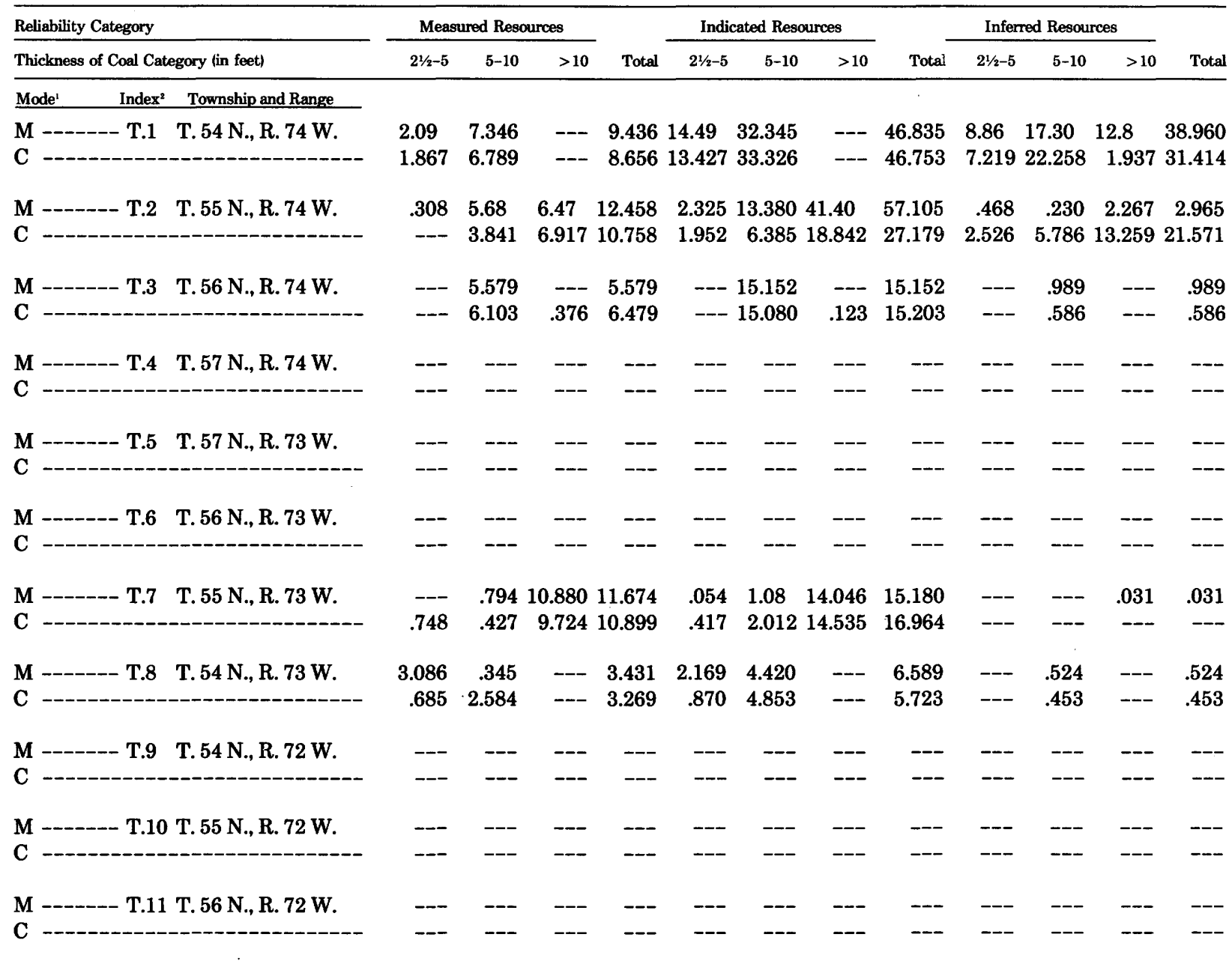

\section{TOTALS}

M - C - -

${ }^{1} \mathbf{M}=$ manual; $\mathbf{C}=$ computer.

${ }^{2}$ Computer code for township-range designation.

not average area thicknesses but uses the value of each grid cell or portion thereof to calculate the numerical tonnage value of the area.

\section{CONCLUSION}

The NCRDS method and the manual method for calculating coal resources apply the rules defined by the U.S. Geological Survey (Wood and others, 1983) to produce reliable maps and resource estimates. Accuracy of both the computer and manual isopach configurations can be debated, and both can be edited to satisfy geological interpretation. The computer does not make subjective decisions concerning the configuration of the isopach; it can only apply programmed mathematical relationships to data submitted by the user. 
Table 4.-Total manually calculated and computer-calculated original resources of subbituminous coal in the Cache coal bed for the Recluse Geologic Model Area, Campbell County, Wyoming

[Manual calculation as of Jan. 1, 1979; computer calculations as of Jan. 1, 1980. Calculations are for coal under 2,000 feet or less of overburden]

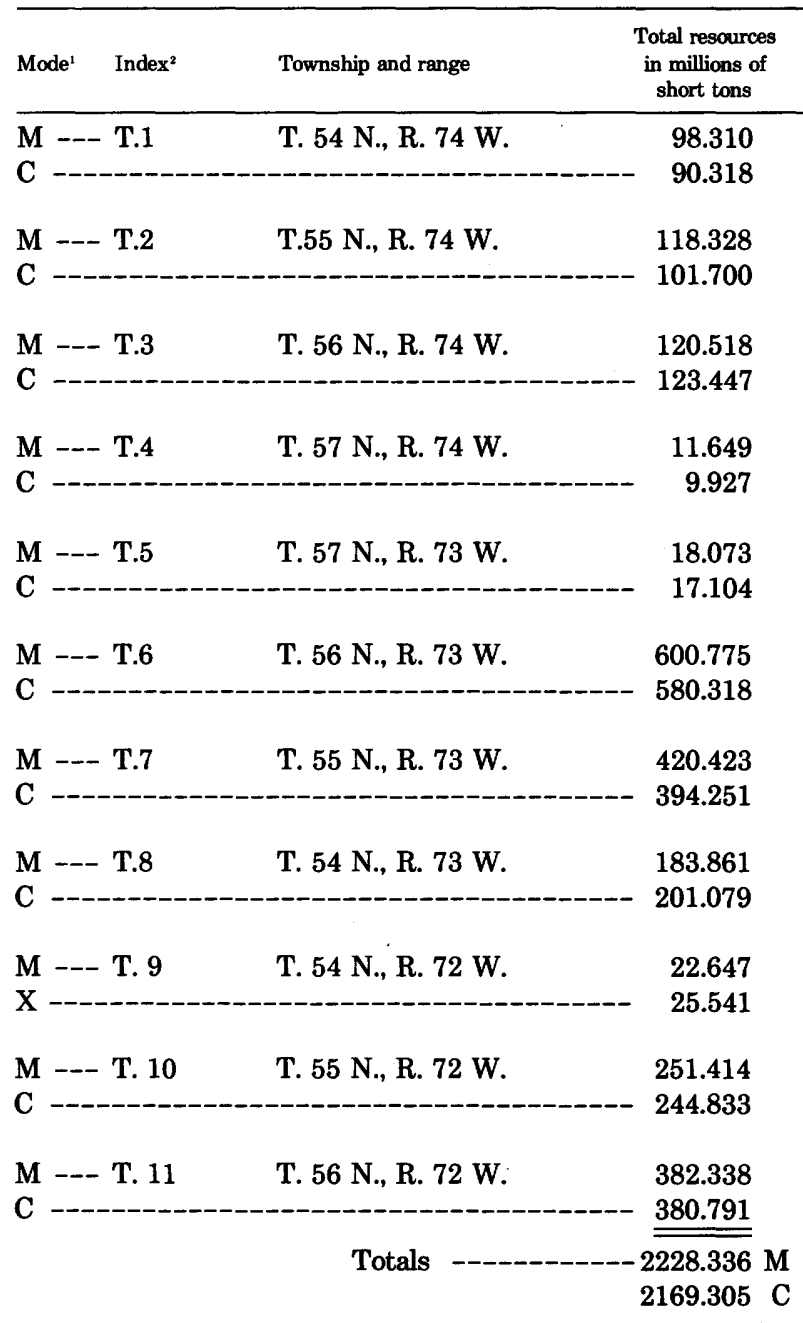

${ }^{1} \mathrm{M}=$ manual; $\mathrm{C}=$ computer.

${ }^{2}$ Computer code for township-range designation.

\section{REFERENCES CITED}

Baker, A. A., 1929, The northward extension of the Sheridan coal field, Big Horn and Rosebud Counties, Montana: U.S. Geological Survey Bulletin 806-B, p. 15-67.
Bass, N. W., 1924, Coal in the Tongue River Valley, Montana: U.S. Department of Interior Press Memorandum 16748, Feb. 12, 1924.

Bryson, R. P., and Bass, N. W., 1973, Geology of the Moorhead coal field, Powder River and Rosebud Counties, Montana: U.S. Geological Survey Bulletin 1338, 116 p. [1974].

Cargill, S. M., Olson, A. C., Medlin, A. L., and Carter, M. D., 1976, PACER-Data entry, retrieval, and update for the National Coal Resources Data System (phase I): U.S. Geological Survey Professional Paper 978, 107 p.

Culbertson, W. C., and Klett, M. C., 1975, Preliminary geologic map and coal sections of the Jones Draw quadrangle, Sheridan County, Wyoming: U.S. Geological Survey Miscellaneous Field Studies Map MF-726, scale 1:24,000, 2 sheets.

Culbertson, W. C., and Mapel, W. J., 1976, Coal in the Wasatch Formation, northwest part of the Powder River Basin near Sheridan, Sheridan County, Wyoming, in Wyoming Geological Association Guidebook, 28th Annual Field Conference, 1976, p. 193-202.

Culbertson, W. C., Kent, B. H., and Mapel, W. J., 1979, Preliminary diagrams showing correlation of coal beds in the Fort Union and Wasatch Formations across the Northern Powder River Basin, northeastern Wyoming and southeastern Montana: U.S. Geological Survey Open-File Report 79-1201, 11 p., 2 sheets.

Hobbs, R. G., 1980, 1976 Coal exploratory drilling: core description and coal analyses, Recluse Geologic Analysis Area, Northern Campbell County, Wyoming: U.S. Geological Survey Open-File Report 80-1160, 53 p.

Kent, B. H., Berlage, L. J., and Boucher, E. M., 1980, Stratigraphic framework of coal beds underlying the western part of the Recluse $1^{\circ} \times 1 / 2^{\circ}$ quadrangle, Campbell County, Wyoming: U.S. Geological Survey Coal Investigations Map C-81C, 2 pls.

Matson, R. E., Blumer, J. W., and Wegelin, L. A., 1973, Quality and reserves of strippable coal, selected deposits, southeastern Montana: Montana Bureau of Mines and Geology Bulletin 91, 135 p.

McKay, E. J., 1973, The preliminary geologic map of the Croton $1 \mathrm{NE}$ (Homestead Draw) quadrangle, Campbell County, Wyoming: U.S. Geological Survey Open-File Report 73-168, scale 1:24,000.

Olive, W. W., 1957, The Spotted Horse coal field, Sheridan and Campbell Counties, Wyoming: U.S. Geological Survey Bulletin $1050,83 \mathrm{p}$.

Olson, A. C., 1977, Graphic Analysis of Resources by Numerical Evaluation Techniques (GARNET): Computers \& Geosciences, v. 3, no. 3, p. 539-545.

1980, GARNET-Computer applications software for the National Coal Resources Data System: U.S. Geological Survey Open-File Report 80-228, 160 p.

Taff, J. A., 1909, The Sheridan coal field, Wyoming: U.S. Geological Survey Bulletin 341-B, p. 123-150.

Thom, W. T., and Dobbin, C. E., 1924, Stratigraphy of Cretaceous-Eocene transition beds in eastern Montana and the Dakotas: Geological Society of America Bulletin, v. 35, p. 481-506.

U.S. Geological Survey, 1971, Homestead Draw SW, Wyo., 7.5-minute quadrangle, Campbell County, Wyoming: scale $1: 24,000$. 


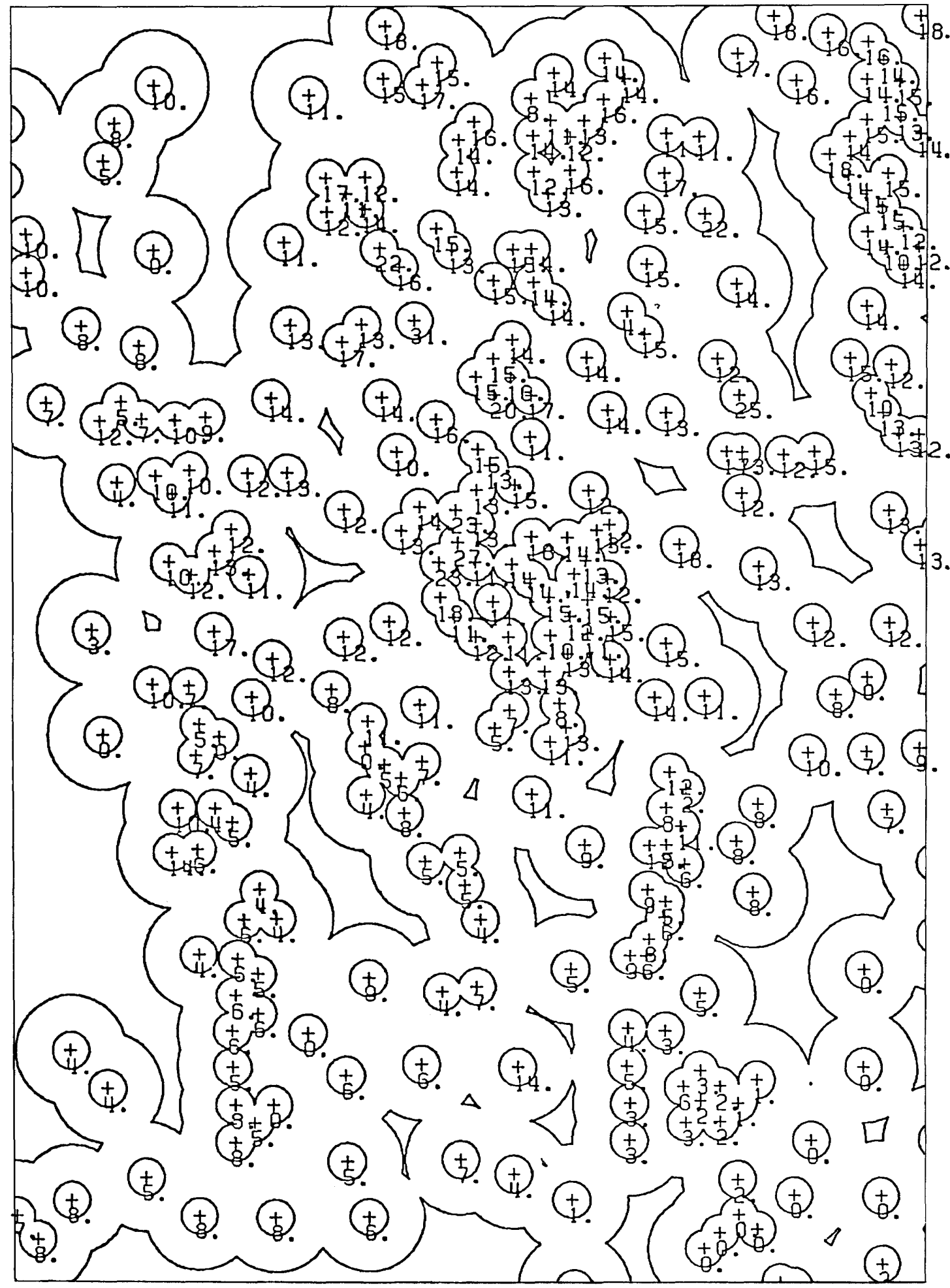

FIGURE 6. Computer-generated resource map showing location of data points and thickness of Cache coal bed at each point. Circular areas represent $1 / 4-, 3 / 4-$, and $3-$ mile (not shown) radii, corresponding to outer limits of measured, indicated, and inferred coal resource reliability categories, respectively. (Latitude $=44^{\circ} 37^{\prime} 30^{\prime \prime}$ to $44^{\circ} 52^{\prime} 30^{\prime \prime} \mathrm{N}$, longitude $=105^{\circ} 30^{\prime} 00^{\prime \prime}$ to $105^{\circ} 45^{\prime} 00^{\prime \prime} \mathrm{W}$. Figure 4 covers the same area.) Original scale at 1:50,000. 


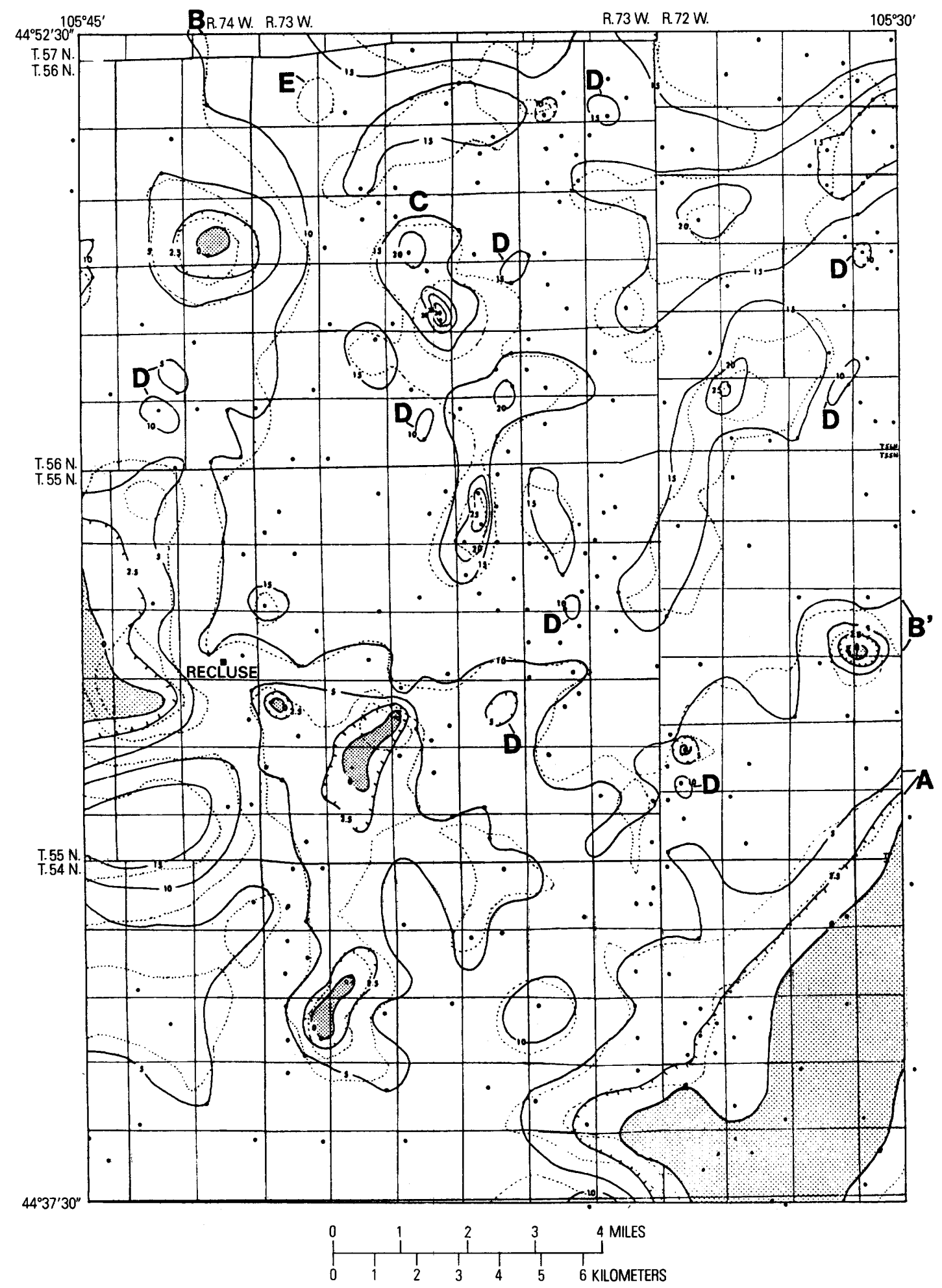

FIGURE 7. Computer-generated isopach map (dotted lines) from figure 5 superimposed on hand-drawn isopach map from figure 4 of the Cache coal bed for comparative use and discussion. Shaded area $=$ coal is absent. Original scale at 1:50,000. 
1971, Pitch Draw, Wyo., 7.5-minute quadrangle, Campbell County, Wyoming: scale 1:24,000.

1971, Recluse, Wyo., 7.5-minute quadrangle, Campbell County, Wyoming: scale 1:24,000.

1971, White Tail Butte, Wyo., 7.5-minute quadrangle, Campbell County, Wyoming: scale 1:24,000.

Wood, G. H., Kehn, T. M., Carter, M. D., and Culbertson, W. C., 1983, Coal resource classification system of the U.S. Geological Survey: U.S. Geological Survey Circular 891, $65 \mathrm{p}$. 


\section{APPENDIXES: SOURCES OF COAL-BED DATA}

APPENDIX A. WHITE TAIL BUTTE QUADRANGLE

APPENDIX B. HOMESTEAD DRAW SW QUADRANGLE

APPENDIX C. PITCH DRAW QUADRANGLE

APPENDIX D. RECLUSE QUADRANGLE 
APPENDIX A.

SOURCES OF COAL-BED DATA IN THE WHITE TAIL BUTTE QUADRANGLE 
[List of wells, locations, and ground elevations for all wells in the Recluse Geologic Model Area including wells that do not penetrate the Cache Coal Bed]

[To convert feet to meters multiply by 0.3048 ]

\begin{tabular}{|c|c|c|c|}
\hline $\begin{array}{l}\text { We11 } \\
\text { No. } \\
\text { on map }\end{array}$ & $\begin{array}{l}\text { Company and } \\
\text { we } 11 \text { No. }\end{array}$ & Location & $\begin{array}{l}\text { Ground } \\
\text { elevation } \\
\text { (ft) }\end{array}$ \\
\hline$B-1$ & $\begin{array}{l}\text { Petroleum, Inc. } \\
1 \text { Government - Phillips }\end{array}$ & $\begin{array}{l}\mathrm{NW} 1 / 4 \mathrm{NE} 1 / 4 \text { sec. } 3, \\
\mathrm{~T} \cdot 56 \mathrm{~N} \cdot, \mathrm{R} \cdot 72 \mathrm{~W} .\end{array}$ & 3,900 \\
\hline$B-2$ & $\begin{array}{l}\text { CRA Inc. and At antic } \\
\text { Richfield Co. } \\
\text { 1-3 Gibbs - Government }\end{array}$ & $\begin{array}{l}\text { SE } 1 / 4 \text { SW } 1 / 4 \text { sec. } 3, \\
\text { T. } 56 \text { N., R. } 72 \text { W. }\end{array}$ & 3,990 \\
\hline$B-3$ & $\begin{array}{l}\text { Pan American Petroleum Co. } \\
1 \text { USA - Moore }\end{array}$ & $\begin{array}{l}\text { NW } 1 / 4 \text { SW } 1 / 4 \text { sec. } 3, \\
\text { T. } 56 \text { N., R. } 72 \text { W. }\end{array}$ & 3,998 \\
\hline$B-4$ & $\begin{array}{l}\text { J. M. Huber Corp. } \\
1-4 \text { Federal - Grace }\end{array}$ & $\begin{array}{l}\text { SE } 1 / 4 \text { SE } 1 / 4 \text { sec. } 4, \\
\text { T. } 56 \text { N., R. } 72 \text { W. }\end{array}$ & 4,055 \\
\hline$B-5$ & $\begin{array}{l}\text { Southland Royalty Co. } \\
1 \text { Whitetail - Federal }\end{array}$ & $\begin{array}{l}\text { SE } 1 / 4 \mathrm{NE} 1 / 4 \text { sec. } 4, \\
\text { T. } 56 \text { N., R. } 72 \text { W. }\end{array}$ & 3,958 \\
\hline$B-6$ & $\begin{array}{l}\text { McMahon-Bullington } \\
\text { Drilling Co. } \\
\text { 2-4 George Emigh }\end{array}$ & $\begin{array}{l}\text { SE } 1 / 4 \text { NW } 1 / 4 \text { sec. } 4, \\
\text { T. } 56 \text { N., R. } 72 \text { W. }\end{array}$ & 3,845 \\
\hline$B-7$ & $\begin{array}{l}\text { Kissinger Petroleum Corp. } \\
1 \text { Pucket Federal }\end{array}$ & $\begin{array}{l}\text { SE } 1 / 4 \text { SE } 1 / 4 \text { sec. } 5 \\
\text { T. } 56 \text { N., R. } 72 \text { W. }\end{array}$ & 4,013 \\
\hline$B-8$ & $\begin{array}{l}\text { Southland Royalty Co. } \\
1-5 \text { Whitetail - USA }\end{array}$ & $\begin{array}{l}\text { NW } 1 / 4 \text { NE } 1 / 4 \text { sec. } 5 \text {, } \\
\text { T. } 56 \text { N., R. } 72 \text { W. }\end{array}$ & 3,921 \\
\hline$B-9$ & $\begin{array}{l}\text { Southland Royalty Co. } \\
5-2 \text { Federal }\end{array}$ & $\begin{array}{l}\text { NW } 1 / 4 \text { SW } 1 / 4 \text { sec. } 5, \\
\text { T. } 56 \text { N., R. } 72 \text { W. }\end{array}$ & 4,028 \\
\hline$B-10$ & $\begin{array}{l}\text { Ames Oil \& Gas Co. and } \\
\text { Terra Resources } \\
1 \text { Terra - Ames - Federal }\end{array}$ & $\begin{array}{l}\text { SE } 1 / 4 \text { SE } 1 / 4 \text { sec. } 6, \\
\text { T. } 56 \text { N., R. } 72 \text { W. }\end{array}$ & 4,138 \\
\hline$B-11$ & $\begin{array}{l}\text { At lantic Richfield Co. } \\
\text { 1-A Arco - Federal - Beard }\end{array}$ & $\begin{array}{l}\text { NW } 1 / 4 \text { SE } 1 / 4 \text { sec. } 1 \\
\text { T. } 56 \text { N., R. } 73 \text { W. }\end{array}$ & 4,114 \\
\hline$B-12$ & $\begin{array}{l}\text { Kissinger Petroleum Corp. } \\
\text { 3-1 Federal }\end{array}$ & $\begin{array}{l}\text { SE } 1 / 4 \text { SW } 1 / 4 \text { sec. } 1, \\
\text { T. } 56 \text { N., R. } 73 \text { W. }\end{array}$ & 4,016 \\
\hline$B-13$ & $\begin{array}{l}\text { Powder River Oil Co. } \\
6-1 \text { Beason }\end{array}$ & $\begin{array}{l}\text { SE } 1 / 4 \mathrm{NW} 1 / 4 \text { sec. } 1, \\
\text { T. } 56 \text { N., R. } 73 \text { W. }\end{array}$ & 4,026 \\
\hline
\end{tabular}




\begin{tabular}{|c|c|c|c|}
\hline $\begin{array}{l}\text { We11 } \\
\text { No. } \\
\text { on map }\end{array}$ & $\begin{array}{l}\text { Company and } \\
\text { we } 11 \text { No. }\end{array}$ & Location & $\begin{array}{l}\text { Ground } \\
\text { elevation } \\
\quad(f t)\end{array}$ \\
\hline$B-14$ & $\begin{array}{l}\text { Eason Oil Co. } \\
1-2 \text { Moore - Hoblit }\end{array}$ & $\begin{array}{l}\text { NW } 1 / 4 \text { SE } 1 / 4 \text { sec. } 2, \\
\text { T. } 56 \text { N., R. } 73 \text { W. }\end{array}$ & 4,086 \\
\hline$B-15$ & $\begin{array}{l}\text { Atlantic Richfield Co. } \\
2-2-\text { A Federal - Beard }\end{array}$ & $\begin{array}{l}\text { SE } 1 / 4 \text { SW } 1 / 4 \text { sec. } 2, \\
\text { T. } 56 \text { N., R. } 73 \text { W. }\end{array}$ & 4,106 \\
\hline$B-16$ & $\begin{array}{l}\text { Montana Bureau of Mines } \\
\text { and Geology } \\
\text { US } 747\end{array}$ & $\begin{array}{l}\text { SE } 1 / 4 \mathrm{NE} 1 / 4 \text { sec. } 3, \\
\text { T. } 56 \mathrm{~N} ., \mathrm{R}_{\bullet} 73 \mathrm{~W} .\end{array}$ & 4,144 \\
\hline$B-17$ & $\begin{array}{l}\text { Kissinger Petroleum Corp. } \\
\text { and Pan American } \\
1-10 \text { Snoddy }\end{array}$ & $\begin{array}{l}\text { NW } 1 / 4 \mathrm{NE} 1 / 4 \text { sec. } 10 \\
\text { T. } 56 \mathrm{~N} \cdot, \mathrm{R} \cdot 73 \mathrm{~W} .\end{array}$ & 4,058 \\
\hline$B-18$ & $\begin{array}{l}\text { Kissinger - Amoco - Exeter } \\
6-11 \text { Anderson - Snoddy }\end{array}$ & $\begin{array}{l}\text { SE } 1 / 4 \mathrm{NW} 1 / 4 \text { sec. } 11 \\
\text { T. } 56 \mathrm{~N} ., \mathrm{R} .73 \mathrm{~W} .\end{array}$ & 4,100 \\
\hline$B-19$ & $\begin{array}{l}\text { Montana Bureau of Mines } \\
\text { and Geology } \\
\text { US } 7410\end{array}$ & $\begin{array}{l}\mathrm{SE} 1 / 4 \mathrm{SW} 1 / 4 \text { sec. } 11 \\
\text { T. } 56 \mathrm{~N} ., \mathrm{R} \cdot 73 \mathrm{~W} .\end{array}$ & 4,235 \\
\hline$B-20$ & $\begin{array}{l}\text { Kissinger - Exeter } \\
\text { 14-11 Phi11ips - Federa1 }\end{array}$ & $\begin{array}{l}\mathrm{SE} 1 / 4 \mathrm{SW} 1 / 4 \text { sec. } 11 \\
\text { T. } 56 \mathrm{~N} ., \mathrm{R} \cdot 73 \mathrm{~W} .\end{array}$ & 4,232 \\
\hline$B-21$ & $\begin{array}{l}\text { Kissinger - Exeter } \\
2-11 \text { Phi11ips - Snoddy }\end{array}$ & $\begin{array}{l}\text { NW } 1 / 4 \mathrm{NE} 1 / 4 \text { sec. } 11 \\
\text { T. } 56 \text { N., R. } 73 \text { W. }\end{array}$ & 4,105 \\
\hline$B-22$ & $\begin{array}{l}\text { Montana Bureau of Mines } \\
\text { and Geology } \\
\text { US } 749\end{array}$ & $\begin{array}{l}\mathrm{NE} 1 / 4 \mathrm{SE} 1 / 4 \text { sec. } 11 \\
\mathrm{~T} .56 \mathrm{~N} ., \mathrm{R} .73 \mathrm{~W} .\end{array}$ & 4,193 \\
\hline$B-23$ & $\begin{array}{l}\text { Kissinger Petroleum Corp. } \\
\text { 8-11 Anderson - Phillips - } \\
\text { Federa1 }\end{array}$ & $\begin{array}{l}\text { SE } 1 / 4 \mathrm{NE} 1 / 4 \text { sec. } 11 \\
\text { T. } 56 \mathrm{~N} ., \mathrm{R} .73 \mathrm{~W} .\end{array}$ & 4,189 \\
\hline$B-24$ & $\begin{array}{l}\text { Kissinger - Exeter } \\
\text { 16-11 Phil1ips - Federal }\end{array}$ & $\begin{array}{l}\text { SE } 1 / 4 \text { SE } 1 / 4 \text { sec. } 11 \\
\text { T. } 56 \text { N., R. } 72 \text { W. }\end{array}$ & 4,142 \\
\hline$B-25$ & $\begin{array}{l}\text { At lantic Richfield Co. } \\
\text { 1-12 Federal - Arco - Beard }\end{array}$ & $\begin{array}{l}\text { NW } 1 / 4 \mathrm{NW} 1 / 4 \text { sec. } 12, \\
\text { T. } 56 \text { N., R. } 73 \text { W. }\end{array}$ & 4,167 \\
\hline$B-26$ & $\begin{array}{l}\text { Montana Bureau of Mines } \\
\text { and Geology } \\
\text { US } 748\end{array}$ & $\begin{array}{l}\text { SW } 1 / 4 \mathrm{NW} 1 / 4 \text { sec. } 12, \\
\text { T. } 56 \text { N., R. } 73 \text { W. }\end{array}$ & 4,212 \\
\hline
\end{tabular}




\begin{tabular}{|c|c|c|c|}
\hline $\begin{array}{l}\text { We11 } \\
\text { No. } \\
\text { on map }\end{array}$ & $\begin{array}{c}\text { Company and } \\
\text { we } 11 \text { No. }\end{array}$ & Location & $\begin{array}{l}\text { Ground } \\
\text { elevation } \\
\text { (ft) }\end{array}$ \\
\hline$B-27$ & $\begin{array}{l}\text { Petroleum Inc. - Atlantic - } \\
\text { Richfield Co. } \\
2 \text { Atlantic - Federal }\end{array}$ & $\begin{array}{l}\text { NW } 1 / 4 \text { sW } 1 / 4 \text { sec. } 7 \\
\text { T. } 56 \text { N., R. } 72 \text { W. }\end{array}$ & 4,005 \\
\hline$B-28$ & $\begin{array}{l}\text { Petroleum Inc. } \\
1 \text { Government - Atlantic }\end{array}$ & $\begin{array}{l}\text { NW } 1 / 4 \text { SE } 1 / 4 \text { sec. } 7, \\
\text { T. } 56 \text { N., R. } 72 \text { W. }\end{array}$ & 4,054 \\
\hline$B-29$ & $\begin{array}{l}\text { CRA Inc. } \\
9-1 \text { Gibbs - Federal }\end{array}$ & $\begin{array}{l}\text { SE } 1 / 4 \text { SW } 1 / 4 \text { sec. } 9, \\
\text { T. } 56 \text { N., R. } 72 \text { W. }\end{array}$ & 4,240 \\
\hline$B-30$ & $\begin{array}{l}\text { CRA Inc. } \\
\text { 789-2 Ames - Federal }\end{array}$ & $\begin{array}{l}\text { NW } 1 / 4 \text { SE } 1 / 4 \text { sec. } 9, \\
\text { T. } 56 \text { N., R. } 72 \text { W. }\end{array}$ & 4,113 \\
\hline$B-31$ & $\begin{array}{l}\text { CRA Inc. } \\
2-9 \text { Kerr - Government }\end{array}$ & $\begin{array}{l}\text { SE } 1 / 4 \text { NE } 1 / 4 \text { sec. } 9, \\
\text { T. } 56 \text { N., R. } 72 \text { W. }\end{array}$ & 4,104 \\
\hline$B-32$ & $\begin{array}{l}\text { Montana Bureau of Mines } \\
\text { and Geology } \\
\text { US } 7420\end{array}$ & $\begin{array}{l}\mathrm{SE} 1 / 4 \mathrm{SE} 1 / 4 \text { sec. } 9, \\
\text { T. } 56 \text { N., R. } 72 \text { W. }\end{array}$ & 4,124 \\
\hline$B-33$ & $\begin{array}{l}\text { J. M. Huber Corp. } \\
\text { 1-10 Federal - Grace }\end{array}$ & $\begin{array}{l}\text { NW } 1 / 4 \text { NW } 1 / 4 \text { sec. } 10, \\
\text { T. } 56 \text { N., R. } 72 \text { W. }\end{array}$ & 4,054 \\
\hline$B-34$ & $\begin{array}{l}\text { CRA Inc. } \\
3-10 \text { Gibbs - Government }\end{array}$ & $\begin{array}{l}\text { SE } 1 / 4 \text { NW } 1 / 4 \text { sec. } 10 \\
\text { T. } 56 \text { N., R. } 72 \text { W. }\end{array}$ & 4,128 \\
\hline$B-35$ & $\begin{array}{l}\text { Ames Oil \& Gas Co. } \\
1 \text { Ames - Federa1 }\end{array}$ & $\begin{array}{l}\text { NW } 1 / 4 \text { SE } 1 / 4 \text { sec. } 10, \\
\text { T. } 56 \text { N., R. } 72 \text { W. }\end{array}$ & 4,136 \\
\hline$B-36$ & $\begin{array}{l}\text { W. West - E. Boland } \\
1-15 \text { Federa1 }\end{array}$ & $\begin{array}{l}\text { SE } 1 / 4 \text { SW } 1 / 4 \text { sec. } 15 \\
\text { T. } 56 \text { N., R. } 72 \text { W. }\end{array}$ & 3,966 \\
\hline$B-37$ & $\begin{array}{l}\text { CRA Inc. } \\
1-15 \text { Chorney - Federal }\end{array}$ & $\begin{array}{l}\text { NW } 1 / 4 \text { NW } 1 / 4 \text { sec. } 15, \\
\text { T. } 56 \text { N., R. } 72 \text { W. }\end{array}$ & 4,084 \\
\hline$B-38$ & $\begin{array}{l}\text { Sierra Trading Corp. } \\
2-15 \text { Federal }\end{array}$ & $\begin{array}{l}\text { NW } 1 / 4 \text { SW } 1 / 4 \text { sec. } 15, \\
\text { T. } 56 \text { N., R. } 72 \text { W. }\end{array}$ & 4,168 \\
\hline$B-39$ & $\begin{array}{l}\text { Sierra Trading Corp. } \\
1-16 \text { State }\end{array}$ & $\begin{array}{l}\text { SE } 1 / 4 \text { SE } 1 / 4 \text { sec. } 16, \\
\text { T. } 56 \text { N., R. } 72 \text { W. }\end{array}$ & 4,024 \\
\hline$B-40$ & $\begin{array}{l}\text { CRA Inc. } \\
2-398 \text { State }\end{array}$ & $\begin{array}{l}\text { SE } 1 / 4 \mathrm{NE} 1 / 4 \text { sec. } 16 \\
\text { T. } 56 \text { N., R. } 72 \text { W. }\end{array}$ & 4,043 \\
\hline$B-41$ & $\begin{array}{l}\text { CRA Inc. } \\
1-397 \text { State }\end{array}$ & $\begin{array}{l}\text { NW } 1 / 4 \text { NE } 1 / 4 \text { sec. } 16, \\
\text { T. } 56 \text { N., R. } 72 \text { W. }\end{array}$ & 4,060 \\
\hline
\end{tabular}




\begin{tabular}{|c|c|c|c|}
\hline $\begin{array}{l}\text { We } 11 \\
\text { No. } \\
\text { on map }\end{array}$ & $\begin{array}{l}\text { Company and } \\
\text { we11 No. }\end{array}$ & Location & $\begin{array}{l}\text { Ground } \\
\text { elevation } \\
\quad(\mathrm{ft})\end{array}$ \\
\hline$B-42$ & $\begin{array}{l}\text { Davis Oil } 1 \text { Co. } \\
1 \text { Donald - Federal }\end{array}$ & $\begin{array}{l}\text { NW } 1 / 4 \text { SE } 1 / 4 \text { sec. } 18, \\
\text { T. } 56 \text { N., R. } 72 \text { W. }\end{array}$ & 4,066 \\
\hline$B-43$ & $\begin{array}{l}\text { Davis Oil Co. } \\
1-Z \text { George Emigh }\end{array}$ & $\begin{array}{l}\text { NW } 1 / 4 \text { NW } 1 / 4 \text { sec. } 18, \\
\text { T. } 56 \text { N., R. } 72 \text { W. }\end{array}$ & 4,124 \\
\hline$B-44$ & $\begin{array}{l}\text { Powder River Co. } \\
8-13 \text { Tays }\end{array}$ & $\begin{array}{l}\text { SE } 1 / 4 \text { NE } 1 / 4 \text { sec. } 13, \\
\text { T. } 55 \text { N., R. } 73 \text { W. }\end{array}$ & 4,037 \\
\hline$B-45$ & $\begin{array}{l}\text { Anderson Oil Co. } \\
1 \text { Kissinger - Exeter- } \\
\text { Federal }\end{array}$ & $\begin{array}{l}\text { NW } 1 / 4 \mathrm{NE} 1 / 4 \text { sec. } 14, \\
\text { T. } 56 \text { N., R. } 73 \text { W. }\end{array}$ & 4,133 \\
\hline$B-46$ & $\begin{array}{l}\text { Montana Bureau of Mines } \\
\text { and Geology } \\
\text { US } 7411\end{array}$ & $\begin{array}{l}\text { SE } 1 / 4 \mathrm{NW} 1 / 4 \text { sec. } 14, \\
\text { T. } 56 \text { N., R. } 73 \text { W. }\end{array}$ & 4,167 \\
\hline$B-47$ & $\begin{array}{l}\text { Davis Oil Co. } \\
2 \text { Phillips - Federal }\end{array}$ & $\begin{array}{l}\mathrm{SE} 1 / 4 \mathrm{SW} 1 / 4 \text { sec. } 14, \\
\text { T. } 56 \text { N., R. } 73 \text { W. }\end{array}$ & 4,118 \\
\hline$B-48$ & $\begin{array}{l}\text { Davis Oil Co. } \\
1 \text { Phillips - Federal }\end{array}$ & $\begin{array}{l}\text { SW } 1 / 4 \text { SW } 1 / 4 \text { sec. } 14, \\
\text { T. } 56 \text { N., R. } 73 \text { W. }\end{array}$ & 4,205 \\
\hline$B-49$ & $\begin{array}{l}\text { Kissinger, Pan American, } \\
\text { Petroleum Corp. \& Eason Oil } \\
\text { 8-22 Snoddy }\end{array}$ & $\begin{array}{l}\mathrm{SE} 1 / 4 \mathrm{NE} 1 / 4 \text { sec. } 22, \\
\text { T. } 56 \text { N., R. } 73 \text { W. }\end{array}$ & 4,106 \\
\hline$B-50$ & $\begin{array}{l}\text { Montana Bureau of Mines } \\
\text { and Geology } \\
\text { US } 7412\end{array}$ & $\begin{array}{l}\text { NW } 1 / 4 \mathrm{NW} 1 / 4 \text { sec. } 23, \\
\text { T. } 56 \text { N., R. } 73 \text { W. }\end{array}$ & 4,180 \\
\hline$B-51$ & $\begin{array}{l}\text { Davis Oil Co. } \\
1 \text { Morse - Federal }\end{array}$ & $\begin{array}{l}\text { SE } 1 / 4 \text { NW } 1 / 4 \text { sec. } 23, \\
\text { T. } 56 \text { N., R. } 73 \text { W. }\end{array}$ & 4,167 \\
\hline$B-52$ & $\begin{array}{l}\text { Davis Oil Co. } \\
2 \text { Morse }\end{array}$ & $\begin{array}{l}\text { NW } 1 / 4 \mathrm{SE} 1 / 4 \text { sec. } 23, \\
\text { T. } 56 \text { N., R. } 73 \text { W. }\end{array}$ & 4,142 \\
\hline$B-53$ & $\begin{array}{l}\text { Montana Bureau of Mines } \\
\text { and Geology } \\
\text { US } 7418\end{array}$ & $\begin{array}{l}\text { SW } 1 / 4 \text { SW } 1 / 4 \text { sec. } 24, \\
\text { T. } 56 \text { N., R. } 73 \text { W. }\end{array}$ & 4,218 \\
\hline$B-54$ & $\begin{array}{l}\text { McMahon-Bullington } \\
\text { Drilling Co. } \\
\text { 1-24 Morse }\end{array}$ & $\begin{array}{l}\mathrm{NE} 1 / 4 \mathrm{NE} 1 / 4 \text { sec. } 24, \\
\text { T. } 56 \text { N., R. } 73 \text { W. }\end{array}$ & 4,001 \\
\hline$B-55$ & $\begin{array}{l}\text { YHS - Kissinger } \\
1 \text { Atlantic - Federal }\end{array}$ & $\begin{array}{l}\text { NW } 1 / 4 \text { SW } 1 / 4 \text { sec. } 20, \\
\text { T. } 56 \text { N., R. } 72 \text { W. }\end{array}$ & 4,131 \\
\hline
\end{tabular}




\begin{tabular}{|c|c|c|c|}
\hline $\begin{array}{l}\text { We11 } \\
\text { No. } \\
\text { on map }\end{array}$ & $\begin{array}{l}\text { Company and } \\
\text { well No. }\end{array}$ & Location & $\begin{array}{l}\text { Ground } \\
\text { elevation } \\
\quad(\mathrm{ft})\end{array}$ \\
\hline$B-56$ & $\begin{array}{l}\text { Davis Oil Co. } \\
1 \text { S. Whitetail }\end{array}$ & $\begin{array}{l}\text { SE } 1 / 4 \text { SE } 1 / 4 \text { sec. } 21 \\
\text { T. } 56 \text { N., R. } 72 \text { W. }\end{array}$ & 3,877 \\
\hline$B-57$ & $\begin{array}{l}\text { Exeter Drilling Co. } \\
4-22 \text { Andrikopoulos - Federal }\end{array}$ & $\begin{array}{l}\text { NW } 1 / 4 \text { NW } 1 / 4 \text { sec. } 22, \\
\text { T. } 56 \text { N., R. } 72 \text { W. }\end{array}$ & 4,012 \\
\hline$B-58$ & $\begin{array}{l}\text { Montana Bureau of Mines } \\
\text { and Geology } \\
\text { US } 7419\end{array}$ & $\begin{array}{l}\text { NW } 1 / 4 \text { NW } 1 / 4 \text { sec. } 22 \\
\text { T. } 56 \text { N., R. } 72 \text { W. }\end{array}$ & 4,027 \\
\hline$B-59$ & $\begin{array}{l}\text { American Minerals Management } \\
1 \text { Whitetail }\end{array}$ & $\begin{array}{l}\text { NW } 1 / 4 \text { NE } 1 / 4 \text { sec. } 22, \\
\text { T. } 56 \text { N., R. } 72 \text { W. }\end{array}$ & 3,924 \\
\hline$B-60$ & $\begin{array}{l}\text { Pan American Petroleum Corp. } \\
1-B \text { USA - Moore }\end{array}$ & $\begin{array}{l}\mathrm{SE} 1 / 4 \mathrm{NW} 1 / 4 \text { sec. } 22, \\
\text { T. } 56 \text { N., R. } 72 \text { W. }\end{array}$ & 4,005 \\
\hline$B-61$ & $\begin{array}{l}\text { Davis Oil Co. } \\
1 \text { Quinn - Federa1 }\end{array}$ & $\begin{array}{l}\text { NW } 1 / 4 \text { SW } 1 / 4 \text { sec. } 27, \\
\text { T. } 56 \text { N., R. } 72 \text { W. }\end{array}$ & 4,136 \\
\hline$B-62$ & $\begin{array}{l}\text { Davis Oil Co. } \\
\text { 1-Z Glenn }\end{array}$ & $\begin{array}{l}\text { NW } 1 / 4 \mathrm{SE} 1 / 4 \text { sec. } 28, \\
\text { T. } 56 \text { N., R. } 72 \text { W. }\end{array}$ & 4,040 \\
\hline$B-63$ & $\begin{array}{l}\text { Southland Royalty Co. } \\
1-30 \text { Chan Federal }\end{array}$ & $\begin{array}{l}\mathrm{NE} 1 / 4 \mathrm{SE} 1 / 4 \text { sec. } 30 \\
\text { T. } 56 \mathrm{~N} ., \mathrm{R} \cdot 72 \mathrm{~W} .\end{array}$ & 4,121 \\
\hline$B-64$ & $\begin{array}{l}\text { Kissinger Petroleum Co. } \\
1-25 \text { Phillips - Federa1 }\end{array}$ & $\begin{array}{l}\mathrm{NE} 1 / 4 \mathrm{NE} 1 / 4 \text { sec. } 25 \\
\text { T. } 56 \mathrm{~N} ., \mathrm{R} \cdot 73 \mathrm{~W} .\end{array}$ & 4,151 \\
\hline$B-65$ & $\begin{array}{l}\text { Davis Oil Co. } \\
1 \text { Aztec - Federal }\end{array}$ & $\begin{array}{l}\text { SW } 1 / 4 \text { NW } 1 / 4 \text { sec. } 25 \text {, } \\
\text { T. } 56 \text { N., R. } 73 \text { W. }\end{array}$ & 4,188 \\
\hline$B-66$ & $\begin{array}{l}\text { Montana Bureau of Mines } \\
\text { and Geology } \\
\text { US } 7228\end{array}$ & $\begin{array}{l}\text { SW } 1 / 4 \text { SE } 1 / 4 \text { sec. } 26 \\
\text { T. } 56 \text { N., R. } 73 \text { W. }\end{array}$ & 4,113 \\
\hline$B-67$ & $\begin{array}{l}\text { Montana Bureau of Mines } \\
\text { and Geology } \\
\text { US } 7416\end{array}$ & $\begin{array}{l}\mathrm{NE} 1 / 4 \mathrm{NW} 1 / 4 \text { sec. } 26 \\
\text { T. } 56 \text { N., R. } 73 \text { W. }\end{array}$ & 4,164 \\
\hline$B-68$ & $\begin{array}{l}\text { Davis Oil Co. } \\
1 \text { Ben }\end{array}$ & $\begin{array}{l}\mathrm{SE} 1 / 4 \mathrm{SW} 1 / 4 \text { sec. } 26 \\
\mathrm{~T} .56 \mathrm{~N}, \mathrm{R}_{\bullet} 73 \mathrm{~W} .\end{array}$ & 4,125 \\
\hline$B-69$ & $\begin{array}{l}\text { Anderson Oil Co. } \\
2 \text { Chorney - Federal }\end{array}$ & $\begin{array}{l}\text { NW } 1 / 4 \text { NW } 1 / 4 \text { sec. } 26, \\
\text { T. } 56 \text { N., R. } 73 \text { W. }\end{array}$ & 4,070 \\
\hline$B-70$ & $\begin{array}{l}\text { Davis Oi1 Co. } \\
1 \text { Powe } 11\end{array}$ & $\begin{array}{l}\text { NW } 1 / 4 \text { SW } 1 / 4 \text { sec. } 26, \\
\text { T. } 56 \text { N., R. } 73 \text { W. }\end{array}$ & 4,160 \\
\hline
\end{tabular}




\begin{tabular}{|c|c|c|c|}
\hline $\begin{array}{l}\text { We11 } \\
\text { No. } \\
\text { on map }\end{array}$ & $\begin{array}{l}\text { Company and } \\
\text { well No. }\end{array}$ & Location & $\begin{array}{l}\text { Ground } \\
\text { elevation } \\
\quad \text { (ft) }\end{array}$ \\
\hline$B-71$ & $\begin{array}{l}\text { Anderson Oil Co. } \\
1 \text { Chorney - Oedekoven-Federal }\end{array}$ & $\begin{array}{l}\text { SE } 1 / 4 \text { SE } 1 / 4 \text { sec. } 27 \\
\text { T. } 56 \text { N., R. } 73 \text { W. }\end{array}$ & 4,186 \\
\hline$B-72$ & $\begin{array}{l}\text { Diamond Shamrock Corp. } \\
\text { 2-27 Hawks - Federal }\end{array}$ & $\begin{array}{l}\text { SE } 1 / 4 \mathrm{NE} 1 / 4 \text { sec. } 27 \\
\text { T. } 56 \text { N., R. } 73 \text { W. }\end{array}$ & 4,206 \\
\hline$B-73$ & $\begin{array}{l}\text { Diamond Shamrock Corp. } \\
\text { 3-27 Hawks - Federa1 }\end{array}$ & $\begin{array}{l}\text { NW } 1 / 4 \text { SE } 1 / 4 \text { sec. } 27 \\
\text { T. } 56 \text { N., R. } 73 \text { W. }\end{array}$ & 4,181 \\
\hline$B-74$ & $\begin{array}{l}\text { Montana Bureau of Mines } \\
\text { and Geology } \\
\text { US } 7415\end{array}$ & $\begin{array}{l}\text { NW } 1 / 4 \text { SE } 1 / 4 \text { sec. } 27 \\
\text { T. } 56 \text { N., R. } 73 \text { W. }\end{array}$ & 4,158 \\
\hline$B-75$ & $\begin{array}{l}\text { Kissinger Petroleum Corp. } \\
10-34 \text { Morse }\end{array}$ & $\begin{array}{l}\text { NW } 1 / 4 \text { SE } 1 / 4 \text { sec. } 34, \\
\text { T. } 56 \text { N., R. } 73 \text { W. }\end{array}$ & 4,170 \\
\hline$B-76$ & $\begin{array}{l}\text { Kissinger Petroleum Corp. } \\
16-34 \text { Morse }\end{array}$ & $\begin{array}{l}\text { SE } 1 / 4 \text { SE } 1 / 4 \text { sec. } 34 \text {, } \\
\text { T. } 56 \text { N., R. } 73 \text { W. }\end{array}$ & 4,139 \\
\hline$B-77$ & $\begin{array}{l}\text { Davis Oil Co. } \\
1 \text { Chan Federal }\end{array}$ & $\begin{array}{l}\text { SE } 1 / 4 \text { NW } 1 / 4 \text { sec. } 35 \text {, } \\
\text { T. } 56 \text { N., R. } 73 \text { W. }\end{array}$ & 4,144 \\
\hline$B-78$ & $\begin{array}{l}\text { Montana Bureau of Mines } \\
\text { and Geology } \\
\text { US } 7417\end{array}$ & $\begin{array}{l}\text { SE } 1 / 4 \text { NW } 1 / 4 \text { sec. } 35 \\
\text { T. } 56 \text { N., R. } 73 \text { W. }\end{array}$ & 4,125 \\
\hline$B-79$ & $\begin{array}{l}\text { Davis Oil Co. } \\
2 \text { Goodstein - State }\end{array}$ & $\begin{array}{l}\text { NE } 1 / 4 \mathrm{NW} 1 / 4 \text { sec. } 36, \\
\text { T. } 56 \mathrm{~N} \cdot, \mathrm{R} \cdot 73 \mathrm{~W} .\end{array}$ & 4,114 \\
\hline$B-80$ & $\begin{array}{l}\text { Davis Oil Co. } \\
1 \text { Marty - Federal }\end{array}$ & $\begin{array}{l}\text { SW } 1 / 4 \text { NW } 1 / 4 \text { sec. } 31, \\
\text { T. } 56 \text { N., R. } 72 \text { W. }\end{array}$ & 4,165 \\
\hline$B-81$ & $\begin{array}{l}\text { Atlantic Richfield Co. } \\
1 \text { White Elk - Federal }\end{array}$ & $\begin{array}{l}\text { NW } 1 / 4 \mathrm{NW} 1 / 4 \text { sec. } 32, \\
\text { T. } 56 \text { N., R. } 72 \text { W. }\end{array}$ & 4,121 \\
\hline$B-82$ & $\begin{array}{l}\text { Davis 0il Co. } \\
1 \text { White Elk - Federal }\end{array}$ & $\begin{array}{l}\text { SW } 1 / 4 \text { SW } 1 / 4 \text { sec. } 32, \\
\text { T. } 56 \text { N., R. } 72 \text { W. }\end{array}$ & 4,115 \\
\hline$B-83$ & $\begin{array}{l}\text { Montana Bureau of Mines } \\
\text { and Geology } \\
\text { US } 7227\end{array}$ & $\begin{array}{l}\text { SW } 1 / 4 \text { NE } 1 / 4 \text { sec. } 32, \\
\Gamma .56 \text { N., R. } 72 \text { W. }\end{array}$ & 4,237 \\
\hline$B-84$ & $\begin{array}{l}\text { Kissinger Petroleum Corp. } \\
1 \text { Vessels - Hondo - Federal }\end{array}$ & $\begin{array}{l}\text { SW } 1 / 4 \text { SW } 1 / 4 \text { sec. } 33 \text {, } \\
\text { T. } 56 \text { N., R. } 72 \text { W. }\end{array}$ & 4,179 \\
\hline$B-85$ & $\begin{array}{l}\text { Montana Bureau of Mines } \\
\text { and Geology } \\
\text { US } 7421\end{array}$ & $\begin{array}{l}\mathrm{NE} 1 / 4 \mathrm{SW} 1 / 4 \text { sec. } 33 \text {, } \\
\text { T. } 56 \mathrm{~N} \cdot, \mathrm{R} \cdot 72 \mathrm{~W} .\end{array}$ & 4,223 \\
\hline
\end{tabular}




\begin{tabular}{|c|c|c|c|}
\hline $\begin{array}{l}\text { We11 } \\
\text { No. } \\
\text { on map }\end{array}$ & $\begin{array}{l}\text { Company and } \\
\text { we11 No. }\end{array}$ & Location & $\begin{array}{l}\text { Ground } \\
\text { elevation } \\
\quad(f t)\end{array}$ \\
\hline$B-86$ & $\begin{array}{l}\text { Davis Oil Co. } \\
4 \text { Quinn - Federal }\end{array}$ & $\begin{array}{l}\text { NE } 1 / 4 \text { NE } 1 / 4 \text { sec. } 33 \text {, } \\
\text { T. } 56 \text { N., R. } 72 \text { W. }\end{array}$ & 4,180 \\
\hline$B-87$ & $\begin{array}{l}\text { Davis Oil Co. } \\
5 \text { Quinn - Federal }\end{array}$ & $\begin{array}{l}\text { SW } 1 / 4 \text { NW } 1 / 4 \text { sec. } 34, \\
\text { T. } 56 \text { N., R. } 72 \text { W. }\end{array}$ & 4,125 \\
\hline$B-88$ & $\begin{array}{l}\text { Davis Oil Co. } \\
1 \text { Graham - Federal }\end{array}$ & $\begin{array}{l}\mathrm{NE} 1 / 4 \mathrm{SW} 1 / 4 \text { sec. } 34, \\
\mathrm{~T} .56 \mathrm{~N}, \mathrm{R}_{\bullet} 72 \mathrm{~W} .\end{array}$ & 4,115 \\
\hline$B-89$ & $\begin{array}{l}\text { Cardinal Petroleum Co. } \\
\text { 10-34 Federal - Andri - Arco }\end{array}$ & $\begin{array}{l}\text { NW } 1 / 4 \text { SE } 1 / 4 \text { sec. } 34, \\
\text { T. } 56 \text { N., R. } 72 \text { W. }\end{array}$ & 4,091 \\
\hline$B-90$ & $\begin{array}{l}\text { Montana Bureau of Mines } \\
\text { and Geology } \\
\text { US } 7423\end{array}$ & $\begin{array}{l}\mathrm{NE} 1 / 4 \mathrm{NE} 1 / 4 \text { sec. } 3, \\
\text { T. } 55 \mathrm{~N} ., \mathrm{R} .72 \mathrm{~W} .\end{array}$ & 4,168 \\
\hline$B-91$ & $\begin{array}{l}\text { R. L. Foree } \\
1 \text { Brunel - Federal }\end{array}$ & $\begin{array}{l}\text { SE } 1 / 4 \text { SE } 1 / 4 \text { sec. } 3 \\
\text { T. } 55 \text { N., R. } 72 \text { W. }\end{array}$ & 4,140 \\
\hline$B-92$ & $\begin{array}{l}\text { Davis Oil Co. } \\
1 \text { Bruce - Federal }\end{array}$ & $\begin{array}{l}\text { NW } 1 / 4 \text { SW } 1 / 4 \text { sec. } 3 \text {, } \\
\text { T. } 55 \text { N., R. } 72 \text { W. }\end{array}$ & 4,072 \\
\hline$B-93$ & $\begin{array}{l}\text { Davis Oil Co. } \\
1 \text { Gem }\end{array}$ & $\begin{array}{l}\text { SW } 1 / 4 \text { NW } 1 / 4 \text { sec. } 5 \\
\text { T. } 55 \text { N., R. } 72 \text { W. }\end{array}$ & 4,088 \\
\hline B-94 & $\begin{array}{l}\text { Davis Oil Co. } \\
3 \text { Morse - Ranch }\end{array}$ & $\begin{array}{l}\text { SE } 1 / 4 \mathrm{NW} 1 / 4 \text { sec. } 1 \\
\text { T. } 55 \text { N., R. } 73 \text { W. }\end{array}$ & 4,082 \\
\hline$B-95$ & $\begin{array}{l}\text { Davis Oil Co. } \\
\text { 1-Z Morse - Ranch }\end{array}$ & $\begin{array}{l}\text { NW } 1 / 4 \text { SW } 1 / 4 \text { sec. } 1, \\
\text { T. } 55 \text { N., R. } 73 \text { W. }\end{array}$ & 4,060 \\
\hline$B-96$ & $\begin{array}{l}\text { Davis Oi1 Co. } \\
4 \text { Gallion - Federa1 }\end{array}$ & $\begin{array}{l}\text { NW } 1 / 4 \text { NW } 1 / 4 \text { sec. } 1 \text {, } \\
\text { T. } 55 \text { N., R. } 73 \text { W. }\end{array}$ & 4,102 \\
\hline$B-97$ & $\begin{array}{l}\text { Davis Oi1 Co. } \\
2 \text { Gallion - Federa1 }\end{array}$ & $\begin{array}{l}\text { SW } 1 / 4 \text { SW } 1 / 4 \text { sec. } 1, \\
\text { T. } 55 \text { N., R. } 73 \text { W. }\end{array}$ & 4,120 \\
\hline B-98 & $\begin{array}{l}\text { Davis 0i1 Co. } \\
1 \text { Ear } 1 \text { - Federal }\end{array}$ & $\begin{array}{l}\text { NE } 1 / 4 \mathrm{SE} 1 / 4 \text { sec. } 2 \text {, } \\
\text { T. } 55 \mathrm{~N}, \mathrm{R} 73 \mathrm{~W} .\end{array}$ & 4,093 \\
\hline B-99 & $\begin{array}{l}\text { Montana Bureau of Mines } \\
\text { and Geology } \\
\text { US } 7413\end{array}$ & $\begin{array}{l}\text { SW } 1 / 4 \mathrm{NE} 1 / 4 \text { sec. } 2, \\
\text { T. } 55 \mathrm{~N}, \mathrm{R}, 73 \mathrm{~W} .\end{array}$ & 4,066 \\
\hline$B-100$ & $\begin{array}{l}\text { Montana Bureau of Mines } \\
\text { and Geology } \\
\text { US } 7414\end{array}$ & $\begin{array}{l}\text { NW } 1 / 4 \text { SE } 1 / 4 \text { sec. } 2, \\
\text { T. } 55 \text { N., R. } 73 \text { W. }\end{array}$ & 4,043 \\
\hline
\end{tabular}




\begin{tabular}{|c|c|c|c|}
\hline $\begin{array}{l}\text { We11 } \\
\text { No. } \\
\text { on map }\end{array}$ & $\begin{array}{l}\text { Company and } \\
\text { we11 No. }\end{array}$ & Location & $\begin{array}{l}\text { Ground } \\
\text { elevation } \\
\quad(f t)\end{array}$ \\
\hline$B-101$ & $\begin{array}{l}\text { Diamond Shamrock Corp. } \\
\text { 43-1 Hawks - Federal Tract }\end{array}$ & $\begin{array}{l}\mathrm{NE} 1 / 4 \mathrm{SW} 1 / 4 \text { sec. } 2, \\
\text { T. } 55 \text { N., R. } 73 \text { W. }\end{array}$ & 4,100 \\
\hline B-102 & $\begin{array}{l}\text { Diamond Shamrock Corp. } \\
\text { 43-2 Hawks - Federal Tract }\end{array}$ & $\begin{array}{l}\text { NW } 1 / 4 \text { NW } 1 / 4 \text { sec. } 2, \\
\text { T. } 55 \text { N., R. } 73 \text { W. }\end{array}$ & 4,112 \\
\hline$B-103$ & $\begin{array}{l}\text { Kissinger - Belco - Worden } \\
2-3 \text { Shamrock - Federal }\end{array}$ & $\begin{array}{l}\mathrm{NW} 1 / 4 \mathrm{NE} 1 / 4 \text { sec. } 3, \\
\text { T. } 55 \mathrm{~N} ., \mathrm{R} \cdot 73 \mathrm{~W} .\end{array}$ & 4,098 \\
\hline B- 104 & $\begin{array}{l}\text { Diamond Shamrock Corp. } \\
\text { 46E-1 Hawks - Federal Tract }\end{array}$ & $\begin{array}{l}\text { NW } 1 / 4 \mathrm{SE} 1 / 4 \text { sec. } 3, \\
\text { T. } 55 \text { N., R. } 73 \text { W. }\end{array}$ & 4,188 \\
\hline B- 105 & $\begin{array}{l}\text { Anchutz Corp. } \\
1-3 \text { Government } 55\end{array}$ & $\begin{array}{l}\text { SW } 1 / 4 \text { SE } 1 / 4 \text { sec. } 3, \\
\text { T. } 55 \text { N., R. } 73 \text { W. }\end{array}$ & 4,139 \\
\hline B-106 & $\begin{array}{l}\text { Pan American Petroleum Corp. } \\
1 \text { Pan American - Clark } \\
\text { Canadian }\end{array}$ & $\begin{array}{l}\text { SW } 1 / 4 \text { SE } 1 / 4 \text { sec. } 10 \\
\text { T. } 55 \text { N., R. } 73 \text { W. }\end{array}$ & 4,041 \\
\hline$B-107$ & $\begin{array}{l}\text { Pan American Petroleum Corp. } \\
1 \text { Sacks Unit }\end{array}$ & $\begin{array}{l}\mathrm{NE} 1 / 4 \mathrm{SE} 1 / 4 \text { sec. } 10 \\
\text { T. } 55 \text { N., R. } 73 \mathrm{~W} .\end{array}$ & 4,106 \\
\hline$B-108$ & $\begin{array}{l}\text { Pan American Petroleum Corp. } \\
\text { 1-"B" USA - Pan American - } \\
\text { Clark Canadian }\end{array}$ & $\begin{array}{l}\text { SW } 1 / 4 \text { SW } 1 / 4 \text { sec. } 11 \\
\text { T. } 55 \text { N., R. } 73 \text { W. }\end{array}$ & 4,100 \\
\hline$B-109$ & $\begin{array}{l}\text { McMahon-Bullington } \\
\text { Drilling Co. } \\
\text { 2-2 Morse }\end{array}$ & $\begin{array}{l}\text { SW } 1 / 4 \text { SW } 1 / 4 \text { sec. } 2, \\
\text { T. } 55 \text { N., R. } 73 \text { W. }\end{array}$ & 4,113 \\
\hline$B-110$ & $\begin{array}{l}\text { Clark Canadian Exploration } \\
\text { Company } \\
\text { 1-11 Federal }\end{array}$ & $\begin{array}{l}\mathrm{NE} 1 / 4 \mathrm{NW} 1 / 4 \text { sec. } 11 \\
\text { T. } 55 \text { N., R. } 73 \text { W. }\end{array}$ & 4,100 \\
\hline $\mathrm{B}-111$ & $\begin{array}{l}\text { Pan American Petroleum Corp. } \\
\text { 2-B Haley }\end{array}$ & $\begin{array}{l}\text { SW } 1 / 4 \mathrm{NE} 1 / 4 \text { sec. } 11 \\
\text { T. } 55 \text { N., R. } 73 \text { W. }\end{array}$ & 4,172 \\
\hline$B-112$ & $\begin{array}{l}\text { Pan American Petroleum Corp. } \\
\text { 8-A Norfolk }\end{array}$ & $\begin{array}{l}\text { SW } 1 / 4 \text { SE } 1 / 4 \text { sec. } 11 \\
\text { T. } 55 \text { N., R. } 73 \text { W. }\end{array}$ & 4,102 \\
\hline$B-113$ & $\begin{array}{l}\text { Pan American Petroleum Corp. } \\
1-" B " \text { Haley }\end{array}$ & $\begin{array}{l}\text { NE } 1 / 4 \mathrm{SE} 1 / 4 \text { sec. } 11 \\
\text { T. } 55 \text { N., R. } 73 \text { W. }\end{array}$ & 4,170 \\
\hline B-114 & $\begin{array}{l}\text { Amoco Production Co. } \\
43 \text { Collums Unit }\end{array}$ & $\begin{array}{l}\mathrm{NE} 1 / 4 \mathrm{NE} 1 / 4 \text { sec. } 11 \\
\text { T. } 55 \text { N., R. } 73 \mathrm{~W} .\end{array}$ & 4,133 \\
\hline
\end{tabular}




\begin{tabular}{|c|c|c|c|}
\hline $\begin{array}{l}\text { We } 11 \\
\text { No. } \\
\text { on map }\end{array}$ & $\begin{array}{l}\text { Company and } \\
\text { we } 11 \text { No. }\end{array}$ & Location & $\begin{array}{l}\text { Ground } \\
\text { elevation } \\
\text { (ft) }\end{array}$ \\
\hline$B-115$ & $\begin{array}{l}\text { Amoco Production Co. } \\
44 \text { Collums Unit }\end{array}$ & $\begin{array}{l}\text { SW } 1 / 4 \text { NW } 1 / 4 \text { sec. } 12 \\
\text { T. } 55 \text { N., R. } 73 \text { W. }\end{array}$ & 4,128 \\
\hline$B-116$ & $\begin{array}{l}\text { Pan American Petroleum Corp. } \\
1 \text { Norfolk Unit }\end{array}$ & $\begin{array}{l}\text { SW } 1 / 4 \text { SW } 1 / 4 \text { sec. } 12, \\
\text { T. } 55 \text { N., R. } 73 \text { W. }\end{array}$ & 4,146 \\
\hline$B-117$ & $\begin{array}{l}\text { Davis Oil Co. } \\
1 \text { Gallion - Federal }\end{array}$ & $\begin{array}{l}\mathrm{NE} 1 / 4 \mathrm{NW} 1 / 4 \text { sec. } 12 \\
\text { T. } 55 \text { N., R. } 73 \text { W. }\end{array}$ & 4,179 \\
\hline$B-118$ & $\begin{array}{l}\text { Pan American Petroleum Corp } \\
1 \text { Pan American Unit }\end{array}$ & $\begin{array}{l}\text { SE } 1 / 4 \text { SW } 1 / 4 \text { sec. } 12 \\
\text { T. } 55 \text { N., R. } 73 \text { W. }\end{array}$ & 4,114 \\
\hline$B-119$ & $\begin{array}{l}\text { Petroleum, Inc. } \\
1 \text { Government - Aztec - Kiel }\end{array}$ & $\begin{array}{l}\text { NE } 1 / 4 \text { NW } 1 / 4 \text { sec. } 7 \\
\text { T. } 55 \text { N., R. } 72 \text { W. }\end{array}$ & 4,118 \\
\hline$B-120$ & $\begin{array}{l}\text { 0. B. Kiel and Cardinal } \\
\text { Petroleum Co. } \\
\text { 1-8 Aztec - Federal }\end{array}$ & $\begin{array}{l}\text { SE } 1 / 4 \mathrm{NW} 1 / 4 \text { sec. } 8, \\
\text { T. } 55 \mathrm{~N} ., \mathrm{R} .72 \mathrm{~W} .\end{array}$ & 3,988 \\
\hline$B-121$ & $\begin{array}{l}\text { National Cooperative } \\
\text { Refinery Association } \\
\text { 7-D Jones - Federal }\end{array}$ & $\begin{array}{l}\text { NW } 1 / 4 \mathrm{NE} 1 / 4 \text { sec. } 10 \\
\text { T. } 55 \text { N., R. } 72 \text { W. }\end{array}$ & 4,175 \\
\hline$B-122$ & $\begin{array}{l}\text { True Oil and Aztec Oil } \\
\text { \& Gas Co. } \\
11-15 \text { Jones - Federal }\end{array}$ & $\begin{array}{l}\text { NW } 1 / 4 \text { NW } 1 / 4 \text { sec. } 15 \\
\text { T. } 55 \text { N., R. } 72 \text { W. }\end{array}$ & 4,111 \\
\hline$B-123$ & $\begin{array}{ll}\text { R. G. } & \text { Boeke1 } \\
11-16 & \text { State }\end{array}$ & $\begin{array}{l}\text { NW } 1 / 4 \text { NW } 1 / 4 \text { sec. } 16 \\
\text { T. } 55 \text { N., R. } 72 \text { W. }\end{array}$ & 3,965 \\
\hline$B-124$ & $\begin{array}{l}\text { Davis Oil Co. } \\
1 \text { Terra - Federal }\end{array}$ & $\begin{array}{l}\text { SW } 1 / 4 \text { NW } 1 / 4 \text { sec. } 18, \\
\text { T. } 55 \text { N., R. } 72 \text { W. }\end{array}$ & 4,080 \\
\hline$B-125$ & $\begin{array}{l}\text { Davis Oil Co. } \\
1 \text { Conway Federal }\end{array}$ & $\begin{array}{l}\text { SW } 1 / 4 \text { SE } 1 / 4 \text { sec. } 32 \text {, } \\
\text { T. } 56 \text { N., R. } 72 \text { W. }\end{array}$ & 4,120 \\
\hline$B-126$ & $\begin{array}{l}\text { Montana Bureau of Mines } \\
\text { and Geology } \\
\text { US } 7558\end{array}$ & $\begin{array}{l}\text { NW } 1 / 4 \mathrm{NE} 1 / 4 \text { sec. } 31 \\
\text { T. } 56 \mathrm{~N} ., \mathrm{R} .72 \mathrm{~W} .\end{array}$ & 4,251 \\
\hline
\end{tabular}


APPENDIX B.

SOURCES OF COAL-BED DATA IN THE HOMESTEAD DRAW SW QUADRANGLE 
[List of wells, locations, and ground elevations for a11 we11s in the Recluse Geologic Model Area including wells that do not penetrate the Cache Coal Bed]

[To convert feet to meters multiply by 0.3048]

\begin{tabular}{|c|c|c|c|}
\hline $\begin{array}{l}\text { We11 } \\
\text { No. } \\
\text { on map }\end{array}$ & $\begin{array}{l}\text { Company and } \\
\text { we } 11 \text { No. }\end{array}$ & Location & $\begin{array}{l}\text { Ground } \\
\text { elevation } \\
\quad(f t)\end{array}$ \\
\hline $\mathrm{H}-1$ & $\begin{array}{l}\text { Powder River Oil Co. } \\
14-3 \text { Beason }\end{array}$ & $\begin{array}{l}\mathrm{SE} 1 / 4 \mathrm{SW} 1 / 4 \text { sec. } 3 \text {, } \\
\text { T. } 56 \mathrm{~N}, \mathrm{R}_{\bullet} 73 \mathrm{~W} .\end{array}$ & 3,979 \\
\hline $\mathrm{H}-2$ & $\begin{array}{l}\text { Kissinger Petroleum Corp. - } \\
\text { Exeter } \\
9-4 \text { Beard - Arco - Fee }\end{array}$ & $\begin{array}{l}\mathrm{NE} 1 / 4 \mathrm{SE} 1 / 4 \text { sec. } 4 \text {, } \\
\text { T. } 56 \mathrm{~N}, \mathrm{R}_{\bullet} 73 \mathrm{~W} .\end{array}$ & 3,940 \\
\hline $\mathrm{H}-3$ & $\begin{array}{l}\text { Kissinger Petroleum Corp. } \\
11-4 \text { Anderson - State }\end{array}$ & $\begin{array}{l}\mathrm{NE} 1 / 4 \mathrm{SW} 1 / 4 \text { sec. } 4, \\
\text { T. } 56 \mathrm{~N}, \mathrm{R}_{\bullet} 73 \mathrm{~W} .\end{array}$ & 3,998 \\
\hline $\mathrm{H}-4$ & $\begin{array}{l}\text { Kissinger Petroleum Corp. } \\
3-4 \text { Kissinger - State }\end{array}$ & $\begin{array}{l}\mathrm{NE} 1 / 4 \mathrm{NW} 1 / 4 \text { sec. } 4, \\
\text { T. } 56 \mathrm{~N} ., \mathrm{R} \cdot 73 \mathrm{~W} .\end{array}$ & 3,889 \\
\hline $\mathrm{H}-5$ & $\begin{array}{l}\text { Powder River Oil Co. } \\
1 \text { Beltz }\end{array}$ & $\begin{array}{l}\text { SE } 1 / 4 \text { SW } 1 / 4 \text { sec. } 5, \\
\text { T. } 56 \text { N., R. } 73 \text { W. }\end{array}$ & 3,928 \\
\hline$H-6$ & $\begin{array}{l}\text { Samedan Oil Corp. } \\
1 \text { Greenough }\end{array}$ & $\begin{array}{l}\mathrm{NE} 1 / 4 \mathrm{SW} 1 / 4 \text { sec. } 1 \text {, } \\
\text { T. } 56 \text { N., R. } 74 \text { W. }\end{array}$ & 3,945 \\
\hline $\mathrm{H}-7$ & $\begin{array}{l}\text { Powder River Oil Co. } \\
1 \text { Greenough }\end{array}$ & $\begin{array}{l}\text { NE } 1 / 4 \mathrm{NW} 1 / 4 \text { sec. } 10, \\
\text { T. } 56 \text { N., R. } 74 \text { W. }\end{array}$ & 4,026 \\
\hline $\mathrm{H}-8$ & $\begin{array}{l}\text { At lantic Richfield Co. } \\
6 \text { Greenough - Government }\end{array}$ & $\begin{array}{l}\text { SE } 1 / 4 \text { SW } 1 / 4 \text { sec. } 10, \\
\text { T. } 56 \text { N., R. } 74 \text { W. }\end{array}$ & 4,150 \\
\hline $\mathrm{H}-9$ & $\begin{array}{l}\text { Apache Corp. } \\
1-11 \text { U.S. - Thomas }\end{array}$ & $\begin{array}{l}\text { NW } 1 / 4 \text { SE } 1 / 4 \text { sec. } 11, \\
\text { T. } 56 \text { N., R. } 74 \text { W. }\end{array}$ & 3,950 \\
\hline $\mathrm{H}-10$ & $\begin{array}{l}\text { Chandler \& Associates, Inc. } \\
1 \text { Southland Royalty Co. }\end{array}$ & $\begin{array}{l}\mathrm{NE} 1 / 4 \mathrm{NE} 1 / 4 \text { sec. } 11, \\
\text { T. } 56 \mathrm{~N} ., \mathrm{R} .74 \mathrm{~W} .\end{array}$ & 3,919 \\
\hline $\mathrm{H}-11$ & $\begin{array}{l}\text { Chandler \& Associates, Inc. } \\
1 \text { Heiby Government }\end{array}$ & $\begin{array}{l}\text { SW } 1 / 4 \text { SE } 1 / 4 \text { sec. } 8, \\
\text { T. } 56 \text { N., R. } 73 \text { W. }\end{array}$ & 3,890 \\
\hline $\mathrm{H}-12$ & $\begin{array}{l}\text { Clyde G. Kissinger } \\
1 \text { Snoddy }\end{array}$ & $\begin{array}{l}\text { SW } 1 / 4 \text { SW } 1 / 4 \text { sec. } 9, \\
\text { T. } 56 \text { N., R. } 73 \text { W. }\end{array}$ & 4,087 \\
\hline $\mathrm{H}-13$ & $\begin{array}{l}\text { Clyde G. Kissinger } \\
\text { 14-10 Phillips Petroleum Co. }\end{array}$ & $\begin{array}{l}\mathrm{SE} 1 / 4 \mathrm{SW} 1 / 4 \text { sec. } 10, \\
\text { T. } 56 \text { N., R. } 73 \text { W. }\end{array}$ & 4,143 \\
\hline
\end{tabular}




\begin{tabular}{|c|c|c|c|}
\hline $\begin{array}{l}\text { We } 11 \\
\text { No. } \\
\text { on map }\end{array}$ & $\begin{array}{c}\text { Company and } \\
\text { we } 11 \text { No. }\end{array}$ & Location & $\begin{array}{l}\text { Ground } \\
\text { elevation } \\
\quad(f t)\end{array}$ \\
\hline $\mathrm{H}-14$ & $\begin{array}{l}\text { Kissinger Petroleum Corp. } \\
\text { 6-10 Phillips - Federal }\end{array}$ & $\begin{array}{l}\text { SE } 1 / 4 \text { NW } 1 / 4 \text { sec. } 10 \\
\text { T. } 56 \text { N., R. } 73 \text { W. }\end{array}$ & 4,035 \\
\hline $\mathrm{H}-15$ & $\begin{array}{l}\text { Davis Oil Co. } \\
1 \text { Lester }\end{array}$ & $\begin{array}{l}\text { SE } 1 / 4 \text { SW } 1 / 4 \text { sec. } 15, \\
\text { T. } 56 \text { N., R. } 73 \text { W. }\end{array}$ & 4,078 \\
\hline $\mathrm{H}-16$ & $\begin{array}{l}\text { Kissinger Petroleum Corp. } \\
12-15 \text { Phillips - Federal }\end{array}$ & $\begin{array}{l}\text { NW } 1 / 4 \text { SW } 1 / 4 \text { sec. } 15, \\
\text { T. } 56 \text { N., R. } 73 \text { W. }\end{array}$ & 4,006 \\
\hline $\mathrm{H}-17$ & $\begin{array}{l}\text { Kissinger Petroleum Corp. - } \\
\text { Worden } \\
14-16 \text { State }\end{array}$ & $\begin{array}{l}\text { SE } 1 / 4 \mathrm{SW} 1 / 4 \text { sec. } 16, \\
\text { T. } 56 \text { N., R. } 73 \text { W. }\end{array}$ & 4,003 \\
\hline $\mathrm{H}-18$ & $\begin{array}{l}\text { Petroleum, Inc. } \\
\text { 1-B State }\end{array}$ & $\begin{array}{l}\text { SW } 1 / 4 \mathrm{NW} 1 / 4 \text { sec. } 16, \\
\text { T. } 56 \text { N., R. } 73 \text { W. }\end{array}$ & 3,925 \\
\hline $\mathrm{H}-19$ & $\begin{array}{l}\text { Chandler \& Associates, Inc. } \\
1 \text { Aztec Government }\end{array}$ & $\begin{array}{l}\mathrm{NE} 1 / 4 \mathrm{NE} 1 / 4 \text { sec. } 17 \\
\text { T. } 56 \text { N., R. } 73 \mathrm{~W} .\end{array}$ & 3,910 \\
\hline $\mathrm{H}-20$ & $\begin{array}{l}\text { Chandler \& Associates, Inc. } \\
3 \text { Aztec Government }\end{array}$ & $\begin{array}{l}\text { SW } 1 / 4 \text { NE } 1 / 4 \text { sec. } 17 \\
\text { T. } 56 \text { N., R. } 73 \text { W. }\end{array}$ & 3,992 \\
\hline $\mathrm{H}-21$ & $\begin{array}{l}\text { Chandler \& Associates, Inc. } \\
1 \text { Aztec Government }\end{array}$ & $\begin{array}{l}\text { SW } 1 / 4 \text { SW } 1 / 4 \text { sec. } 17, \\
\text { T. } 56 \text { N., R. } 73 \text { W. }\end{array}$ & 4,077 \\
\hline $\mathrm{H}-22$ & $\begin{array}{l}\text { Ladd \& Lewis - Boeke1 } \\
1-13 \text { Lockhard }\end{array}$ & $\begin{array}{l}\text { SE } 1 / 4 \text { SW } 1 / 4 \text { sec. } 13 \text {, } \\
\text { T. } 56 \text { N., R. } 74 \text { W. }\end{array}$ & 3,897 \\
\hline $\mathrm{H}-23$ & $\begin{array}{l}\text { Apache Corp. } \\
1 \text { U.S. - Thomas }\end{array}$ & $\begin{array}{l}\text { NW } 1 / 4 \mathrm{SE} 1 / 4 \text { sec. } 15 \\
\text { T. } 56 \text { N., R. } 74 \text { W. }\end{array}$ & 4,140 \\
\hline $\mathrm{H}-24$ & $\begin{array}{l}\text { Eason 0i1 Co. } \\
5-22 \text { Government }\end{array}$ & $\begin{array}{l}\text { NW } 1 / 4 \text { NE } 1 / 4 \text { sec. } 22, \\
\text { T. } 56 \text { N., R. } 74 \text { W. }\end{array}$ & 4,157 \\
\hline $\mathrm{H}-25$ & $\begin{array}{l}\text { Apache Corp. } \\
4 \text { U.S. - Cochise }\end{array}$ & $\begin{array}{l}\text { SE } 1 / 4 \text { SW } 1 / 4 \text { sec. } 23 \text {, } \\
\text { T. } 56 \mathrm{~N}, \mathrm{R} .74 \mathrm{~W} .\end{array}$ & 4,090 \\
\hline $\mathrm{H}-26$ & $\begin{array}{l}\text { Kissinger Petroleum Corp. } \\
\text { 13-20 Atlantic Richfield Co. }\end{array}$ & $\begin{array}{l}\text { SW } 1 / 4 \text { SW } 1 / 4 \text { sec. } 20 \\
\text { T. } 56 \text { N., R. } 73 \text { W. }\end{array}$ & 4,079 \\
\hline $\mathrm{H}-27$ & $\begin{array}{l}\text { Kissinger Petroleum Corp. } \\
13-21 \text { Snoddy }\end{array}$ & $\begin{array}{l}\text { SW } 1 / 4 \text { SW } 1 / 4 \text { sec. } 21, \\
\text { T. } 56 \text { N., R. } 73 \text { W. }\end{array}$ & 4,095 \\
\hline
\end{tabular}




\begin{tabular}{|c|c|c|c|}
\hline $\begin{array}{l}\text { We11 } \\
\text { No. } \\
\text { on map }\end{array}$ & $\begin{array}{l}\text { Company and } \\
\text { wel1 No. }\end{array}$ & Location & $\begin{array}{l}\text { Ground } \\
\text { elevation } \\
(f t)\end{array}$ \\
\hline $\mathrm{H}-28$ & $\begin{array}{l}\text { Kissinger Petroleum Corp. } \\
2-21 \text { Anderson - Federal }\end{array}$ & NW $1 / 4 \mathrm{NE} 1 / 4$ sec. 21 , & 4,104 \\
\hline $\mathrm{H}-29$ & $\begin{array}{l}\text { Diamond Shamrock Corp. } \\
1-21 \text { Hawks - Government }\end{array}$ & $\begin{array}{l}\text { SE } 1 / 4 \mathrm{SE} 1 / 4 \text { sec. } 21, \\
\text { T. } 56 \text { N., R. } 73 \text { W. }\end{array}$ & 4,105 \\
\hline $\mathrm{H}-30$ & $\begin{array}{l}\text { Diamond Shamrock Corp. } \\
1-28 \text { Hawks - Federa1 }\end{array}$ & $\begin{array}{l}\text { SE } 1 / 4 \text { SW } 1 / 4 \text { sec. } 28, \\
\text { T. } 56 \text { N., R. } 73 \text { W. }\end{array}$ & 4,150 \\
\hline $\mathrm{H}-31$ & $\begin{array}{l}\text { Powder River Oil Co. } \\
1-29 \text { Smith }\end{array}$ & $\begin{array}{l}\text { NE } 1 / 4 \text { NE } 1 / 4 \text { sec. } 29, \\
\text { T. } 56 \text { N., R. } 73 \text { W. }\end{array}$ & 4,098 \\
\hline $\mathrm{H}-32$ & $\begin{array}{l}\text { Kissinger - MacPet } \\
\text { 16-30 Anchutz - Lester }\end{array}$ & $\begin{array}{l}\text { SE } 1 / 4 \text { SE } 1 / 4 \text { sec. } 30, \\
\text { T. } 56 \text { N., R. } 73 \text { W. }\end{array}$ & 4,015 \\
\hline $\mathrm{H}-33$ & $\begin{array}{l}\text { Sinclair Oil \& Gas Co. } \\
\text { 1-A Burnett - Federal }\end{array}$ & $\begin{array}{l}\text { NW } 1 / 4 \text { NW } 1 / 4 \text { sec. } 25, \\
\text { T. } 56 \text { N., R. } 74 \text { W. }\end{array}$ & 4,080 \\
\hline $\mathrm{H}-34$ & $\begin{array}{l}\text { Sinclair Oil \& Gas Co. } \\
1 \text { Bradshaw - Herr - Federal }\end{array}$ & $\begin{array}{l}\text { SE } 1 / 4 \text { SE } 1 / 4 \text { sec. } 26, \\
\text { T. } 56 \text { N., R. } 74 \text { W. }\end{array}$ & 4,193 \\
\hline $\mathrm{H}-35$ & $\begin{array}{l}\text { Montana Bureau of Mines } \\
\text { and Geology } \\
\text { US } 745\end{array}$ & $\begin{array}{l}\text { NE } 1 / 4 \text { NW } 1 / 4 \text { sec. } 26, \\
\text { T. } 56 \text { N., R. } 74 \text { W. }\end{array}$ & 4,133 \\
\hline $\mathrm{H}-36$ & $\begin{array}{l}\text { Eason Oi } 1 \text { Co. } \\
4-27 \text { Government }\end{array}$ & $\begin{array}{l}\text { SE } 1 / 4 \mathrm{SE} 1 / 4 \text { sec. } 27, \\
\text { T. } 56 \text { N., R. } 74 \text { W. }\end{array}$ & 4,053 \\
\hline $\mathrm{H}-37$ & $\begin{array}{l}\text { Atlantic Richfield Co. } \\
1 \text { McBee }\end{array}$ & $\begin{array}{l}\text { NW } 1 / 4 \mathrm{NE} 1 / 4 \text { sec. } 35 \\
\text { T. } 56 \text { N., R. } 74 \text { W. }\end{array}$ & 4,129 \\
\hline $\mathrm{H}-38$ & $\begin{array}{l}\text { The Anchutz Corp. } \\
1 \text { Federal 382-A }\end{array}$ & $\begin{array}{l}\text { SE } 1 / 4 \text { SE } 1 / 4 \text { sec. } 35, \\
\text { T. } 56 \text { N., R. } 74 \text { W. }\end{array}$ & 4,081 \\
\hline $\mathrm{H}-39$ & $\begin{array}{l}\text { The Anchutz Corp. } \\
39-3-36 \text { State }\end{array}$ & $\begin{array}{l}\text { NW } 1 / 4 \mathrm{NW} 1 / 4 \text { sec. } 36, \\
\text { T. } 56 \text { N., R. } 74 \text { W. }\end{array}$ & 4,156 \\
\hline $\mathrm{H}-40$ & $\begin{array}{l}\text { The Anchutz Corp. } \\
39-2-36 \text { State }\end{array}$ & $\begin{array}{l}\text { SE } 1 / 4 \text { SW } 1 / 4 \text { sec. } 36, \\
\text { T. } 56 \text { N., R. } 74 \text { W. }\end{array}$ & 4,191 \\
\hline$H-41$ & $\begin{array}{l}\text { The Anchutz Corp. } \\
\text { 39-4-36 State }\end{array}$ & $\begin{array}{l}\text { NW } 1 / 4 \text { NE } 1 / 4 \text { sec. } 36, \\
\text { T. } 56 \text { N., R. } 74 \text { W. }\end{array}$ & 4,133 \\
\hline $\mathrm{H}-42$ & $\begin{array}{l}\text { The Anchutz Corp. } \\
36-7 \text { State }\end{array}$ & $\begin{array}{l}\text { SE } 1 / 4 \mathrm{SE} 1 / 4 \text { sec. } 36, \\
\text { T. } 56 \text { N., R. } 74 \text { W. }\end{array}$ & 4,095 \\
\hline $\mathrm{H}-43$ & $\begin{array}{l}\text { At lantic Richfield Co. } \\
3 \text { Burnett - Federal }\end{array}$ & $\begin{array}{l}\text { NW } 1 / 4 \text { NW } 1 / 4 \text { sec. } 31, \\
\text { T. } 56 \text { N., R. } 73 \text { W. }\end{array}$ & 4,099 \\
\hline
\end{tabular}


Sources of coal-bed data in the Homestead Draw SW Quadrangle--Continued

\begin{tabular}{|c|c|c|c|}
\hline $\begin{array}{l}\text { We11 } \\
\text { No. } \\
\text { on map }\end{array}$ & $\begin{array}{l}\text { Company and } \\
\text { we11 No. }\end{array}$ & Location & $\begin{array}{l}\text { Ground } \\
\text { elevation } \\
\quad \text { (ft) }\end{array}$ \\
\hline $\mathrm{H}-44$ & $\begin{array}{l}\text { Davis Oil Co. } \\
1 \text { Wilson }\end{array}$ & $\begin{array}{l}\text { SW } 1 / 4 \text { SE } 1 / 4 \text { sec. } 31 \\
\text { T. } 56 \text { N., R. } 73 \text { W. }\end{array}$ & 4,120 \\
\hline$H-45$ & $\begin{array}{l}\text { Eason Oil Co. } \\
1 \text { Morse - Ranch }\end{array}$ & $\begin{array}{l}\text { SW } 1 / 4 \mathrm{SW} 1 / 4 \text { sec. } 32 \\
\text { T. } 56 \text { N., R. } 73 \text { W. }\end{array}$ & 4,098 \\
\hline$H-46$ & $\begin{array}{l}\text { Petroleum - Lewis Corp. } \\
\text { 10-33 Lester }\end{array}$ & $\begin{array}{l}\text { NW } 1 / 4 \mathrm{SE} 1 / 4 \text { sec. } 33 \\
\text { T. } 56 \text { N., R. } 73 \text { W. }\end{array}$ & 4,139 \\
\hline $\mathrm{H}-47$ & $\begin{array}{l}\text { Kissinger Petroleum Corp. } \\
\text { 4-34 Morse - Lester }\end{array}$ & $\begin{array}{l}\text { NW } 1 / 4 \text { NW } 1 / 4 \text { sec. } 34 \\
\text { T. } 56 \text { N., R. } 73 \text { W. }\end{array}$ & 4,169 \\
\hline$H-48$ & $\begin{array}{l}\text { Diamond Shamrock Corp. } \\
1 \text { Hawks - Federa1 46G }\end{array}$ & $\begin{array}{l}\text { NE } 1 / 4 \text { SW } 1 / 4 \text { sec. } 3, \\
\text { T. } 55 \text { N., R. } 73 \text { W. }\end{array}$ & 4,207 \\
\hline $\mathrm{H}-49$ & $\begin{array}{l}\text { Di amond Shamrock Corp. } \\
1-C \text { Hawks - Federal }\end{array}$ & $\begin{array}{l}\text { SE } 1 / 4 \mathrm{NW} 1 / 4 \text { sec. } 3 \\
\text { T. } 55 \text { N., R. } 73 \text { W. }\end{array}$ & 4,178 \\
\hline $\mathrm{H}-50$ & $\begin{array}{l}\text { Pan American Petroleum Corp. } \\
1 \text { Haley Unit }\end{array}$ & $\begin{array}{l}\text { SW } 1 / 4 \text { SW } 1 / 4 \text { sec. } 3 \\
\text { T. } 55 \text { N., R. } 73 \text { W. }\end{array}$ & 4,092 \\
\hline$H-51$ & $\begin{array}{l}\text { Diamond Shamrock Corp. } \\
3 \text { Hawks - Federa1 Tract } 47\end{array}$ & $\begin{array}{l}\text { SE } 1 / 4 \text { NE } 1 / 4 \text { sec. } 4, \\
\text { T. } 55 \text { N., R. } 73 \text { W. }\end{array}$ & 4,216 \\
\hline $\mathrm{H}-52$ & $\begin{array}{l}\text { Petroleum - Lewis Corp. } \\
1-4 \text { HMM }\end{array}$ & $\begin{array}{l}\text { NW } 1 / 4 \text { SE } 1 / 4 \text { sec. } 4, \\
\text { T. } 55 \text { N., R. } 73 \text { W. }\end{array}$ & 4,202 \\
\hline $\mathrm{H}-53$ & $\begin{array}{l}\text { C. E. Bream - U.S. Smelting } \\
\text { Refining \& Mining Co. } \\
\text { 2-5 Federa1 } 762\end{array}$ & $\begin{array}{l}\text { SE } 1 / 4 \text { NE } 1 / 4 \text { sec. } 5 \\
\text { T. } 55 \text { N., R. } 73 \text { W. }\end{array}$ & 4,116 \\
\hline $\mathrm{H}-54$ & $\begin{array}{l}\text { The Anchutz Corp. } \\
4-F \text { Oedekoven }\end{array}$ & $\begin{array}{l}\text { NE } 1 / 4 \text { SW } 1 / 4 \text { sec. } 6, \\
\text { T. } 55 \text { N., R. } 73 \text { W. }\end{array}$ & 4,166 \\
\hline $\mathrm{H}-55$ & $\begin{array}{l}\text { The Anchutz Corp. } \\
\text { 3-F Oedekoven }\end{array}$ & $\begin{array}{l}\text { SW } 1 / 4 \text { SW } 1 / 4 \text { sec. } 6 \\
\text { T. } 55 \text { N., R. } 73 \text { W. }\end{array}$ & 4,177 \\
\hline$H-56$ & $\begin{array}{l}\text { Davis Oil Co. } \\
3 \text { Long }\end{array}$ & $\begin{array}{l}\text { NW } 1 / 4 \text { NE } 1 / 4 \text { sec. } 1, \\
\text { T. } 55 \text { N., R. } 74 \text { W. }\end{array}$ & 4,134 \\
\hline $\mathrm{H}-57$ & $\begin{array}{l}\text { The Anchutz Corp. } \\
2 \text { Long Federal }\end{array}$ & $\begin{array}{l}\text { SW } 1 / 4 \text { SE } 1 / 4 \text { sec. } 1, \\
\text { T. } 55 \text { N., R. } 74 \text { W. }\end{array}$ & 4,138 \\
\hline $\mathrm{H}-58$ & $\begin{array}{l}\text { Stonehenge Oil Co., Inc. } \\
1 \text { Kirby - USA }\end{array}$ & $\begin{array}{l}\text { SW } 1 / 4 \text { SE } 1 / 4 \text { sec. } 11 \\
\text { T. } 55 \text { N., R. } 74 \text { W. }\end{array}$ & 4,045 \\
\hline$H-59$ & $\begin{array}{l}\text { The Anchutz Corp. } \\
\text { 1-E Long - Oedekoven }\end{array}$ & $\begin{array}{l}\mathrm{NE} 1 / 4 \mathrm{NE} 1 / 4 \text { sec. } 12, \\
\text { T. } 55 \text { N., R. } 74 \text { W. }\end{array}$ & 4,156 \\
\hline
\end{tabular}




\begin{tabular}{|c|c|c|c|}
\hline $\begin{array}{l}\text { We11 } \\
\text { No. } \\
\text { on map }\end{array}$ & $\begin{array}{l}\text { Company and } \\
\text { we11 No. }\end{array}$ & Location & $\begin{array}{l}\text { Ground } \\
\text { elevation } \\
\quad(\mathrm{ft})\end{array}$ \\
\hline $\mathrm{H}-60$ & $\begin{array}{l}\text { The Anchutz Corp. } \\
\text { 3-E Oedekoven }\end{array}$ & $\begin{array}{l}\text { SW } 1 / 4 \text { SW } 1 / 4 \text { sec. } 7 \\
\text { T. } 55 \text { N., R. } 73 \text { W. }\end{array}$ & 4,146 \\
\hline$H-61$ & $\begin{array}{l}\text { Chandler \& Associates Oil, } \\
\text { Inc. - Fulton Producing Co. } \\
1 \text { Maribo - Allard }\end{array}$ & $\begin{array}{l}\text { NW } 1 / 4 \text { NE } 1 / 4 \text { sec. } 7 \\
\text { T. } 55 \text { N., R. } 73 \text { W. }\end{array}$ & 4,169 \\
\hline $\mathrm{H}-62$ & $\begin{array}{l}\text { Montana Bureau of Mines } \\
\text { and Geology } \\
\text { US } 746\end{array}$ & $\begin{array}{l}\text { SW } 1 / 4 \text { SE } 1 / 4 \text { sec. } 8, \\
\text { T. } 55 \text { N., R. } 73 \text { W. }\end{array}$ & 4,154 \\
\hline $\mathrm{H}-63$ & $\begin{array}{l}\text { Petroleum-Lewis, Ltd. - } \\
\text { Laos Petroleum Corp. } \\
\text { 1-8 Wilson }\end{array}$ & $\begin{array}{l}\text { SE } 1 / 4 \text { SE } 1 / 4 \text { sec. } 8, \\
\text { T. } 55 \text { N., R. } 73 \text { W. }\end{array}$ & 4,134 \\
\hline $\mathrm{H}-64$ & $\begin{array}{l}\text { The Anchutz Corp. } \\
1-9 \text { State } 53\end{array}$ & $\begin{array}{l}\text { SE } 1 / 4 \text { SW } 1 / 4 \text { sec. } 9, \\
\text { T. } 55 \text { N., R. } 73 \text { W. }\end{array}$ & 4,098 \\
\hline $\mathrm{H}-65$ & $\begin{array}{l}\text { Pan American Petroleum Corp. } \\
1 \text { Haley }\end{array}$ & $\begin{array}{l}\text { SW } 1 / 4 \text { NW } 1 / 4 \text { sec. } 10 \\
\text { T. } 55 \text { N., R. } 73 \text { W. }\end{array}$ & 4,089 \\
\hline$H-66$ & $\begin{array}{l}\text { Pan American Petroleum Corp. } \\
\text { 3-B Pan American - Clark - } \\
\text { Canadian }\end{array}$ & $\begin{array}{l}\text { NE } 1 / 4 \text { SW } 1 / 4 \text { sec. } 10, \\
\text { T. } 55 \text { N., R. } 73 \text { W. }\end{array}$ & 4,060 \\
\hline $\mathrm{H}-67$ & $\begin{array}{l}\text { Montana Bureau of Mines } \\
\text { and Geology } \\
\text { US } 7554\end{array}$ & $\begin{array}{l}\text { NE } 1 / 4 \text { SE } 1 / 4 \text { sec. } 6, \\
\text { T. } 55 \text { N., R. } 73 \text { W. }\end{array}$ & 4,141 \\
\hline$H-68$ & $\begin{array}{l}\text { Montana Bureau of Mines } \\
\text { and Geology } \\
\text { US } 7555\end{array}$ & $\begin{array}{l}\text { SE } 1 / 4 \text { NE } 1 / 4 \text { sec. } 19, \\
\text { T. } 56 \text { N., R. } 73 \text { W. }\end{array}$ & 4,082 \\
\hline$H-69$ & $\begin{array}{l}\text { Montana Bureau of Mines } \\
\text { and Geology } \\
\text { US } 7556\end{array}$ & $\begin{array}{l}\mathrm{NE} 1 / 4 \mathrm{SE} 1 / 4 \text { sec. } 30, \\
\text { T. } 56 \text { N., R. } 73 \text { W. }\end{array}$ & 4,024 \\
\hline $\mathrm{H}-70$ & $\begin{array}{l}\text { Montana Bureau of Mines } \\
\text { and Geology } \\
\text { US } 7557\end{array}$ & $\begin{array}{l}\text { SW } 1 / 4 \text { SE } 1 / 4 \text { sec. } 33, \\
\text { T. } 56 \text { N., R. } 73 \text { W. }\end{array}$ & 4,144 \\
\hline
\end{tabular}


APPENDIX C.

SOURCES OF COAL-BED DATA IN THE PITCH DRAW QUADRANGLE 
[List of wells, locations, and ground elevations for all wells in the Recluse Geologic Model Area including wells that do not penetrate the Cache Coal Bed]

[To convert feet to meters multiply by 0.3048 ]

\begin{tabular}{|c|c|c|c|}
\hline $\begin{array}{l}\text { We11 } \\
\text { No. } \\
\text { on map }\end{array}$ & $\begin{array}{l}\text { Company and } \\
\text { we } 11 \text { No. }\end{array}$ & Location & $\begin{array}{l}\text { Ground } \\
\text { elevation } \\
\quad(f t)\end{array}$ \\
\hline $\mathrm{P}-1$ & $\begin{array}{l}\text { Davis Oil Co. } \\
1 \text { Basil - State }\end{array}$ & $\begin{array}{l}\mathrm{SE} 1 / 4 \mathrm{SE} 1 / 4 \text { sec. } 16, \\
\text { T. } 55 \mathrm{~N} ., \mathrm{R} .72 \mathrm{~W} .\end{array}$ & 4,096 \\
\hline $\mathrm{P}-2$ & $\begin{array}{l}\text { Davis Oil Co. } \\
1 \text { E1liott }\end{array}$ & $\begin{array}{l}\mathrm{SE} 1 / 4 \mathrm{SE} 1 / 4 \text { sec. } 13 \\
\text { T. } 55 \text { N., R. } 73 \text { W. }\end{array}$ & 3,994 \\
\hline$P-3$ & $\begin{array}{l}\text { Pan American Petroleum Co. } \\
7-A \text { Norfolk }\end{array}$ & $\begin{array}{l}\mathrm{SE} 1 / 4 \mathrm{NW} 1 / 4 \text { sec. } 13 \\
\text { T. } 55 \mathrm{~N} ., \mathrm{R} .73 \mathrm{~W} .\end{array}$ & 4,122 \\
\hline$P-4$ & $\begin{array}{l}\text { Pan American Petroleum Co. } \\
\text { 4-A Norfolk }\end{array}$ & $\begin{array}{l}\mathrm{NE} 1 / 4 \mathrm{NE} 1 / 4 \text { sec. } 14, \\
\text { T. } 55 \mathrm{~N} ., \mathrm{R} .73 \mathrm{~W} .\end{array}$ & 4,140 \\
\hline$P-5$ & $\begin{array}{l}\text { Davis Oil Co. } \\
1 \text { Collums - Federal }\end{array}$ & $\begin{array}{l}\text { SW } 1 / 4 \text { SE } 1 / 4 \text { sec. } 14, \\
\text { T. } 55 \text { N., R. } 73 \text { W. }\end{array}$ & 4,003 \\
\hline$P-6$ & $\begin{array}{l}\text { Stuarco Oil Co. } \\
32 \text { Government Tract } 68\end{array}$ & $\begin{array}{l}\text { SW } 1 / 4 \mathrm{NE} 1 / 4 \text { sec. } 14, \\
\text { T. } 55 \mathrm{~N} ., \mathrm{R} .73 \mathrm{~W} .\end{array}$ & 4,013 \\
\hline$P-7$ & $\begin{array}{l}\text { Pan American Petroleum Co. } \\
2-A \text { Norfolk }\end{array}$ & $\begin{array}{l}\text { SW } 1 / 4 \text { NW } 1 / 4 \text { sec. } 14, \\
\text { T. } 55 \text { N., R. } 73 \text { W. }\end{array}$ & 3,997 \\
\hline$P-8$ & $\begin{array}{l}\text { Diamond Shamrock Corp. } \\
1 \text { Hays - Government } \\
\text { Tract 92-E }\end{array}$ & $\begin{array}{l}\text { SW } 1 / 4 \text { SW } 1 / 4 \text { sec. } 14, \\
\text { T. } 55 \text { N., R. } 73 \text { W. }\end{array}$ & 4,079 \\
\hline$P-9$ & $\begin{array}{l}\text { Montana Bureau of Mines } \\
\text { and Geology } \\
\text { US } 7470\end{array}$ & $\begin{array}{l}\text { SW } 1 / 4 \text { SE } 1 / 4 \text { sec. } 22, \\
\text { T. } 55 \mathrm{~N} ., \mathrm{R} .73 \mathrm{~W} .\end{array}$ & 4,107 \\
\hline$P-10$ & $\begin{array}{l}\text { Diamond Shamrock Corp. } \\
1 \text { Hayes - Government }\end{array}$ & $\begin{array}{l}\text { NE } 1 / 4 \mathrm{NE} 1 / 4 \text { s:ec. } 22, \\
\text { T. } 55 \text { N., R. } 73 \text { W. }\end{array}$ & 4,073 \\
\hline$P-11$ & $\begin{array}{l}\text { Davis Oil Co. } \\
4 \text { Collums - Federal }\end{array}$ & $\begin{array}{l}\text { SW } 1 / 4 \text { NE } 1 / 4 \text { sec. } 23 \text {, } \\
\text { T. } 55 \text { N., R. } 73 \text { W. }\end{array}$ & 4,085 \\
\hline $\mathrm{P}-12$ & $\begin{array}{l}\text { Davis Oil Co. } \\
2 \text { Collums - Federal }\end{array}$ & $\begin{array}{l}\text { NE } 1 / 4 \mathrm{NE} 1 / 4 \text { sec. } 23, \\
\text { T. } 55 \mathrm{~N} ., \mathrm{R} \cdot 73 \mathrm{~W} .\end{array}$ & 4,129 \\
\hline$P-13$ & $\begin{array}{l}\text { 0. B. Kiel, Jr. - Cardinal } \\
\text { Petroleum } \\
\text { 1-19 Aztec - Federal }\end{array}$ & $\begin{array}{l}\text { NW } 1 / 4 \text { NE } 1 / 4 \text { sec. } 19, \\
\text { T. } 55 \text { N., R. } 72 \text { W. }\end{array}$ & 4,067 \\
\hline
\end{tabular}




\begin{tabular}{|c|c|c|c|}
\hline $\begin{array}{l}\text { We11 } \\
\text { No. } \\
\text { on map }\end{array}$ & $\begin{array}{l}\text { Company and } \\
\text { we } 11 \text { No. }\end{array}$ & Location & $\begin{array}{l}\text { Ground } \\
\text { elevation } \\
\quad(f t)\end{array}$ \\
\hline$P-14$ & $\begin{array}{l}\text { Davidor - Davidor } \\
1-21 \text { Government }\end{array}$ & $\begin{array}{l}\text { SW } 1 / 4 \text { SW } 1 / 4 \text { sec. } 21 \\
\text { T. } 55 \text { N., R. } 72 \text { W. }\end{array}$ & 4,054 \\
\hline$P-15$ & $\begin{array}{l}\text { Davis Oil Co. } \\
1 \text { Tyree }\end{array}$ & $\begin{array}{l}\text { NE } 1 / 4 \text { NW } 1 / 4 \text { sec. } 21 \\
\text { T. } 55 \text { N., R. } 72 \text { W. }\end{array}$ & 4,109 \\
\hline$P-16$ & $\begin{array}{l}\text { Davis Oil Co. } \\
\text { l Rita }\end{array}$ & $\begin{array}{l}\text { SE } 1 / 4 \text { SE } 1 / 4 \text { sec. } 21 \\
\text { T. } 55 \mathrm{~N} ., \mathrm{R} .72 \mathrm{~W} .\end{array}$ & 4,090 \\
\hline$P-17$ & $\begin{array}{l}\text { True Oil Co. - Central Oil } \\
\text { 34-22 Federal - Chorney }\end{array}$ & $\begin{array}{l}\text { SW } 1 / 4 \text { SE } 1 / 4 \text { sec. } 22, \\
\text { T. } 55 \text { N., R. } 72 \text { W. }\end{array}$ & 4,039 \\
\hline $\mathrm{P}-18$ & $\begin{array}{l}\text { Davis Oil Co. } \\
1 \text { Kinsley - Moore - Federal }\end{array}$ & $\begin{array}{l}\text { NW } 1 / 4 \text { SW } 1 / 4 \text { sec. } 27 \\
\text { T. } 55 \text { N., R. } 72 \text { W. }\end{array}$ & 4,178 \\
\hline$P-19$ & $\begin{array}{l}\text { Davis Oil Co. } \\
\text { 1 E1don - Federal }\end{array}$ & $\begin{array}{l}\mathrm{NE} 1 / 4 \mathrm{SW} 1 / 4 \text { sec. } 29 \\
\text { T. } 55 \mathrm{~N} ., \mathrm{R} \cdot 72 \mathrm{~W} .\end{array}$ & 4,033 \\
\hline $\mathrm{P}-20$ & $\begin{array}{l}\text { Pan American Petroleum Co. } \\
1-B \text { Norfolk }\end{array}$ & $\begin{array}{l}\text { SE } 1 / 4 \mathrm{NW} 1 / 4 \text { sec. } 30 \\
\text { T. } 55 \text { N., R. } 72 \text { W. }\end{array}$ & 3,885 \\
\hline$P-21$ & $\begin{array}{l}\text { Pan American Petroleum Co. } \\
1-C \text { Norfolk }\end{array}$ & $\begin{array}{l}\text { SE } 1 / 4 \text { SW } 1 / 4 \text { sec. } 30 \\
\text { T. } 55 \text { N., R. } 72 \text { W. }\end{array}$ & 3,951 \\
\hline $\mathrm{P}-22$ & $\begin{array}{l}\text { Davis Oil Co. } \\
1-Z \text { Norford }\end{array}$ & $\begin{array}{l}\text { NW } 1 / 4 \text { NW } 1 / 4 \text { sec. } 30, \\
\text { T. } 55 \text { N., R. } 72 \text { W. }\end{array}$ & 3,929 \\
\hline $\mathrm{P}-23$ & $\begin{array}{l}\text { Continental Oil Co. } \\
1-30 \text { Conoco - Federal }\end{array}$ & $\begin{array}{l}\mathrm{NW} 1 / 4 \mathrm{SW} 1 / 4 \text { sec. } 30 \\
\mathrm{~T} .55 \mathrm{~N} ., \mathrm{R} \cdot 72 \mathrm{~W} .\end{array}$ & 3,956 \\
\hline $\mathrm{P}-24$ & $\begin{array}{l}\text { Davis Oil Co. } \\
\text { l Decker - Federal }\end{array}$ & $\begin{array}{l}\text { SE } 1 / 4 \mathrm{SE} 1 / 4 \text { sec. } 25, \\
\text { T. } 55 \text { N., R. } 73 \text { W. }\end{array}$ & 4,008 \\
\hline $\mathrm{P}-25$ & DELETED & & \\
\hline$P-26$ & $\begin{array}{l}\text { Davis Oil Co. } \\
1 \text { Schulte - State }\end{array}$ & $\begin{array}{l}\text { SW } 1 / 4 \text { SW } 1 / 4 \text { sec. } 25, \\
\text { T. } 55 \text { N., R. } 73 \text { W. }\end{array}$ & 4,163 \\
\hline $\mathrm{P}-27$ & $\begin{array}{l}\text { Southland Royalty Co. } \\
\text { 1-3-26 Federal }\end{array}$ & $\begin{array}{l}\text { NE } 1 / 4 \text { NW } 1 / 4 \text { sec. } 26, \\
\text { T. } 55 \text { N., R. } 73 \text { W. }\end{array}$ & 4,193 \\
\hline $\mathrm{P}-28$ & $\begin{array}{l}\text { Pan American Petroleum Co. } \\
1-\mathrm{R} \text { State of Wyoming }\end{array}$ & $\begin{array}{l}\text { SE } 1 / 4 \text { NE } 1 / 4 \text { sec. } 36, \\
\text { T. } 55 \text { N., R. } 73 \text { W. }\end{array}$ & 4,042 \\
\hline
\end{tabular}




\begin{tabular}{|c|c|c|c|}
\hline $\begin{array}{l}\text { We } 11 \\
\text { No. } \\
\text { on map }\end{array}$ & $\begin{array}{l}\text { Company and } \\
\text { we11 No. }\end{array}$ & Location & $\begin{array}{l}\text { Ground } \\
\text { elevation } \\
\text { (ft) }\end{array}$ \\
\hline $\mathrm{P}-29$ & $\begin{array}{l}\text { Southland Royalty Co. } \\
3-31 \text { Federal }\end{array}$ & $\begin{array}{l}\text { SW } 1 / 4 \text { SW } 1 / 4 \text { sec. } 31, \\
\text { T. } 55 \text { N., R. } 72 \text { W. }\end{array}$ & 3,976 \\
\hline $\mathrm{p}-30$ & $\begin{array}{l}\text { Davis Oil Co. } \\
1 \text { Rogers - Federal }\end{array}$ & $\begin{array}{l}\text { NW } 1 / 4 \mathrm{NW} 1 / 4 \text { sec. } 31, \\
\text { T. } 55 \text { N., R. } 72 \text { W. }\end{array}$ & 4,071 \\
\hline $\mathrm{P}-31$ & $\begin{array}{l}\text { Davis Oil Co. } \\
2 \text { Rogers - Federal }\end{array}$ & $\begin{array}{l}\text { SE } 1 / 4 \text { NW } 1 / 4 \text { sec. } 31, \\
\text { T. } 55 \text { N., R. } 72 \text { W. }\end{array}$ & 4,031 \\
\hline $\mathrm{P}-32$ & $\begin{array}{l}\text { Davis Oil Co. } \\
1-Z \text { Norland }\end{array}$ & $\begin{array}{l}\text { NW } 1 / 4 \text { NW } 1 / 4 \text { sec. } 32, \\
\text { T. } 55 \text { N., R. } 72 \text { W. }\end{array}$ & 3,824 \\
\hline $\mathrm{P}-33$ & $\begin{array}{l}\text { Davis Oil Co. } \\
1 \text { Spring Creek }\end{array}$ & $\begin{array}{l}\text { SE } 1 / 4 \text { SW } 1 / 4 \text { sec. } 32, \\
\text { T. } 55 \text { N., R. } 72 \text { W. }\end{array}$ & 3,826 \\
\hline$P-34$ & $\begin{array}{l}\text { R. G. Boeke1 } \\
\text { 42-34 Hanks }\end{array}$ & $\begin{array}{l}\text { SE } 1 / 4 \mathrm{NE} 1 / 4 \text { sec. } 34, \\
\text { T. } 55 \text { N., R. } 72 \text { W. }\end{array}$ & 3,772 \\
\hline$P-35$ & $\begin{array}{l}\text { Davis 0il Co. } \\
1 \text { oldham - Federal }\end{array}$ & $\begin{array}{l}\text { SE } 1 / 4 \mathrm{NE} 1 / 4 \text { sec. } 3 \text {, } \\
\text { T. } 54 \text { N., R. } 72 \text { W. }\end{array}$ & 3,954 \\
\hline $\mathrm{P}-36$ & $\begin{array}{l}\text { Jeff Hawks and Donnel } \\
\text { Drilling Co. } \\
1 \text { Heydecker }\end{array}$ & $\begin{array}{l}\text { SE } 1 / 4 \text { SE } 1 / 4 \text { sec. } 4 \text {, } \\
\text { T. } 54 \text { N., R. } 72 \text { W. }\end{array}$ & 4,051 \\
\hline$P-37$ & $\begin{array}{l}\text { Davis Oil Co. } \\
1 \text { Bery } 1 \text { - Federal }\end{array}$ & $\begin{array}{l}\text { NW } 1 / 4 \text { NW } 1 / 4 \text { sec. } 6, \\
\text { T. } 54 \text { N., R. } 72 \text { W. }\end{array}$ & 3,935 \\
\hline $\mathrm{P}-38$ & $\begin{array}{l}\text { Davis Oil Co. } \\
1 \text { Guy - Federal }\end{array}$ & $\begin{array}{l}\text { SE } 1 / 4 \text { NE } 1 / 4 \text { sec. } 1 \text {, } \\
\text { T. } 54 \text { N., R. } 73 \text { W. }\end{array}$ & 3,917 \\
\hline $\mathrm{P}-39$ & $\begin{array}{l}\text { Davis 0i1 Co. } \\
2 \text { Guy - Federal }\end{array}$ & $\begin{array}{l}\text { NE } 1 / 4 \text { SE } 1 / 4 \text { sec. } 1, \\
\text { T. } 54 \text { N., R. } 73 \text { W. }\end{array}$ & 3,886 \\
\hline$P-40$ & $\begin{array}{l}\text { Forest 0il Corp. } \\
1-1-1 \text { Government }\end{array}$ & $\begin{array}{l}\text { NW } 1 / 4 \text { SE } 1 / 4 \text { sec. } 1, \\
\text { T. } 54 \text { N., R. } 73 \text { W. }\end{array}$ & 3,916 \\
\hline$P-41$ & $\begin{array}{l}\text { Southland Royalty Co. } \\
2-1 \text { Norfolk }\end{array}$ & $\begin{array}{l}\text { SE } 1 / 4 \text { SE } 1 / 4 \text { sec. } 2, \\
\text { T. } 54 \text { N., R. } 73 \text { W. }\end{array}$ & 4,013 \\
\hline$P-42$ & $\begin{array}{l}\text { Davis 0il Co. } \\
2 \text { Partridge - Federal }\end{array}$ & $\begin{array}{l}\text { NW } 1 / 4 \text { NE } 1 / 4 \text { sec. } 3 \text {, } \\
\text { T. } 54 \text { N., R. } 73 \text { W. }\end{array}$ & 4,099 \\
\hline$P-43$ & $\begin{array}{l}\text { Davis Oil Co. } \\
1 \text { Lytle - Federal }\end{array}$ & $\begin{array}{l}\mathrm{NW} 1 / 4 \mathrm{NE} 1 / 4 \text { sec. } 10, \\
\text { T. } 54 \text { N., R. } 73 \text { W. }\end{array}$ & 4,147 \\
\hline$P-44$ & $\begin{array}{l}\text { Southland Royalty Co. } \\
1-12 \text { Norfolk }\end{array}$ & $\begin{array}{l}\text { NW } 1 / 4 \text { SE } 1 / 4 \text { sec. } 12 . \\
\text { T. } 54 \text { N., R. } 73 \text { W. }\end{array}$ & 3,890 \\
\hline
\end{tabular}




\begin{tabular}{|c|c|c|c|}
\hline $\begin{array}{l}\text { We11 } \\
\text { No. } \\
\text { on map }\end{array}$ & $\begin{array}{c}\text { Company and } \\
\text { well No. }\end{array}$ & Location & $\begin{array}{l}\text { Ground } \\
\text { elevation } \\
\text { (ft) }\end{array}$ \\
\hline$P-45$ & $\begin{array}{l}\text { The Anchutz Corp. } \\
1 \text { Heydecker - Government }\end{array}$ & $\begin{array}{l}\text { NW } 1 / 4 \text { SW } 1 / 4 \text { sec. } 7, \\
\text { T. } 54 \text { N., R. } 72 \text { W. }\end{array}$ & 3,930 \\
\hline$P-46$ & $\begin{array}{l}\text { Davis Oil Co. } \\
1 \text { Forest - Federa1 }\end{array}$ & $\begin{array}{l}\text { NW } 1 / 4 \text { NE } 1 / 4 \text { sec. } 7 \\
\text { T. } 54 \text { N., R. } 72 \text { W. }\end{array}$ & 4,006 \\
\hline$P-47$ & $\begin{array}{l}\text { Davis Oil Co. } \\
1 \text { Manly - State }\end{array}$ & $\begin{array}{l}\text { NE } 1 / 4 \text { NE } 1 / 4 \text { sec. } 16, \\
\text { T. } 54 \text { N., R. } 72 \text { W. }\end{array}$ & 4,116 \\
\hline$P-48$ & $\begin{array}{l}\text { Southland Royalty Co. } \\
6 \text { Norfolk }\end{array}$ & $\begin{array}{l}\text { SE } 1 / 4 \text { NW } 1 / 4 \text { sec. } 17 \\
\text { T. } 54 \text { N., R. } 72 \text { W. }\end{array}$ & 4,039 \\
\hline$P-49$ & $\begin{array}{l}\text { Southland Royalty Co. } \\
5 \text { Norfolk }\end{array}$ & $\begin{array}{l}\text { NW } 1 / 4 \text { SW } 1 / 4 \text { sec. } 17 \\
\text { T. } 54 \text { N., R. } 72 \text { W. }\end{array}$ & 4,019 \\
\hline$P-50$ & $\begin{array}{l}\text { Southland Royalty Co. } \\
4 \text { Norfolk }\end{array}$ & $\begin{array}{l}\text { SE } 1 / 4 \mathrm{SE} 1 / 4 \text { sec. } 18, \\
\text { T. } 54 \text { N., R. } 72 \text { W. }\end{array}$ & 4,083 \\
\hline$P-51$ & $\begin{array}{l}\text { Chevron Oil Co. } \\
4 \text { Federal }(42-18)\end{array}$ & $\begin{array}{l}\text { SE } 1 / 4 \mathrm{NE} 1 / 4 \text { sec. } 18, \\
\text { T. } 54 \mathrm{~N} ., \mathrm{R} .72 \mathrm{~W} .\end{array}$ & 3,980 \\
\hline$P-52$ & $\begin{array}{l}\text { Chevron Oil Co. } \\
3 \text { Federal }(31-18)\end{array}$ & $\begin{array}{l}\text { NW } 1 / 4 \mathrm{NE} 1 / 4 \text { sec. } 18, \\
\text { T. } 54 \text { N., R. } 72 \text { W. }\end{array}$ & 4,105 \\
\hline$P-53$ & $\begin{array}{l}\text { Southland Royalty Co. } \\
3 \text { Norfolk }\end{array}$ & $\begin{array}{l}\text { NW } 1 / 4 \text { SE } 1 / 4 \text { sec. } 18, \\
\text { T. } 54 \text { N., R. } 72 \text { W. }\end{array}$ & 4,064 \\
\hline $\mathrm{P}-54$ & $\begin{array}{l}\text { Southland Royalty Co. } \\
1 \text { Norfolk }\end{array}$ & $\begin{array}{l}\text { SE } 1 / 4 \text { SW } 1 / 4 \text { sec. } 18 \text {, } \\
\text { T. } 54 \text { N., R. } 72 \text { W. }\end{array}$ & 4,070 \\
\hline $\mathrm{P}-55$ & $\begin{array}{l}\text { Chevron Oil Co. } \\
1 \text { Federal }(22-18)\end{array}$ & $\begin{array}{l}\text { SE } 1 / 4 \text { NW } 1 / 4 \text { sec. } 18, \\
\text { T. } 54 \text { N., R. } 72 \text { W. }\end{array}$ & 4,096 \\
\hline$P-56$ & $\begin{array}{l}\text { Davis Oil Co. } \\
3 \text { Merritt - Federal }\end{array}$ & $\begin{array}{l}\text { NW } 1 / 4 \text { SE } 1 / 4 \text { sec. } 13 \text {, } \\
\text { T. } 54 \text { N., R. } 73 \text { W. }\end{array}$ & 3,974 \\
\hline$P-57$ & $\begin{array}{l}\text { Davis Oi1 Co. } \\
5 \text { Merritt - Federal }\end{array}$ & $\begin{array}{l}\mathrm{NW} 1 / 4 \mathrm{NE} 1 / 4 \text { sec. } 13 \text {, } \\
\text { T. } 54 \text { N., R. } 73 \text { W. }\end{array}$ & 4,077 \\
\hline $\mathrm{P}-58$ & $\begin{array}{l}\text { Davis Oil Co. } \\
\text { l Bing - Federal }\end{array}$ & $\begin{array}{l}\text { NW } 1 / 4 \text { NW } 1 / 4 \text { sec. } 14 \\
\text { T. } 54 \text { N., R. } 73 \text { W. }\end{array}$ & 3,962 \\
\hline$P-59$ & $\begin{array}{l}\text { Davis Oil Co. } \\
1 \text { Esther - Federal }\end{array}$ & $\begin{array}{l}\text { NW } 1 / 4 \text { SW } 1 / 4 \text { sec. } 23 \\
\text { T. } 54 \text { N., R. } 73 \text { W. }\end{array}$ & 4,068 \\
\hline$P-60$ & $\begin{array}{l}\text { Mule Creek Oil Co. } \\
\text { 1-4423 Mule Creek Downer }\end{array}$ & $\begin{array}{l}\text { SE } 1 / 4 \mathrm{SE} 1 / 4 \text { sec. } 23, \\
\text { T. } 54 \text { N., R. } 73 \text { W. }\end{array}$ & 4,032 \\
\hline
\end{tabular}




\begin{tabular}{|c|c|c|c|}
\hline $\begin{array}{l}\text { We11 } \\
\text { No. } \\
\text { on map }\end{array}$ & $\begin{array}{c}\text { Company and } \\
\text { well No. }\end{array}$ & Location & $\begin{array}{l}\text { Ground } \\
\text { elevation } \\
\quad(\mathrm{ft})\end{array}$ \\
\hline$P-61$ & $\begin{array}{l}\text { Forest Oil Corp. } \\
1-24-1 \text { Government }\end{array}$ & $\begin{array}{l}\text { NW } 1 / 4 \text { NE } 1 / 4 \text { sec. } 24, \\
\text { T. } 54 \text { N., R. } 73 \text { W. }\end{array}$ & 4,085 \\
\hline$P-62$ & $\begin{array}{l}\text { Montana Bureau of Mines } \\
\text { and Geology } \\
\text { US } 7344\end{array}$ & $\begin{array}{l}\text { SW } 1 / 4 \text { SW } 1 / 4 \text { sec. } 19, \\
\text { T. } 54 \text { N., R. } 72 \text { W. }\end{array}$ & 4,212 \\
\hline$P-63$ & $\begin{array}{l}\text { Stuarco Oil Co. - Bel Oil } \\
\text { Corp. } \\
\text { 22-19 Harrington - Federal }\end{array}$ & $\begin{array}{l}\text { SE } 1 / 4 \text { NW } 1 / 4 \text { sec. } 19, \\
\text { T. } 54 \text { N., R. } 72 \text { W. }\end{array}$ & 4,180 \\
\hline$P-64$ & $\begin{array}{l}\text { Sinclair Oil Co. } \\
1 \text { Williams - Batz }\end{array}$ & $\begin{array}{l}\text { NW } 1 / 4 \text { SW } 1 / 4 \text { sec. } 20, \\
\text { T. } 54 \text { N. , R. } 72 \text { W. }\end{array}$ & 4,124 \\
\hline$P-65$ & $\begin{array}{l}\text { Davis Oil Co. } \\
1 \text { Batz - Federal }\end{array}$ & $\begin{array}{l}\text { SE } 1 / 4 \text { SE } 1 / 4 \text { sec. } 20, \\
\text { T. } 54 \text { N., R. } 72 \text { W. }\end{array}$ & 4,159 \\
\hline$P-66$ & $\begin{array}{l}\text { Petroleum Inc. } \\
1-C \text { Government - Aztec }\end{array}$ & $\begin{array}{l}\text { NW } 1 / 4 \text { NW } 1 / 4 \text { sec. } 21, \\
\text { T. } 54 \text { N., R. } 72 \text { W. }\end{array}$ & 4,223 \\
\hline$P-67$ & $\begin{array}{l}\text { Davis 0il Co. } \\
\text { l Federal - Bing }\end{array}$ & $\begin{array}{l}\text { SW } 1 / 4 \text { SW } 1 / 4 \text { sec. } 22, \\
\text { T. } 54 \text { N., R. } 72 \text { W. }\end{array}$ & 4,183 \\
\hline$P-68$ & $\begin{array}{l}\text { Walter Duncan 0il Properties } \\
1 \text { Collins - Government }\end{array}$ & $\begin{array}{l}\text { NE } 1 / 4 \mathrm{NE} 1 / 4 \text { sec. } 22, \\
\text { T. } 54 \text { N., R. } 72 \text { W. }\end{array}$ & 4,224 \\
\hline$P-69$ & $\begin{array}{l}\text { Walter Duncan - Inter. Am. } \\
14-27 \mathrm{~A} \text { Government }\end{array}$ & $\begin{array}{l}\text { SW } 1 / 4 \text { SW } 1 / 4 \text { sec. } 27, \\
\text { T. } 54 \text { N., R. } 72 \text { W. }\end{array}$ & 4,093 \\
\hline $\mathrm{P}-70$ & $\begin{array}{l}\text { Davis Oil Co. } \\
1 \text { Mee - Federa1 }\end{array}$ & $\begin{array}{l}\text { SE } 1 / 4 \mathrm{NW} 1 / 4 \text { sec. } 29 \text {, } \\
\text { T. } 54 \text { N., R. } 72 \text { W. }\end{array}$ & 4,257 \\
\hline P-71 & $\begin{array}{l}\text { Davis Oil Co. } \\
\text { l Brad - Federal }\end{array}$ & $\begin{array}{l}\text { NW } 1 / 4 \text { NW } 1 / 4 \text { sec. } 29, \\
\text { T. } 54 \text { N., R. } 72 \text { W. }\end{array}$ & 4,256 \\
\hline$P-72$ & $\begin{array}{l}\text { Stuarco Oil Co. } \\
30-42 \text { Harrington - Federa } 1\end{array}$ & $\begin{array}{l}\text { SE } 1 / 4 \mathrm{NE} 1 / 4 \text { sec. } 30, \\
\text { T. } 54 \text { N., R. } 72 \text { W. }\end{array}$ & 4,197 \\
\hline $\mathrm{P}-73$ & $\begin{array}{l}\text { Forest Oil Corp. } \\
2-30-2 \text { Government }\end{array}$ & $\begin{array}{l}\text { NW } 1 / 4 \mathrm{SE} 1 / 4 \text { sec. } 30, \\
\text { T. } 54 \text { N., R. } 72 \text { W. }\end{array}$ & 4,159 \\
\hline$P-74$ & $\begin{array}{l}\text { Montana Bureau of Mines } \\
\text { and Geology } \\
\text { US } 7346\end{array}$ & $\begin{array}{l}\text { SE } 1 / 4 \mathrm{NW} 1 / 4 \text { sec. } 26, \\
\text { T. } 54 \text { N., R. } 73 \text { W. }\end{array}$ & 4,205 \\
\hline
\end{tabular}




\begin{tabular}{|c|c|c|c|}
\hline $\begin{array}{l}\text { We11 } \\
\text { No. } \\
\text { on map }\end{array}$ & $\begin{array}{l}\text { Company and } \\
\text { we11 No. }\end{array}$ & Location & $\begin{array}{l}\text { Ground } \\
\text { elevation } \\
\quad(f t)\end{array}$ \\
\hline $\mathrm{P}-75$ & $\begin{array}{l}\text { Davis Oil Co. } \\
1 \text { Williams }\end{array}$ & $\begin{array}{l}\mathrm{NE} 1 / 4 \mathrm{NE} 1 / 4 \text { sec. } 35, \\
\text { T. } 54 \text { N., R. } 73 \text { W. }\end{array}$ & 4,187 \\
\hline $\mathrm{P}-76$ & $\begin{array}{l}\text { Davis Oil Co. } \\
3 \text { Harrington - Federal }\end{array}$ & $\begin{array}{l}\text { NW } 1 / 4 \text { NE } 1 / 4 \text { sec. } 32, \\
\text { T. } 54 \text { N., R. } 72 \text { W. }\end{array}$ & 4,061 \\
\hline $\mathrm{P}-77$ & $\begin{array}{l}\text { Davis 0il Co. } \\
2 \text { Harrington - Federal }\end{array}$ & $\begin{array}{l}\mathrm{NE} 1 / 4 \mathrm{NE} 1 / 4 \text { sec. } 32, \\
\text { T. } 54 \text { N., R. } 72 \text { W. }\end{array}$ & 3,974 \\
\hline $\mathrm{p}-78$ & $\begin{array}{l}\text { Montana Bureau of Mines } \\
\text { and Geology } \\
\text { US } 7559\end{array}$ & $\begin{array}{l}\mathrm{SE} 1 / 4 \mathrm{SE} 1 / 4 \text { sec. } 25, \\
\mathrm{~T} .55 \mathrm{~N} ., \mathrm{R} .73 \mathrm{~W} .\end{array}$ & 3,975 \\
\hline
\end{tabular}


APPENDIX D.

SOURCES OF COAL-BED DATA IN THE RECLUSE QUADRANGLE 
[List of wells, locations, and ground elevations for all wells in the Recluse Geologic Model Area including wells that do not penetrate the Cache Coal Bed]

[To convert feet to meters multiply by 0.3048 ]

\begin{tabular}{|c|c|c|c|}
\hline $\begin{array}{l}\text { We11 } \\
\text { No. } \\
\text { on map }\end{array}$ & $\begin{array}{l}\text { Company and } \\
\text { well No. }\end{array}$ & Location & $\begin{array}{l}\text { Ground } \\
\text { elevation } \\
\quad(f t)\end{array}$ \\
\hline$R-1$ & $\begin{array}{l}\text { Mule Creek Oil Co. } \\
1-4416 \text { Government - Meyer }\end{array}$ & $\begin{array}{l}\text { SE } 1 / 4 \text { SE } 1 / 4 \text { sec. } 16, \\
\text { T. } 55 \text { N., R. } 73 \text { W. }\end{array}$ & 4,110 \\
\hline$R-2$ & DELETED & & \\
\hline$R-3$ & $\begin{array}{l}\text { The Anchutz Corp. } \\
1 \text { Reed }\end{array}$ & $\begin{array}{l}\text { NW } 1 / 4 \text { SE } 1 / 4 \text { sec. } 17, \\
\text { T. } 55 \text { N., R. } 73 \text { W. }\end{array}$ & 4,109 \\
\hline$R-4$ & $\begin{array}{l}\text { Petro - Lewis, Ladd, Gary, } \\
\text { CRA Inc. } \\
\text { 1-18 Wilson }\end{array}$ & $\begin{array}{l}\text { SE } 1 / 4 \text { NE } 1 / 4 \text { sec. } 18 \text {, } \\
\text { T. } 55 \text { N., R. } 73 \text { W. }\end{array}$ & 4,095 \\
\hline$R-5$ & $\begin{array}{l}\text { Petroleum Inc. } \\
\text { 5-18 Federal }\end{array}$ & $\begin{array}{l}\text { SW } 1 / 4 \text { SE } 1 / 4 \text { sec. } 18, \\
\text { T. } 55 \text { N., R. } 73 \text { W. }\end{array}$ & 4,197 \\
\hline$R-6$ & $\begin{array}{l}\text { The Anchutz Corp. } \\
2-D \text { Oedekoven }\end{array}$ & $\begin{array}{l}\text { NE } 1 / 4 \mathrm{SE} 1 / 4 \text { sec. } 13, \\
\text { T. } 55 \text { N., R. } 74 \text { W. }\end{array}$ & 4,091 \\
\hline$R-7$ & $\begin{array}{l}\text { The Anchutz Corp. } \\
\text { 3-D Oedekoven }\end{array}$ & $\begin{array}{l}\mathrm{NE} 1 / 4 \mathrm{SW} 1 / 4 \text { sec. } 13, \\
\text { T. } 55 \text { N., R. } 74 \text { W. }\end{array}$ & 4,119 \\
\hline $\mathrm{R}-8$ & $\begin{array}{l}\text { Amarillo Oil Co. } \\
1 \text { Ralph Taylor }\end{array}$ & $\begin{array}{l}\text { SE } 1 / 4 \mathrm{NE} 1 / 4 \text { sec. } 23 \text {, } \\
\text { T. } 55 \text { N., R. } 74 \text { W. }\end{array}$ & 4,166 \\
\hline$R-9$ & $\begin{array}{l}\text { The Anchutz Corp. } \\
1-C \text { Oedekoven }\end{array}$ & $\begin{array}{l}\mathrm{NE} 1 / 4 \mathrm{SE} 1 / 4 \text { sec. } 24, \\
\text { T. } 55 \mathrm{~N} ., \mathrm{R} .74 \mathrm{~W} .\end{array}$ & 4,112 \\
\hline$R-10$ & $\begin{array}{l}\text { The Anchutz Corp. } \\
\text { 7-C Oedekoven }\end{array}$ & $\begin{array}{l}\mathrm{NE} 1 / 4 \mathrm{NE} 1 / 4 \text { sec. } 24, \\
\text { T. } 55 \text { N., R. } 74 \text { W. }\end{array}$ & 4,103 \\
\hline $\mathrm{R}-11$ & $\begin{array}{l}\text { The Anchutz Corp. } \\
\text { 3-C Oedekoven }\end{array}$ & $\begin{array}{l}\text { SW } 1 / 4 \text { NW } 1 / 4 \text { sec. } 19, \\
\text { T. } 55 \text { N., R. } 74 \text { W. }\end{array}$ & 4,112 \\
\hline $\mathrm{R}-12$ & $\begin{array}{l}\text { The Anchutz Corp. - Phillips } \\
\text { Petroleum Co. } \\
\text { 2-B Oedekoven }\end{array}$ & $\begin{array}{l}\text { SW } 1 / 4 \text { SE } 1 / 4 \text { sec. } 19, \\
\text { T. } 55 \text { N., R. } 73 \text { W. }\end{array}$ & 4,137 \\
\hline$R-13$ & $\begin{array}{l}\text { Davis Oil Co. } \\
\text { 4-A Paul - Federal }\end{array}$ & $\begin{array}{l}\text { SW } 1 / 4 \text { NW } 1 / 4 \text { sec. } 21, \\
\text { T. } 55 \text { N., R. } 73 \text { W. }\end{array}$ & 4,045 \\
\hline
\end{tabular}




\begin{tabular}{|c|c|c|c|}
\hline $\begin{array}{l}\text { We11 } \\
\text { No. } \\
\text { on map }\end{array}$ & $\begin{array}{c}\text { Company and } \\
\text { we11 No. }\end{array}$ & Location & $\begin{array}{l}\text { Ground } \\
\text { elevation } \\
\quad \text { (ft) }\end{array}$ \\
\hline $\mathrm{R}-14$ & $\begin{array}{l}\text { Davis Oil Co. } \\
3 \text { Paul - Federal }\end{array}$ & $\begin{array}{l}\text { NW } 1 / 4 \text { NW } 1 / 4 \text { sec. } 21, \\
\text { T. } 55 \text { N., R. } 73 \text { W. }\end{array}$ & 4,123 \\
\hline$R-15$ & $\begin{array}{l}\text { The Anchutz Corp. } \\
\text { 2-88 Federal }\end{array}$ & $\begin{array}{l}\mathrm{NE} 1 / 4 \mathrm{SW} 1 / 4 \text { sec. } 21 \\
\text { T. } 55 \text { N., R. } 73 \text { W. }\end{array}$ & 4,069 \\
\hline $\mathrm{R}-16$ & $\begin{array}{l}\text { Montana Bureau of Mines } \\
\text { and Geology } \\
\text { US } 7469\end{array}$ & $\begin{array}{l}\text { NE } 1 / 4 \text { SW } 1 / 4 \text { sec. } 21, \\
\text { T. } 55 \text { N., R. } 73 \text { W. }\end{array}$ & 4,063 \\
\hline $\mathrm{R}-17$ & $\begin{array}{l}\text { The Anchutz Corp. } \\
1-87 \text { Government }\end{array}$ & $\begin{array}{l}\mathrm{SW} 1 / 4 \mathrm{SE} 1 / 4 \text { sec. } 21 \\
\text { T. } 55 \mathrm{~N} ., \mathrm{R} \cdot 73 \mathrm{~W} .\end{array}$ & 4,078 \\
\hline $\mathrm{R}-18$ & $\begin{array}{l}\text { Stuarco Oil Co., Inc. } \\
21-43 \text { Government }\end{array}$ & $\begin{array}{l}\text { NE } 1 / 4 \mathrm{SE} 1 / 4 \text { sec. } 21 \\
\text { T. } 55 \text { N., R. } 73 \text { W. }\end{array}$ & 4,056 \\
\hline$R-19$ & $\begin{array}{l}\text { Davis Oil Co. } \\
1 \text { Squaw Creek - Federa1 }\end{array}$ & $\begin{array}{l}\text { SE } 1 / 4 \text { SW } 1 / 4 \text { sec. } 27 \\
\text { T. } 55 \text { N., R. } 73 \text { W. }\end{array}$ & 4,086 \\
\hline$R-20$ & $\begin{array}{l}\text { Davis Oil Co. } \\
\text { l Vincent }\end{array}$ & $\begin{array}{l}\text { SW } 1 / 4 \mathrm{NE} 1 / 4 \text { sec. } 28, \\
\text { T. } 55 \mathrm{~N} \cdot, \mathrm{R}_{\bullet} 73 \mathrm{~W} .\end{array}$ & 4,093 \\
\hline$R-21$ & $\begin{array}{l}\text { The Anchutz Corp. } \\
1-88 \text { Government }\end{array}$ & $\begin{array}{l}\text { NW } 1 / 4 \text { NW } 1 / 4 \text { sec. } 28, \\
\text { T. } 55 \text { N., R. } 73 \text { W. }\end{array}$ & 4,029 \\
\hline$R-22$ & $\begin{array}{l}\text { Phillips Petroleum Co. } \\
2-A \text { Vincent }\end{array}$ & $\begin{array}{l}\text { SE } 1 / 4 \mathrm{NW} 1 / 4 \text { sec. } 30, \\
\text { T. } 55 \mathrm{~N} ., \mathrm{R} .73 \mathrm{~W} .\end{array}$ & 4,139 \\
\hline$R-23$ & $\begin{array}{l}\text { The Anchutz Corp. - Phillips } \\
\text { Petroleum - Petroleum Inc. } \\
\text { 2-A Oedekoven }\end{array}$ & $\begin{array}{l}\text { SW } 1 / 4 \text { NW } 1 / 4 \text { sec. } 30, \\
\text { T. } 55 \text { N., R. } 73 \text { W. }\end{array}$ & 4,153 \\
\hline$R-24$ & $\begin{array}{l}\text { Phillips Petroleum Co. } \\
\text { 3-A Vincent }\end{array}$ & $\begin{array}{l}\text { SE } 1 / 4 \text { SE } 1 / 4 \text { sec. } 25, \\
\text { T. } 55 \text { N., R. } 74 \text { W. }\end{array}$ & 4,136 \\
\hline$R-25$ & $\begin{array}{l}\text { J. M. Huber Corp. } \\
1-25 \text { Federal - Sullivan }\end{array}$ & $\begin{array}{l}\text { SW } 1 / 4 \text { NE } 1 / 4 \text { sec. } 25, \\
\text { T. } 55 \text { N., R. } 74 \text { W. }\end{array}$ & 4,211 \\
\hline$R-26$ & $\begin{array}{ll}\text { R. G. } & \text { Boeke1 } \\
31-36 & \text { State }\end{array}$ & $\begin{array}{l}\text { SW } 1 / 4 \text { SE } 1 / 4 \text { sec. } 25, \\
\text { T. } 55 \text { N., R. } 74 \text { W. }\end{array}$ & 4,228 \\
\hline$R-27$ & $\begin{array}{l}\text { The Anchutz Corp. } \\
1 \text { Butcher }\end{array}$ & $\begin{array}{l}\text { SW } 1 / 4 \text { NE } 1 / 4 \text { sec. } 31, \\
\text { T. } 55 \text { N., R. } 73 \text { W. }\end{array}$ & 4,139 \\
\hline
\end{tabular}




\begin{tabular}{|c|c|c|c|}
\hline $\begin{array}{l}\text { We } 11 \\
\text { No. } \\
\text { on map }\end{array}$ & $\begin{array}{l}\text { Company and } \\
\text { we11 No. }\end{array}$ & Location & $\begin{array}{l}\text { Ground } \\
\text { elevation } \\
\quad(f t)\end{array}$ \\
\hline$R-28$ & $\begin{array}{l}\text { Montana Bureau of Mines } \\
\text { and Geology } \\
\text { US } 7468\end{array}$ & $\begin{array}{l}\text { NW } 1 / 4 \text { SE } 1 / 4 \text { sec. } 32, \\
\text { T. } 55 \text { N., R. } 73 \text { W. }\end{array}$ & 4,074 \\
\hline$R-29$ & $\begin{array}{l}\text { Davis Oil Co. } \\
\text { l Partridge - Federal }\end{array}$ & $\begin{array}{l}\text { NE } 1 / 4 \text { NE } 1 / 4 \text { sec. } 33, \\
\text { T. } 55 \text { N., R. } 73 \text { W. }\end{array}$ & 4,009 \\
\hline$R-30$ & $\begin{array}{l}\text { Davis Oil Co. } \\
1 \text { Rothwel1 - Federal }\end{array}$ & $\begin{array}{l}\text { SE } 1 / 4 \text { NW } 1 / 4 \text { sec. } 34 . \\
\text { T. } 55 \text { N., R. } 73 \text { W. }\end{array}$ & 4,018 \\
\hline$R-31$ & $\begin{array}{l}\text { Exeter - Union Texas } \\
1 \text { Carson - Federal }\end{array}$ & $\begin{array}{l}\text { SW } 1 / 4 \text { SW } 1 / 4 \text { sec. } 4, \\
\text { T. } 54 \text { N., R. } 73 \text { W. }\end{array}$ & 4,153 \\
\hline$R-32$ & $\begin{array}{l}\text { Kewanee Oil Co. } \\
1 \text { Henry }\end{array}$ & $\begin{array}{l}\mathrm{NE} 1 / 4 \mathrm{NE} 1 / 4 \text { sec. } 6, \\
\text { T. } 54 \text { N., R. } 73 \text { W. }\end{array}$ & 4,164 \\
\hline$R-32 A$ & $\begin{array}{l}\text { Petroleum Inc. } \\
1 \text { Kewanee }\end{array}$ & $\begin{array}{l}\text { NE } 1 / 4 \mathrm{NW} 1 / 4 \text { sec. } 6, \\
\text { T. } 54 \text { N., R. } 73 \text { W. }\end{array}$ & 4,228 \\
\hline$R-33$ & $\begin{array}{l}\text { Belco Petroleum } \\
1-6 \text { Cook }\end{array}$ & $\begin{array}{l}\text { SW } 1 / 4 \text { SE } 1 / 4 \text { sec. } 6, \\
\text { T. } 54 \text { N., R. } 73 \text { W. }\end{array}$ & 4,110 \\
\hline$R-34$ & $\begin{array}{l}\text { Belco Petroleum } \\
1-6 \text { Wolff }\end{array}$ & $\begin{array}{l}\text { NE } 1 / 4 \text { SW } 1 / 4 \text { sec. } 6, \\
\text { T. } 54 \text { N., R. } 73 \text { W. }\end{array}$ & 4,146 \\
\hline$R-35$ & $\begin{array}{l}\text { Trend Exploration, Ltd. } \\
\text { l-C Oedekoven }\end{array}$ & $\begin{array}{l}\mathrm{NE} 1 / 4 \mathrm{SE} 1 / 4 \text { sec. } 1, \\
\text { T. } 54 \text { N., R. } 74 \text { W. }\end{array}$ & 4,094 \\
\hline$R-36$ & $\begin{array}{l}\text { Fred Goodstein } \\
1-11 \text { MKM }\end{array}$ & $\begin{array}{l}\text { SW } 1 / 4 \text { SW } 1 / 4 \text { sec. } 11, \\
\text { T. } 54 \text { N., R. } 74 \text { W. }\end{array}$ & 4,174 \\
\hline$R-37$ & $\begin{array}{l}\text { A11 Minerals } \\
1 \text { Oedekoven }\end{array}$ & $\begin{array}{l}\text { NE } 1 / 4 \text { SW } 1 / 4 \text { sec. } 7 \\
\text { T. } 54 \text { N., R. } 73 \text { W. }\end{array}$ & 4,169 \\
\hline$R-38$ & $\begin{array}{l}\text { Belco Petroleum } \\
2 \text { Oedekoven }\end{array}$ & $\begin{array}{l}\text { NE } 1 / 4 \text { NW } 1 / 4 \text { sec. } 7, \\
\text { T. } 54 \text { N., R. } 73 \text { W. }\end{array}$ & 4,126 \\
\hline$R-39$ & $\begin{array}{l}\text { Al1 Minerals } \\
1 \text { Schaffer }\end{array}$ & $\begin{array}{l}\text { SW } 1 / 4 \text { NE } 1 / 4 \text { sec. } 7, \\
\text { T. } 54 \text { N., R. } 73 \text { W. }\end{array}$ & 4,057 \\
\hline$R-40$ & $\begin{array}{l}\text { Peet Oi } 1 \text { Co. } \\
1 \text { Federal }\end{array}$ & $\begin{array}{l}\text { NE } 1 / 4 \text { SW } 1 / 4 \text { sec. } 8, \\
\text { T. } 54 \text { N., R. } 73 \text { W. }\end{array}$ & 4,075 \\
\hline$R-41$ & $\begin{array}{l}\text { Davis Oil } 1 \text { Co. } \\
1 \text { Breene - Federal }\end{array}$ & $\begin{array}{l}\text { NW } 1 / 4 \text { NW } 1 / 4 \text { sec. } 10, \\
\text { T. } 54 \text { N., R. } 73 \text { W. }\end{array}$ & 4,181 \\
\hline$R-42$ & $\begin{array}{l}\text { Davis Oil Co. } \\
1 \text { Mohawk State }\end{array}$ & $\begin{array}{l}\text { NE } 1 / 4 \text { NE } 1 / 4 \text { sec. } 16, \\
\text { T. } 54 \text { N., R. } 73 \text { W. }\end{array}$ & 4,047 \\
\hline
\end{tabular}




\begin{tabular}{|c|c|c|c|}
\hline $\begin{array}{l}\text { We11 } \\
\text { No. } \\
\text { on map }\end{array}$ & $\begin{array}{c}\text { Company and } \\
\text { well No. }\end{array}$ & Location & $\begin{array}{l}\text { Ground } \\
\text { elevation } \\
\quad(f t)\end{array}$ \\
\hline$R-43$ & $\begin{array}{l}\text { Southland Royalty Co. } \\
1-17 \text { Davis - Federal }\end{array}$ & $\begin{array}{l}\mathrm{NE} 1 / 4 \mathrm{NE} 1 / 4 \text { sec. } 17 \\
\text { T. } 54 \mathrm{~N} ., \mathrm{R} .73 \mathrm{~W} .\end{array}$ & 4,098 \\
\hline$R-44$ & $\begin{array}{l}\text { Texaco, Inc. } \\
1-\mathrm{K} \text { State of Wyoming }\end{array}$ & $\begin{array}{l}\text { NE } 1 / 4 \text { SE } 1 / 4 \text { sec. } 18, \\
\text { T. } 54 \text { N., R. } 73 \text { W. }\end{array}$ & 4,168 \\
\hline$R-45$ & $\begin{array}{l}\text { Texaco, Inc. } \\
2-\mathrm{K} \text { State of Wyoming }\end{array}$ & $\begin{array}{l}\text { SW } 1 / 4 \text { SE } 1 / 4 \text { sec. } 18, \\
\text { T. } 54 \text { N., R. } 73 \text { W. }\end{array}$ & 4,127 \\
\hline$R-46$ & $\begin{array}{l}\text { Texaco, Inc. } \\
1 \text { Government - Simms Nct-1 }\end{array}$ & $\begin{array}{l}\text { NE } 1 / 4 \text { SW } 1 / 4 \text { sec. } 18, \\
\text { T. } 54 \text { N., R. } 73 \text { W. }\end{array}$ & 4,142 \\
\hline$R-47$ & $\begin{array}{l}\text { Texaco, Inc. } \\
1 \text { Carson }\end{array}$ & $\begin{array}{l}\text { NE } 1 / 4 \text { NW } 1 / 4 \text { sec. } 18, \\
\text { T. } 54 \text { N., R. } 73 \text { W. }\end{array}$ & 4,189 \\
\hline$R-48$ & $\begin{array}{l}\text { Cayman Corp. } \\
1 \text { Reed }\end{array}$ & $\begin{array}{l}\text { SW } 1 / 4 \text { NE } 1 / 4 \text { sec. } 14, \\
\text { T. } 54 \text { N., R. } 74 \text { W. }\end{array}$ & 4,113 \\
\hline$R-49$ & $\begin{array}{l}\text { Aztec 0il \& Gas Co. } \\
1-23 \text { Federal SC }\end{array}$ & $\begin{array}{l}\text { SW } 1 / 4 \text { SW } 1 / 4 \text { sec. } 23 \text {, } \\
\text { T. } 54 \text { N., R. } 74 \text { W. }\end{array}$ & 4,257 \\
\hline$R-50$ & $\begin{array}{l}\text { MKM Exploration } \\
\text { 1-A Parnel1 }\end{array}$ & $\begin{array}{l}\text { NW } 1 / 4 \text { SW } 1 / 4 \text { sec. } 24, \\
\text { T. } 54 \text { N., R. } 74 \text { W. }\end{array}$ & 4,174 \\
\hline$R-51$ & $\begin{array}{l}\text { Texaco, Inc. } \\
1-M \text { State of Wyoming }\end{array}$ & $\begin{array}{l}\text { NE } 1 / 4 \text { NW } 1 / 4 \text { sec. } 19, \\
\text { T. } 54 \text { N., R. } 73 \text { W. }\end{array}$ & 4,095 \\
\hline$R-52$ & $\begin{array}{l}\text { Davis Oil Co. } \\
1 \text { Great Northern - State }\end{array}$ & $\begin{array}{l}\text { SE } 1 / 4 \mathrm{NE} 1 / 4 \text { sec. } 20, \\
\text { T. } 54 \text { N., R. } 73 \text { W. }\end{array}$ & 4,242 \\
\hline$R-53$ & $\begin{array}{l}\text { Southland Royalty Co. } \\
\text { I Bing - Wylie }\end{array}$ & $\begin{array}{l}\text { SE } 1 / 4 \mathrm{NW} 1 / 4 \text { sec. } 22, \\
\text { T. } 54 \text { N., R. } 73 \text { W. }\end{array}$ & 3,988 \\
\hline$R-54$ & $\begin{array}{l}\text { Davis Oil Co. } \\
1 \text { Norfolk - State }\end{array}$ & $\begin{array}{l}\text { NW } 1 / 4 \text { NW } 1 / 4 \text { sec. } 28, \\
\text { T. } 54 \text { N., R. } 73 \text { W. }\end{array}$ & 3,992 \\
\hline$R-55$ & $\begin{array}{l}\text { Davis Oil Co. } \\
1 \text { Joan - State }\end{array}$ & $\begin{array}{l}\text { NE } 1 / 4 \text { NE } 1 / 4 \text { sec. } 30, \\
\text { T. } 54 \text { N., R. } 73 \text { W. }\end{array}$ & 4,163 \\
\hline$R-56$ & $\begin{array}{l}\text { Montana Bureau of Mines } \\
\text { and Geology } \\
\text { US } 7466\end{array}$ & $\begin{array}{l}\text { NW } 1 / 4 \text { SE } 1 / 4 \text { sec. } 30, \\
\text { T. } 54 \text { N., R. } 73 \text { W. }\end{array}$ & 4,068 \\
\hline$R-57$ & $\begin{array}{l}\text { Glen A. Dow - Trend } \\
\text { Exploration } \\
1 \text { Government - Aztec }\end{array}$ & $\begin{array}{l}\mathrm{NE} 1 / 4 \mathrm{NE} 1 / 4 \text { sec. } 25, \\
\text { T. } 54 \text { N., R. } 74 \text { W. }\end{array}$ & 4,162 \\
\hline
\end{tabular}


Sources of coal-bed data in the Recluse Quadrangle--Continued

\begin{tabular}{|c|c|c|c|}
\hline $\begin{array}{l}\text { We11 } \\
\text { No. } \\
\text { on map }\end{array}$ & $\begin{array}{l}\text { Company and } \\
\text { we } 11 \text { No. }\end{array}$ & Location & $\begin{array}{l}\text { Ground } \\
\text { elevation } \\
\quad(\mathrm{ft})\end{array}$ \\
\hline$R-58$ & $\begin{array}{ll}\text { Miami } & \text { Oi } 1 \\
1-430 & \text { Federal }\end{array}$ & $\begin{array}{l}\text { SW } 1 / 4 \mathrm{NE} 1 / 4 \text { sec. } 27, \\
\text { T. } 54 \text { N., R. } 74 . \mathrm{W} \text {. }\end{array}$ & 4,190 \\
\hline$R-59$ & $\begin{array}{l}\text { Midwest Oil Co. } \\
1 \text { Sorenson }\end{array}$ & $\begin{array}{l}\mathrm{NE} 1 / 4 \mathrm{NW} 1 / 4 \text { sec. } 27, \\
\text { T. } 54 \text { N., R. } 74 \text { W. }\end{array}$ & 4,215 \\
\hline$R-60$ & $\begin{array}{l}\text { Montana Bureau of Mines } \\
\text { and Geology } \\
\text { US } 7552\end{array}$ & $\begin{array}{l}\text { NW } 1 / 4 \mathrm{SW} 1 / 4 \text { sec. } 24, \\
\text { T. } 54 \text { N., R. } 74 \text { W. }\end{array}$ & 4,181 \\
\hline$R-61$ & $\begin{array}{l}\text { Montana Bureau of Mines } \\
\text { and Geology } \\
\text { US } 7553\end{array}$ & $\begin{array}{l}\text { SE } 1 / 4 \text { NE } 1 / 4 \text { sec. } 3, \\
\text { T. } 54 \text { N., R. } 74 \text { W. }\end{array}$ & 4,143 \\
\hline
\end{tabular}

